\title{
Physiological Endpoints for Potential SSRI Interactions in Fish
}

\author{
N. Kreke and D. R. Dietrich \\ Environmental Toxicology, Department of Biology, University of Konstanz, Konstanz, Germany
}

\begin{abstract}
Selective serotonin reuptake inhibitors (SSRIs) are among the pharmaceutical compounds frequently detected in sewage treatment plant effluents and surface waters, albeit at very low concentrations, and have therefore become a focus of interest as environmental pollutants. These neuroactive drugs are primarily used in the treatment of depression but have also found broader use as medication for other neurological dysfunctions, consequently resulting in a steady increase of prescriptions worldwide. SSRIs, via inhibition of the serotonin (5-hydroxytryptamine, 5-HT) reuptake mechanism, induce an increase in extracellular 5-HT concentration within the central nervous system of mammals. The phylogenetically ancient and highly conserved neurotransmitter and neurohormone 5-HT has been found in invertebrates and vertebrates, although its specific physiological role and mode of action is unknown for many species. Consequently, it is difficult to assess the impact of chronic SSRI exposure in the environment, especially in the aquatic ecosystem. In view of this, the current knowledge of the functions of 5-HT in fish physiology is reviewed and, via comparison to the physiological role and function of 5-HT in mammals, a characterization of the potential impact of chronic SSRI exposure on fish is provided. Moreover, the insight on the physiological function of 5-HT strongly suggests that the experimental approaches currently used are inadequate if not entirely improper for routine environmental risk assessment of pharmaceuticals (e.g., SSRIs), as relevant endpoints are not assessed or impossible to determine.
\end{abstract}

Keywords antidepressants, environmental risk, fish serotonergic system, HPG axis, HPI axis, 5-hydroxytryptamine, immune system, SSRIs

\section{INTRODUCTION}

\section{Antidepressants in the Aquatic Environment}

In recent years, the issue of pharmaceutical residues in the aquatic environment has received increasing attention. Many compounds have been found to be not or only partially biologically degraded in sewage treatment plants (STPs). ${ }^{1}$ Consequently, some of these bioactive substances are continuously discharged into receiving waters, potentially leading to chronic exposure of aquatic species. ${ }^{2}$ Although environmental concentrations of pharmaceuticals are extremely low (nanograms per liter) when compared to other pollutants, such as pesticides, household and personal care products, aquatic organisms may be affected at a subtoxic level, as has been reported for estrogens. ${ }^{3}$ Subtle effects may result in long-term changes that may become manifest at the individual and population level, only to be detected following several generations of a given species in

Address correspondence to Daniel R. Dietrich, Environmental Toxicology, University of Konstanz, PO Box X-918, 78457 Konstanz. E-mail: daniel.dietrich@uni-konstanz.de an ecosystem. ${ }^{2-4}$ Such subtle effects, and not the routinely determined overt toxicity at extremely high concentrations, are causally related to a highly specific mode of action. This obviously pertains to pharmaceuticals, which are tailored toward interaction with a specific molecular target or system, and thus a specific mode of action is desired in order to demonstrate efficacy in patients at relatively low concentrations of the pharmaceutical. However, as the pharmacological targets in humans, for example, neurotransmitter systems in the brain, are often phylogenetically highly conserved across numerous kingdoms and phyla, including fish, a potential for adverse effects in environmental species, even at the low concentrations observed in the environment, may be hypothesized. ${ }^{5}$ When potential subtle effects in various species are considered, it is quite obvious that the standardized ecotoxicological tests employing acute exposure to pharmaceutical concentrations several orders of magnitude above those observed in the environment are incapable of delivering useful data for environmental risk assessment of pharmaceuticals.

Selective serotonin reuptake inhibitors (SSRIs) are best known for their antidepressive properties, but are also 
administered in the treatment of other psychatric disorders, e.g., anxiety, eating disorders, and obsessive-compulsive disorder in connection with Tourette's syndrome. Since fluoxetine

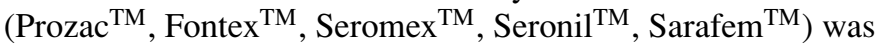
marketed as one of the first SSRIs available for clinical application in the $1980 \mathrm{~s},{ }^{6}$ the use of SSRIs in human therapeutics has increased steadily. The number of SSRI prescriptions in Canada rose from 8.7 million to 15.7 million between 1999 and 2003, representing an increase of $80.3 \% .^{7} \mathrm{~A}$ similar trend is apparent in the United States, where the number of prescriptions for fluoxetine rose from 7.3 million in 2000 to 23.0 million in 2005 . $^{8}$ Paxil $^{\mathrm{TM}}$ (paroxetine hydrochloride) headed the RxList of the Top300 prescriptions for 2005, based on the number of U.S. prescriptions dispensed. ${ }^{9}$ Comparable developments have been observed in Australia and in many European countries. ${ }^{10}$ In Norway, there has been a $320 \%$ increase in SSRI consumption since 1996. ${ }^{11}$ Consequently, the issue of SSRIs and their metabolites as micropollutants in the aquatic environment has received more and more attention over the past years. As these drugs require chronic administration to elicit the desired therapeutic effect in patients, it can be assumed that when the current prescription trend is sustained and the per capita wastewater treatment effluent to surface water ratio steadily increases, the environmental concentrations of these pharmaceuticals will also increase. It should also be taken into account that there may be seasonal variations, that is, the number of SSRI prescriptions may peak during the fall and winter, caused by a higher incidence of anxiety and depression ("winter depression").

Fluoxetine and several other SSRIs have been detected in sewage water as well as in surface waters (Table 1). Paroxetine and sertraline were detected in raw sewage effluents from a psychiatric hospital in Troms $\emptyset$ (Norway) at concentrations of $20 \mathrm{ng} / \mathrm{L}$ and $100 \mathrm{ng} / \mathrm{L}$, respectively. ${ }^{12}$ In a subsequent study, water samples from three different STPs and a pump station were analyzed for the presence of the five most common SSRI formulations: citalopram, sertraline, paroxetine, fluoxetine, and fluvoxamine. ${ }^{11}$ The highest levels were found for citalopram, with $612 \mathrm{ng} / \mathrm{L}$ and $382 \mathrm{ng} / \mathrm{L}$ in the Hamna STP influent and effluent, respectively, demonstrating the limited retention and biological degradation of SSRIs in STPs. Fluoxetine was also detected in U.S. streams at an estimated maximum concentration of $12 \mathrm{ng} / \mathrm{L}^{13}$ and in STP effluents at concentrations of up to $540 \mathrm{ng} / \mathrm{L}^{14}$; however, the latter value is rather high compared to other analytical data and most likely not representative for the SSRI levels in U.S. STP effluents. In Canada, the distribution of fluoxetine in surface waters near STPs demonstrated maximum concentrations of $99 \mathrm{ng} / \mathrm{L}$ and $46 \mathrm{ng} / \mathrm{L}$ in effluent and receiving water, respectively. ${ }^{15}$ The pharmacologically active

TABLE 1

SSRI detection in the aquatic environment. Note LOD, limit of detection; n.a., not available; STP, sewage treatment plant

\begin{tabular}{|c|c|c|c|c|c|}
\hline Compound & $\begin{array}{c}\text { Concentration } \\
(\mathrm{ng} / \mathrm{L})\end{array}$ & Sampling site & $\begin{array}{c}\text { Number of samples, } \\
\text { detection method } \\
\text { (recovery) }\end{array}$ & $\begin{array}{l}\text { LOD } \\
(\mathrm{ng} / \mathrm{L})\end{array}$ & Reference \\
\hline & $38 \pm 3$ & Burlington STP effluent & \multirow{2}{*}{$n=3, \mathrm{LC}-\mathrm{ESI}-\mathrm{MS} / \mathrm{MS}$} & \multirow{2}{*}{$5-20$} & \multirow{2}{*}{15} \\
\hline & $99 \pm 7$ & Little River STP effluent & & & \\
\hline Fluoxetine & 12 (estimated) & U.S. streams & $n=84, \mathrm{LC}-\mathrm{ESI}-\mathrm{MS},(\leq 60 \%)$ & 18 & 13 \\
\hline Fluoxetine & 540 & STP effluent & $n=3 ?$ LC-ESI-MS, $(79-82 \%)$ & n. a. & 14 \\
\hline \multirow[t]{3}{*}{ Fluoxetine } & 17 & STP influent & \multirow[t]{3}{*}{$n=6$, LC-ESI-MS/MS } & \multirow[t]{3}{*}{0.1} & \multirow[t]{3}{*}{16} \\
\hline & 25 & STP effluent & & & \\
\hline & 2.6 & Las Vegas Wash & & & \\
\hline Paroxetine & 20 & Åsgård sewer & $n=1$, semiquantitative LC-ESI-MS/MS & n. a. & 12 \\
\hline Sertraline & 100 & Åsgård sewer & $n=1$, semiquantitative LC-ESI-MS/MS & n. a. & 12 \\
\hline \multirow[t]{7}{*}{ Citalopram } & 32.7 & Sjølund pump station & \multirow[t]{7}{*}{ LC-ESI-MS } & \multirow[t]{7}{*}{ n. a. } & \multirow[t]{7}{*}{11} \\
\hline & 13.0 & Langnes STP influent & & & \\
\hline & 9.2 & Langnes STP effluent & & & \\
\hline & 145 & Breivika STP influent & & & \\
\hline & 62.0 & Breivika STP effluent & & & \\
\hline & 612 & Hamna STP influent & & & \\
\hline & 382 & Hamna STP effluent & & & \\
\hline
\end{tabular}


fluoxetine metabolite norfluoxetine (see next section) was either not determined ${ }^{13}$ or not detected ${ }^{14,15}$ in these studies due to methodological restrictions. ${ }^{16}$ However, some information is available from a most recent study where norfluoxetine was reported in water samples (STP influent and effluent, surface water, drinking water) with the highest concentration of $9.9 \mathrm{ng} / \mathrm{L}$ in STP influent. ${ }^{16}$ However it must be noted that the available analytical data on environmental SSRI levels are somewhat biased, as most data stem from sampling sites specifically chosen for SSRI contamination, i.e., downstream of STPs of intensely urbanized areas $^{13}$ or in the vicinity of STPs receiving hospital effluents. ${ }^{11,12}$ Moreover, in order to properly evaluate the environmental contamination and bioavailability of SSRIs, the ready dissipation of SSRI (e.g., fluoxetine) from the aqueous phase to sediments has to be accounted for. ${ }^{17}$ Indeed, information on the presence of SSRIs in sediments and therefore aqueous to sediment partitioning and the respective environmental consequences is yet lacking.

Despite rapid analytical developments, there is still a dearth of knowledge regarding the environmental half-life and bioavailability of norfluoxetine in the aquatic environment. In addition to ambient exposure, norfluoxetine may be produced via metabolic conversion of fluoxetine in aquatic organisms. In a preliminary study, Brooks and coworkers ${ }^{18}$ examined three different fish species, bluegill (Lepomis macrochirus), channel catfish (Ictalurus punctatus), and black crappie (Pomoxis nigromaculatus), from an effluent-dominated stream in northern Texas. Brain, liver, and muscle tissue samples were analyzed for the presence of fluoxetine, sertraline, and their respective metabolites, norfluoxetine and desmethylsertraline. Unfortunately, the study failed to provide data on the concentrations of these compounds in the ambient water at the sampling sites. Nonetheless, the target compounds were found in all tissues of the species examined at levels greater than $0.1 \mathrm{ng} / \mathrm{g}$ homogenate, with a detection limit of $0.01 \mathrm{ng} / \mathrm{g}$. In all three species, the highest concentrations were detected in brain (mean \pm standard deviation: fluoxetine $1.58 \pm$ $0.74 \mathrm{ng} / \mathrm{g}$; norfluoxetine $8.86 \pm 5.9 \mathrm{ng} / \mathrm{g}$; sertraline $4.27 \pm 1.4$ $\mathrm{ng} / \mathrm{g}$; desmethylsertraline $15.6 \pm 14.3 \mathrm{ng} / \mathrm{g}$ ) and liver (fluoxetine $1.34 \pm 0.65 \mathrm{ng} / \mathrm{g}$; norfluoxetine $10.27 \pm 5.73 \mathrm{ng} / \mathrm{g}$; sertraline $3.59 \pm 1.67 \mathrm{ng} / \mathrm{g}$; desmethylsertraline $12.94 \pm 10.45 \mathrm{ng} / \mathrm{g})$. The physiological consequences of these concentrations in exposed fish are yet unclear, as presently almost no information is available on SSRI pharmacokinetics and pharmacodynamics in fish species.

Uptake of lipophilic xenobiotics $\left(\log K_{\text {ow }}>3\right)$ into the bloodstream in fish primarily occurs across the gills; that is, the amount of uptake via ingestion appears to be negligible in view of the normally low feeding rates and water intake of fish. ${ }^{19}$ In contrast to the situation in mammals (intestinal uptake), xenobiotics absorbed via fish gills are distributed systemically and thus are not subject to a "first-pass effect" in the liver-that is, metabolic conversion and partial excretion prior to systemic distribution. ${ }^{20}$ The latter considerations are important when mammalian data are employed in the evaluation of fish pharmacokinetics and exposure levels. Nonetheless, mammalian toxico- and pharmacodynamics and metabolism of SSRIs may serve as a basis to estimate the behavior and potential adverse effects of these pharmaceuticals in fish.

\section{Physicochemical Properties and Pharmacokinetics of SSRIs}

Compounds classified as SSRIs share a common primary mode of action as antidepressants, i.e. inhibition of the specific serotonin transporter (5-hydroxytryptamine transporter, 5-HTT) in the central nervous system. However, the pharmacologically active substances display some considerable differences in their chemical structure, pharmacokinetic properties, and metabolism $^{21}$ (Table 2).

Although all of the SSRIs presented in Table 2 are moderately to highly lipophilic, fluoxetine has by far the largest volume of distribution (up to $100 \mathrm{~L} / \mathrm{kg}$ body weight), indicating extensive tissue accumulation. ${ }^{6}$ Fluoxetine also appears to represent a special case with regard to pharmacological activity as its metabolic conversion, mainly $N$-demethylation catalyzed by the cytochrome P-450 (P450) isoenzyme CYP2D6 ${ }^{22}$ in the human liver, results in the production of the equally active metabolite norfluoxetine. Under steady-state conditions, the concentration of norfluoxetine usually exceeds the concentration of fluoxetine. ${ }^{6}$ The pharmacological half-life $\left(t_{1 / 2}\right)$ of fluoxetine ranges between 1 and 4 days, while norfluoxetine is even more stable in human plasma $\left(t_{1 / 2}=7-15\right.$ days). The half-lives of the other SSRIs range between 24 and $36 \mathrm{~h}$ (Table 2). As a consequence of the high volume of distribution and thus long $t_{1 / 2}$ of fluoxetine, treatments of 1 to 22 months are necessary to achieve steady-state conditions in human patients. The primary excretion route for all SSRI formulations and their metabolites is via urine. ${ }^{21}$

The various SSRIs often not only are substrates for specific cytochrome P-450 isoenzymes but also display inhibitory activity and may either regulate their own metabolism via a negative feedback mechanism or block other P450 isoenzymes; therefore, a common feature of all formulations is their potential for drug-drug interactions with other classes of pharmaceuticals, as reviewed by Hiemke and Härtter. ${ }^{6}$ For example, clinical pharmacokinetic studies demonstrated that fluoxetine, as well as its main metabolite norfluoxetine, may affect the biotransformation pathways of other pharmaceutical compounds, such as the tricyclic antidepressant clomipramine ${ }^{21}$ and the sedative midazolam $^{23}$ metabolized by CYP2D6 and CYP3A4, respectively, thereby impairing the clearance of these substances. Fluvoxamine was shown to be an inhibitor of several CYP subtypes, including CYP1A2, CYP2D6, and CYP3A4, ${ }^{6}$ and may also interfere with the metabolism of CYP2C9 substrates. ${ }^{24}$ Further potential interactions of SSRI formulations with various drugs through P450 enzyme inhibition have been summarized by Park and colleagues. ${ }^{25}$

As mentioned earlier, norfluoxetine and the sertraline metabolite desmethylsertraline were detected in different tissues 


\section{TABLE 2}

Physicochemical and pharmacokinetic properties of commonly prescribed SSRIs. ${ }^{201}$ Note. bw., body weight; conc., concentration; Me, methyl group; n.a., not available; $\mathrm{Ph}$, phenyl group

\begin{tabular}{|c|c|c|c|c|}
\hline $\begin{array}{l}\text { Generic name } \\
\text { (CAS number) }\end{array}$ & Structure & $\begin{array}{l}\text { Chemical formula, } \\
\mathrm{MW}\left(\mathrm{g} \mathrm{mol}^{-1}\right) \text {, } \\
\log K_{\text {ow }}\end{array}$ & $\begin{array}{l}\text { Therapeutic dose, } \\
V_{d}(\mathrm{~L} / \mathrm{kg} \text { bw. })^{6} \\
\text { bioavailability }^{21}, \\
\text { plasma conc. (ng/ml) }\end{array}$ & 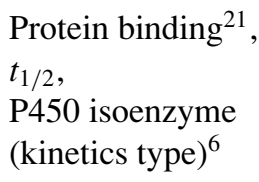 \\
\hline $\begin{array}{l}\text { Fluoxetine } \\
\qquad(54910-89-3)\end{array}$ & & $\begin{array}{l}\mathrm{C}_{17} \mathrm{H}_{18} \mathrm{~F}_{3} \mathrm{NO} \\
309.33 \\
1.57^{14}-5.37^{202}\end{array}$ & $\begin{array}{l}20-60 \mathrm{mg} / \mathrm{day}^{22} \\
14-100 \\
<90 \% \\
50-480^{22} \\
\quad \text { (NFX: } 50-450 \text { ) }\end{array}$ & $\begin{array}{l}>95 \% \\
1 \text { to } 4 \text { days } \\
\text { CYP2D6 } \\
\text { CYP2C9 } \\
\text { (nonlinear) }\end{array}$ \\
\hline $\begin{array}{l}\text { Fluvoxamine } \\
\quad(54739-18-3)\end{array}$ & & $\begin{array}{l}\mathrm{C}_{15} \mathrm{H}_{21} \mathrm{~F}_{3} \mathrm{~N}_{2} \mathrm{O}_{2} \\
318.34 \\
3.63^{202}\end{array}$ & $\begin{array}{l}150 \mathrm{mg} / \text { day }^{21} \\
\sim 25 \\
\sim 50 \% \\
\text { n.a. }\end{array}$ & $\begin{array}{l}77 \% \\
15.6 \mathrm{~h} \\
\text { CYP1A2 } \\
\text { CYP2D6 } \\
\text { (nonlinear) }\end{array}$ \\
\hline $\begin{array}{l}\text { Paroxetine } \\
\quad(61869-08-7)\end{array}$ & & $\begin{array}{l}\mathrm{C}_{19} \mathrm{H}_{20} \mathrm{FNO}_{3} \\
329.37 \\
3.369^{202}-4.74^{203}\end{array}$ & $\begin{array}{l}20 \mathrm{mg} / \text { day }^{21} \\
2-12 \\
\sim 50 \% \\
10.7^{204}\end{array}$ & $\begin{array}{l}\sim 95 \% \\
\sim 24 \mathrm{~h} \\
\text { CYP2D6 } \\
\quad \text { (nonlinear) }\end{array}$ \\
\hline $\begin{array}{l}\text { Sertraline } \\
\quad(79617-96-2)\end{array}$ & & $\begin{array}{l}\mathrm{C}_{17} \mathrm{H}_{17} \mathrm{Cl}_{2} \mathrm{~N} \\
306.23 \\
5.29^{205}-5.567^{202}\end{array}$ & $\begin{array}{l}50 \mathrm{mg} / \text { day }^{21} \\
>20 \\
\text { n.a. } \\
\text { n.a. }\end{array}$ & $\begin{array}{l}>95 \% \\
26 \mathrm{~h} \\
\text { CYP2B6 } \\
\text { CYP2C19 } \\
\text { CYP2C9 } \\
\text { (linear) }\end{array}$ \\
\hline $\begin{array}{l}\text { Citalopram } \\
(59729-33-8)\end{array}$ & & $\begin{array}{l}\mathrm{C}_{20} \mathrm{H}_{21} \mathrm{FN}_{2} \mathrm{O} \\
324.39 \\
3.74^{205}-4.222\end{array}$ & $\begin{array}{l}40 \mathrm{mg} / \mathrm{day}^{21} \\
14^{21}-20^{206} \\
\sim 80 \% \\
\text { n.a. }\end{array}$ & $\begin{array}{l}80 \% \\
35 \mathrm{~h} \\
\text { CYP2C19 } \\
\quad \text { (linear) }\end{array}$ \\
\hline
\end{tabular}

of several fish species ${ }^{18}$ and may at least partially be produced by enzymatic conversion. Presumably, the enzymes responsible for SSRI metabolism in fish also belong to the cytochrome P-450 superfamily, as these key metabolizing enzymes are highly conserved among vertebrates and may display a sim- ilar substrate specificity. ${ }^{26}$ In the Japanese puffer fish (Takifugu rubripes), also known as fugu, orthologous nucleotide sequences from 17 of 18 mammalian P450 families were detected. ${ }^{27}$ Even though McArthur et al. ${ }^{28}$ observed that teleost and mammalian $\mathrm{P} 450$ genes belonging to the CYP3A subfamily have undergone 
independent diversification in the course of gene duplication events that may have coincided with the acquisition of new functions, it can be expected that SSRIs may interact with and inhibit some $\mathrm{P} 450$ isoenzymes in fish. This would be of particular concern with regard to the interaction with $\mathrm{P} 450$ isoenzymes responsible for steroid metabolism and thus hormonal homeostasis in fish and in view of the presence of heterogeneous pharmaceutical mixtures in the aquatic environment.

In order to assess the potential risk of SSRI exposure to aquatic wildlife, i.e. fish species, a better understanding of the involved physiological and pharmacological mechanisms would be advantageous. As serotonin is a phylogenetically ancient neurotransmitter, it is highly conceivable that SSRIs, active in humans and other mammals, could display similar pharmacological activites in fish. However, due to the complexity of the serotonergic system and, in particular, its interactions with other neurotransmitter and hormone systems, the downstream effects of SSRI action on known pharmacological target molecules in fish may differ considerably. In addition, SSRIs may affect other signal transduction pathways in fish that are either not present or differently regulated in humans. ${ }^{2}$ As a consequence, standardized acute exposure experiments investigating the ecotoxic potential of SSRIs are most likely not sufficient to assess the risk of chronic exposure to low environmental concentrations.

It is beyond the scope of this review to address the potential cumulative/synergistic/additive effects of mixtures of SSRIs or other pharmaceutical agents acting on the serotonergic system (tricyclic antidepressants [TCAs], monoamine oxidase [MAO] inhibitors). Nevertheless, the possible occurrence of these interactions under environmental exposure conditions should be kept in mind. In order to evaluate the potential impacts of chronic SSRI exposure in the aquatic environment and in view of the potential interactions of SSRIs with fish P450 enzymes, 5-HT receptors, and 5-HTT, the currently known anatomical features and physiological functions of the mammalian and fish serotonergic system are compared.

\section{THE SEROTONERGIC SYSTEM}

\section{Mammals}

In addition to its role as vasoconstrictive agent in blood vessels, serotonin (5-hydroxytryptamine, 5-HT) is best known as a neurotransmitter of the central nervous system. The analysis of various mammalian species, representing different phyla, with methods such as immunohistofluorescence and radiography, revealed that the anatomical organization of the vertebrate serotonergic system is highly conserved. ${ }^{29}$ A characteristic accumulation of 5-HT-positive cells occurs in the midline raphe region of the mammalian brain, projecting numerous fibers into different areas of the telencephalon. ${ }^{29}$ In the mammalian brain, serotonergic neurons generated during embryonic development of the organism represent one of the most ramified neuronal networks.
In chemical terms, 5-HT is a hydrophilic indoleamine derived from the amino acid tryptophan. It has been recognized that the key enzyme for 5-HT synthesis is the tryptophan hydroxylase (TPH), which converts tryptophan to 5-hydroxytryptophan (Figure 1), a process limited by tryptophan availability. ${ }^{30}$

5 -HT is stored in presynaptic vesicles or in storage cells to be released in response to a stimulating signal. As neurotransmitter,

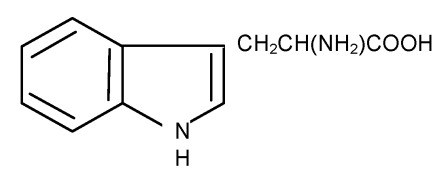

Tryptophan

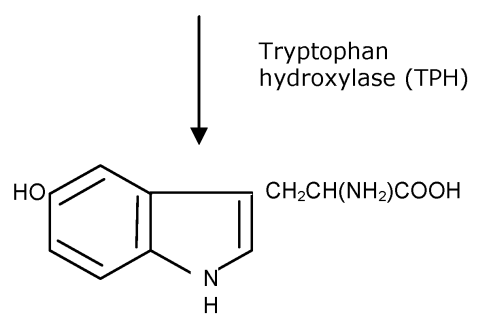

5-hydroxytryptophan (5-HTP)

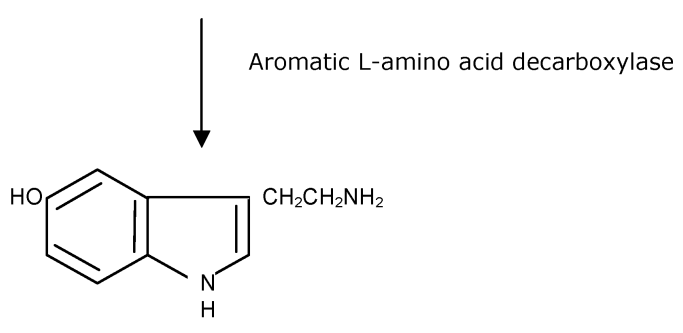

5-hydroxytryptamine (5-HT), Serotonin

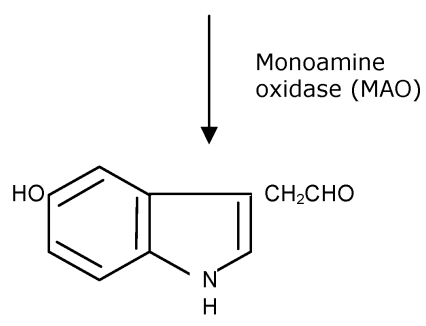

5-hydroxyindoleacetaldehyde

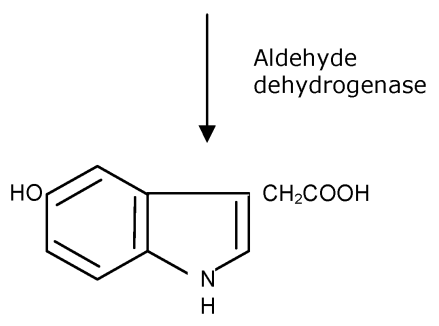

5-hydroxyindoleacetic acid (5-HIAA)

FIG. 1. Serotonin metabolism, modified from Fuller. ${ }^{197}$ 
TABLE 3

5-HT receptor subtypes and signaling pathways in various species, classification based on pharmacological profile, second messenger system and nucleotide sequence homologies. ${ }^{32,60,207,208}$ Note. AC, adenylate cyclase; PLC, phospholipase C; a) predicted, based on mRNA fragments; b) $\mathrm{G}_{\mathrm{i} / 0}, \mathrm{G}_{\mathrm{s}}$, and $\mathrm{G}_{\mathrm{q}}$ are $\mathrm{G}$ protein subtypes; c) $5-\mathrm{HT}_{1 \mathrm{~B}}$ (rodents)/5- $\mathrm{HT}_{1 D \beta}$ (human): species homologues ( $97 \%$ sequence similarity) ${ }^{32}$; d) no functional protein detected.

\begin{tabular}{|c|c|c|c|}
\hline Family & $\begin{array}{l}\text { Transduction } \\
\text { pathway }{ }^{b}\end{array}$ & Subtypes & Species \\
\hline \multirow[t]{5}{*}{$5-\mathrm{HT}_{1}$} & $\begin{array}{l}\mathrm{G}_{\mathrm{i} / 0} \text { inhibition of } \mathrm{AC} \text {, } \\
\text { stimulation of } \\
\mathrm{K}^{+} \text {efflux }\end{array}$ & $5-\mathrm{HT}_{1 \mathrm{~A}}$ & $\begin{array}{l}\text { Human, rodents (mouse, rat), other mammals (cat, cow, dog), } \\
\text { chicken }^{\text {a) }} \text {, frog, fish (Arctic charr, fugu, tilapia, trout), sea urchin }{ }^{\text {a) }}\end{array}$ \\
\hline & & $5-\mathrm{HT}_{1 \mathrm{~B}} / 5-\mathrm{HT}_{1 D \beta}^{\mathrm{c})}$ & $\begin{array}{l}\text { Human, rodents (mouse, rat, guinea pig, hamster), other mammals } \\
\left(\text { cow, pig, oppossum), chicken }{ }^{\text {a) }} \text {, fish (trout, zebrafish }{ }^{\text {a) }}\right), \text { sea urchin }^{\text {a) }}\end{array}$ \\
\hline & & $5-\mathrm{HT}_{1 \mathrm{D}} / 5-\mathrm{HT}_{1 D \alpha}$ & $\begin{array}{l}\text { Human, rodents (mouse, rat, guinea pig), other mammals (cow, pig), } \\
\text { fish (fugu, tilapia) }\end{array}$ \\
\hline & & $5-\mathrm{HT}_{1 \mathrm{E}}$ & Human, rodents (mouse, rat, guinea pig), other mammals (cow, $d^{\prime} g^{\mathrm{a})}$ ) \\
\hline & & $5-\mathrm{HT}_{1 \mathrm{~F}}$ & Human, rodents (mouse, rat, guinea pig), pig \\
\hline \multirow[t]{3}{*}{$5-\mathrm{HT}_{2}$} & $\begin{array}{l}\mathrm{G}_{\mathrm{q}} \text { stimulation of PLC, } \\
\text { inhibition of } \mathrm{K}^{+} \\
\text {efflux }\end{array}$ & $5-\mathrm{HT}_{2 \mathrm{~A}}$ & $\begin{array}{l}\text { Human, rodents (mouse, rat, guinea pig), other mammals (cow, dog, } \\
\text { pig, rhesus monkey), fish (zebrafish }{ }^{\mathrm{a})} \text { ) }\end{array}$ \\
\hline & & $5-\mathrm{HT}_{2 \mathrm{~B}}$ & $\begin{array}{l}\text { Human, rodents (mouse, rat, guinea pig), other mammals (cow, dog, } \\
\text { pig), fish (zebrafish) }\end{array}$ \\
\hline & & $5-\mathrm{HT}_{2 \mathrm{C}}$ & $\begin{array}{l}\text { Human, rodents (mouse, rat), other mammals (chimpanzee, cow, pig), } \\
\text { fish }\left(\text { (zebrafish }^{\text {a) }}\right) \text {, sea urchin }{ }^{\text {a) }}\end{array}$ \\
\hline \multirow[t]{5}{*}{$5-\mathrm{HT}_{3}$} & $\begin{array}{l}\text { ligand-gated ion } \\
\text { channels }\end{array}$ & $5-\mathrm{HT}_{3 \mathrm{~A}}$ & Human, rodents (mouse, rat), other mammals (dog, ferret) \\
\hline & & $5-\mathrm{HT}_{3 \mathrm{~B}}$ & Human, rodents (mouse, rat), rabbit \\
\hline & & $5-\mathrm{HT}_{3 \mathrm{C}}$ & Human \\
\hline & & $5-\mathrm{HT}_{3 \mathrm{D}}$ & Human \\
\hline & & $5-\mathrm{HT}_{3 \mathrm{E}}$ & Human \\
\hline $5-\mathrm{HT}_{4}$ & $\mathrm{G}_{\mathrm{s}}$ stimulation of $\mathrm{AC}$ & $?$ & Human, rodents (mouse, rat), cow, fish (zebrafish ${ }^{\text {a) }}$ ) \\
\hline $5-h t_{5}^{d)}$ & $\mathrm{G}_{\mathrm{i} / 0} ?$ & $\begin{array}{l}5-h t_{5 \mathrm{~A}} \\
5-h t_{5 \mathrm{~B}}\end{array}$ & $\begin{array}{l}\text { Human, rodents (mouse, rat, guinea pig), fish }\left(\text { zebrafish }^{\mathrm{a})}\right) \\
\text { Rodents (mouse, } \text { rat }^{\mathrm{a})} \text { ) }\end{array}$ \\
\hline $5-\mathrm{HT}_{6}$ & $\mathrm{G}_{\mathrm{s}}$ & $?$ & Human, rodents (mouse, rat), chimpanzee, fish (swordtail, zebrafish ${ }^{\mathrm{a}}$ ) \\
\hline $5-\mathrm{HT}_{7}$ & $\mathrm{G}_{\mathrm{s}}$ & $?$ & $\begin{array}{l}\text { Human, rodents (mouse, rat, guinea pig, golden hamster), fruit fly, fish } \\
\left(\text { (zebrafish }^{\text {a) }}\right)\end{array}$ \\
\hline
\end{tabular}

5-HT binds to presynaptic and postsynaptic receptors resulting in activation of intracellular messenger systems. By activating somatodendritic autoreceptors, 5-HT has an inhibitory effect on its own release from serotonergic neurons in the dorsal raphe region. ${ }^{31}$ On the basis of structural and functional properties, seven families of 5-HT receptors have been recognized in mammals to date, with some containing several subtype ${ }^{32}$, resulting in a total of at least 15 members. ${ }^{33}$ With the exception of the 5$\mathrm{HT}_{3}$ family, which is a member of the ligand-gated ion channel receptor superfamily, all known 5-HT receptors are coupled to a G-protein ${ }^{32}$ (Table 3).

The 5-HT receptor class represents one of the most versatile neurotransmitter receptor classes known to date with most likely more subtypes being identified in the future. ${ }^{34}$ Moreover, the occurrence of multiple splice variants, RNA edited isoforms or receptor homo- and heterodimerizations cannot be excluded. ${ }^{32}$ As integral elements of serotonergic signal transduction, 5-HT receptors represent the primary drug target sites. Consequently, pharmaceutical development has provided for various substances with agonistic or antagonistic properties applicable to research and for medicinal purposes (Table 4).

Following interaction with and consequently activation of postsynaptic receptors, 5-HT is removed from the extracellular space, thereby terminating neurotransmission (Figure 2). Removal occurs by means of active transport into presynaptic nerve endings, where 5-HT is stored in vesicles via an unspecific vesicular monoamine transporter (VMAT). ${ }^{35}$ Vesicular 5-HT may be recycled or degraded by a monoamine oxidase (MAO) and an aldehyde dehydrogenase to the main product 5-hydroxyindole acetic acid (5-HIAA). In terrestrial vertebrates, two MAO forms have been described. ${ }^{36} \mathrm{MAO}$ A is mainly responsible for deamination of serotonin and norepinephrine and can be inhibited by 


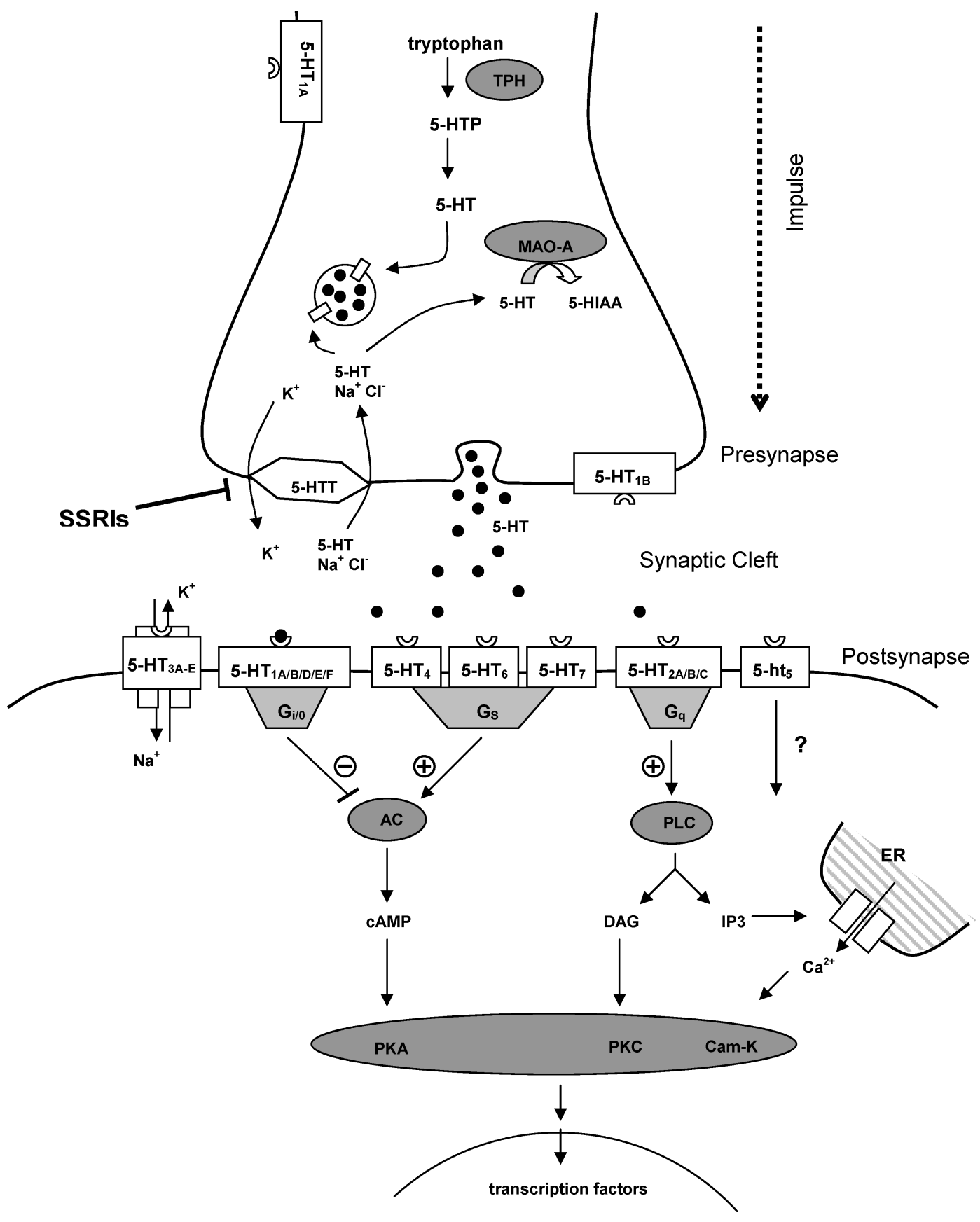

FIG. 2. Serotonergic neurotransmission in mammals. AC, adenylate cyclase; $\mathrm{Cam}-\mathrm{K}, \mathrm{Ca}^{2+} /$ calmodulin-dependent protein kinase; DAG, diacylglycerol; ER, endoplasmatic reticulum; IP3, inositol triphosphate; PKA, protein kinase A; PKC, protein kinase C; PLC, phospholipase $\mathrm{C} ; \longrightarrow=$ inhibition; $\longrightarrow=$ stimulation; 5 -ht $\mathrm{h}_{5}=$ predicted 5-HT receptor subtype 5 , based on mRNA fragments.

harmaline and clorgyline, while MAO B primarily deaminates benzylamine and phenylethylamine and is inhibited by deprenyl and pargyline. ${ }^{37}$

The specific 5-HT transporter (5-HTT)—representing the main target for the pharmacological action of SSRIs-is located in the presynaptic plasma membrane (Figure 2) and is primarily responsible for the synaptic clearance of 5-HT after neurotransmitter release. ${ }^{38}$ In contrast to the numerous 5 -HT receptors reported, as yet only one 5-HTT protein has been identified. ${ }^{34}$ As a monoamine transporter, 5-HTT belongs to the solute-linked carrier 6 (SLC6) family, a diverse set of $\mathrm{Na}^{+} / \mathrm{Cl}^{-}$-dependent neurotransmitter transporters comprising five subfamilies. ${ }^{39}$ Three 
TABLE 4

Selected 5-HT receptor agonists and antagonists

\begin{tabular}{llc}
\hline Function & \multicolumn{1}{c}{ Substance } & $\begin{array}{c}\text { 5-HT receptor } \\
\text { subtype }\end{array}$ \\
\hline Agonist & 2-methyl-5-HT & 3 \\
& 8-OH-DPAT & $1 \mathrm{~A}$ \\
& $\alpha$-methylserotonin & 2 \\
Antagonist & Chlorophenyl piperazine & 1 \\
& Cyproheptadine & $2 \mathrm{~A}$ \\
& Ketanserin & $2 \mathrm{~A}$ \\
& LY53857 & 2 \\
& Metergoline & 1 \\
& Methiothepin & 1 \\
& Methysergide & $1+2$ \\
& Metoclopramide & 3 \\
& Mianserin & 2 \\
& Ritanserin & $2 \mathrm{~A}$ \\
& Spiperone & $1 \mathrm{~A}$ \\
\hline
\end{tabular}

of these subfamilies, including the monoamine transporters, are thought to share a common structural motif, namely, 12 transmembrane domains with a larger extracellular loop containing potential glycosylation sites between domains 3 and 4, and several cytoplasmic phosphorylation sites ${ }^{40,41}$ (Figure 3). The mammalian 5-HTT has been described in the central and peripheral nervous system and also in nonneuronal tissue such as platelet, placental, and pulmonary membranes. ${ }^{42,43}$ The process of 5-HT uptake by the 5-HTT is not yet fully understood but it appears to be a two-step mechanism, i.e. symport of 5-HT with $\mathrm{Na}^{+}$ and $\mathrm{Cl}^{-}$ions into the cell and subsequent export of $\mathrm{K}^{+} .{ }^{40} \mathrm{Ap}$ parently, there are several mechanisms involved in the regulation of 5-HTT activity. Short-term changes in transporter activ- ity may be induced by posttranslational modifications such as phosphorylation. ${ }^{44}$ Potential target sites for phosphorylation are located at the cytoplasmic $\mathrm{NH}_{2}$ and $\mathrm{COOH}$ termini of the 5-HTT molecule (Figure 3). It has been shown that activation of protein kinase $\mathrm{C}$ (PKC) causes internalization of 5-HTT followed by a decrease of 5-HTT-mediated 5-HT uptake in the human cell line HEK-293 in vitro. ${ }^{45}$ In a subsequent study, inhibitors of protein phosphatases 1 and 2 as well as PKC activators were observed to diminish 5-HT transport activity in the same cell model. ${ }^{41}$ Therefore, direct phosphorylation of 5-HTT as well as unbalanced protein kinase activity may play a role in the regulation of 5-HT reuptake.

SSRIs block the presynaptic 5-HTT and prevent the clearance of 5-HT from the synaptic cleft (Figure 2), thereby causing an elevation of extracellular 5-HT concentrations. ${ }^{46}$ In human therapeutic regimens, chronic treatment with SSRIs is required to achieve the desired pharmacological effect. This is at least partially due to an autoinhibitory effect of 5-HT on its own release via presynaptic $5-\mathrm{HT}_{1 \mathrm{~A}}$ autoreceptors. Furthermore, long-term modulation of serotonergic signaling by SSRIs is most likely not purely based on their direct inhibitory action on the 5-HTT but also mediated by alterations in 5-HTT gene expression levels. ${ }^{44}$

\section{Fish}

The distribution of serotonergic neurons in the central nervous system has been examined in several fish species, and 5HT-containing cells and serotonergic fibers have been found in different parts of the brain. Kah and Chambolle ${ }^{47}$ identified 5-HT fibers and perikarya in various regions of the goldfish (Carassius auratus) brain via immunohistochemistry. The telencephalon was found to be highly innervated by serotonergic fibers from other brain areas, though it did not contain any immunoreactive perikarya. 5-HT immunoreactive fibers were also detected in parts of the pituitary and the midbrain tegmentum. Serotonergic

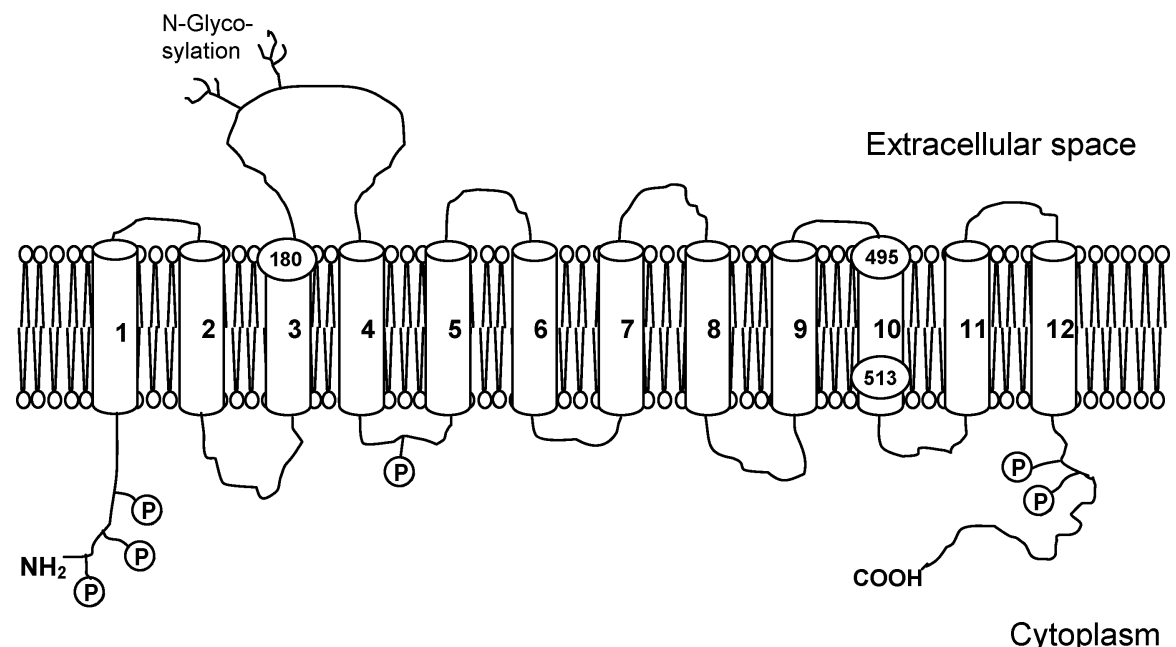

FIG. 3. Structure of the mammalian 5-HTT with 12 transmembrane domains, redrawn from Mortensen et al., ${ }^{62}$ with permission. P phosphorylation sites; $180,495,513$, protein residues affecting SSRI potency. 


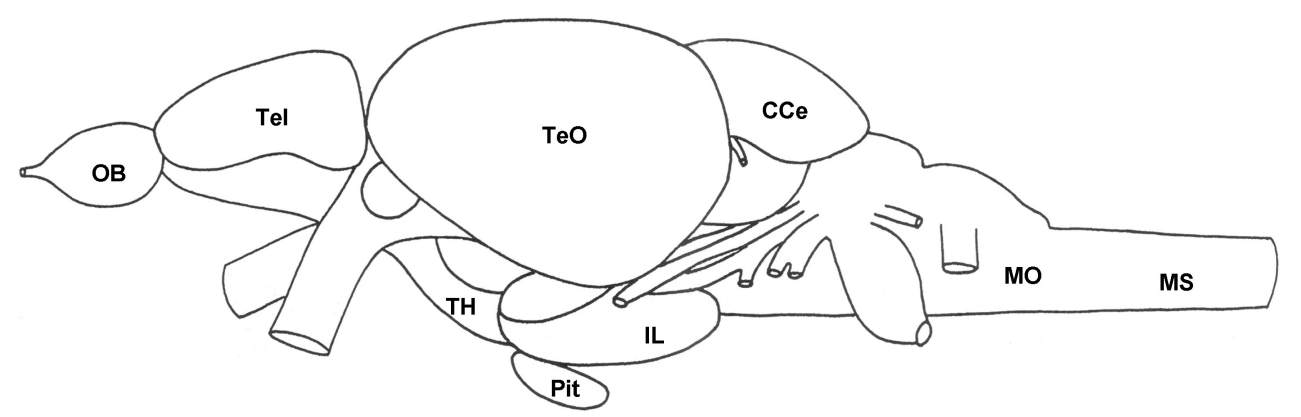

FIG. 4. Lateral view of the zebrafish brain, modified from Wulliman et al. ${ }^{198}$ Cce, corpus cerebelli; IL, inferior lobe; MO, medulla oblongata; MS, medulla spinalis; $\mathrm{OB}$, olfactory bulb; Pit, pituitary; Tel, telencephalon; TeO, tectum opticum; $\mathrm{TH}$, tuberal hypothalamus.

perikarya were localized in the posterior hypothalamus region of the diencephalon, in the ventral medulla oblongata and in an area between midbrain and medulla oblongata, called isthmus ( $n u$ cleus isthmi). The isthmus is homologous to the raphe region in terrestrial vertebrates and seems to be phylogenetically ancient. A similar arrangement of serotonergic neurons has been found in the brain of zebrafish (Danio rerio) ${ }^{48}$ (Figure 4 ). In addition to serotonergic fibers in the forebrain - consisting of olfactory bulb and telencephalon-and in the tectum opticum, 5-HT neurons were detected in the pineal stalk, hypothalamus, posterior tuberculum, and a large cluster in the tegmentum forming a medial raphe nucleus.

To complement studies on the anatomical organization of the 5-HT neuronal network, efforts to detect the various proteins that are involved in the function of the serotonergic system have resulted in the identification of several key components of the 5-HT metabolism and signal transduction system in fish, including enzymes, metabolites, receptors, and transporter mechanisms known from mammalian studies. The presence of TPH or TPH subtypes has been detected in different organs of several fish species, including the pineal organs of adult rainbow trout (Oncorhynchus mykiss) and pike (Esox lucius) $)^{49}$ the hypothalamus of adult Atlantic croaker (Micropogonias undulatus), ${ }^{50}$ and the brain and retina of zebrafish embryos. ${ }^{51,52}$ In addition, the catabolic enzyme MAO has been found in fish species such as perch (Perca fluviatilis), ${ }^{37}$ goldfish,,${ }^{53}$ rainbow trout,,${ }^{54,55}$ carp, ${ }^{55}$ pike, ${ }^{56}$ catfish (Ictalurus melas), ${ }^{57}$ Atlantic croaker, ${ }^{50}$ and zebrafish. ${ }^{58}$ However, in contrast to the serotonergic system of terrestrial vertebrates, which features the two MAO types A and $\mathrm{B}$, only one form of MAO has been detected in fish. ${ }^{36,55,56}$ While the MAO protein in some fish species has been reported to be distinct from both MAO A and MAO B ${ }^{36}$ evidence for pharmacological and structural similarities between fish MAO and mammalian MAO, especially MAO A, have been described in goldfish ${ }^{53}$ and zebrafish. ${ }^{58}$

To date, knowledge on the presence of functional 5-HT receptors in fish is still limited. Using molecular cloning techniques, $5-\mathrm{HT}_{1}$ receptor genes were identified in fugu by Yamaguchi and coworkers, ${ }^{59}$ and three genomic clones, named F1A $\alpha, \mathrm{F} 1 \mathrm{~A} \beta$, and F1D, were isolated. Following alignment of the deduced amino acid sequences, the highest similarity between fugu and human 5-HT1 receptor genes was observed in transmembrane regions, with $88.5 \%$ for $\mathrm{F} 1 \mathrm{~A} \alpha$ and $86.2 \%$ for $\mathrm{F} 1 \mathrm{~A} \beta$ when compared to the human 5-HT1A receptor gene and $78.6 \%$ for F1D and the human 5-HT1D receptor. Furthermore, it was determined that all physiologically essential amino acid residues that have been identified for human 5-HT1 receptors were conserved in fugu, indicating ligand binding properties that are similar to the equivalent human receptors. However, the occurrence of additional phosphorylation sites in fugu 5-HT receptor molecules suggested that the regulation of fugu 5-HT1 receptors may be different from their human homologues. The presence of several 5-HT receptor types has also been predicted for zebrafish on the basis of sequence similarities between zebrafish mRNA fragments and human mRNA (Table 3). ${ }^{60}$ Despite the suggestive evidence just described, it has to be taken into account that similarities in nucleotide sequences may not directly translate into protein expression, let alone functional analogy as a 5-HT receptor with equivalent signal transduction.

The same caveats apply for the investigation of putative 5-HTTs. Although recognizable 5-HTT homologues, based on nucleotide sequences, have been found to be expressed near-ubiquitously in animal phyla, ${ }^{39}$ the regulation and properties of the transporter protein may be diverse. Therefore, functional experiments are required to characterize the 5-HT transport mechanism in different species. In zebrafish, mRNA fragments have been detected that show similarities to the mRNA sequence of the human 5 -HTT. ${ }^{60}$ Recently, Wang and colleagues $^{61}$ cloned two 5-HTT cDNAs-serta (DQ285098) and sertb (DQ285099)-from zebrafish that demonstrated an amino acid sequence similarity of $66-69 \%$ and $75 \%$, respectively, compared to other vertebrate 5-HTTs. The expression patterns of both 5-HTT genes were determined by in situ hybridization. While the gene product of serta was detected in raphe nuclei, ventral posterior tuberculum, and pineal organ, sertb was found to be expressed in the medulla oblongata and in the retina. In order to examine the functionality of the gene product, serta cDNA was cloned into a vector and transfected 
into human embryonic kidney cells (HEK293 cell line) along with an enhanced green fluorescent protein expression vector. Fluorescent colonies were then used to perform 5-HT transport assays with $\left[{ }^{3} \mathrm{H}\right]-5-\mathrm{HT}$, which confirmed the occurrence of 5-HT uptake. Furthermore, 5-HT transport was inhibited by fluvoxamine maleate with an inhibiting concentration $\left(\mathrm{IC}_{50}\right)$ of $183.4 \mathrm{nM}$ $(79.7 \mu \mathrm{g} / \mathrm{L})$. This $\mathrm{IC}_{50}$ was comparable to values obtained for human and bovine 5 -HTT yielding $\mathrm{IC}_{50}$ values of $176 \pm 18 \mathrm{nM}$ $(76.5 \pm 8 \mu \mathrm{g} / \mathrm{L})$ and $138 \pm 9 \mathrm{nM}(59.9 \pm 4 \mu \mathrm{g} / \mathrm{L})$, respectively. ${ }^{62}$

The presence of a 5-HTT-like transporter was also revealed in various brain areas, e.g., in preoptic and diencephalic regions, of Japanese medaka (Oryzias latipes) by an in vitro autoradiographic binding assay. ${ }^{63}$ The iodinated cocaine analog $\left[{ }^{125} \mathrm{I}\right]-$ RTI-55, which was used as radioligand as it has been reported to bind to the 5-HTT in mammals, was completely displaced by fluoxetine hydrochloride at a concentration of $10 \mu \mathrm{M}(3.46$ $\mathrm{mg} / \mathrm{L}$ ). This provides support for the classification of this transporter as 5-HTT and suggests that 5-HT transport may be similar in mammals and fish. However, ligand binding to the 5-HT transporter-like protein alone does not prove that actual transport takes place. Therefore, further studies are needed to confirm the functional capability of this putative 5-HTT in medaka and to determine whether it may be susceptible to SSRI inhibition.

In summary, several components of the serotonergic system as known from mammalian studies have been identified in fish to date. 5-HT has been detected as neurotransmitter not only in the fish brain, but also in other fish organs and tissues where it seems to be involved in the modulation of regulatory processes, e.g., an endocrine/paracrine factor in enterochromaffin cells lining the gut, gill vasculature, specialized cells of the retina, several types of immunocompetent cells, and possibly in ovarian follicles (Krieger, personal communication). Accordingly, 5-HTT has been identified in zebrafish retina ${ }^{61}$ and was also found in ovarian follicles of zebrafish (Krieger, personal communication). Therefore, as the molecular composition of the serotonergic system in fish appears to be comparable to the mammalian system, it is reasonable to assume that environmental SSRI exposure may affect serotonergic signaling in fish by increasing 5-HT availability via 5-HTT inhibition. Nevertheless, the understanding of 5-HT function in fish physiology and the regulation of 5-HT uptake via 5-HTT is still rather limited.

\section{PHYSIOLOGICAL EFFECTS OF 5-HT IN SELECTED TISSUES}

\section{5-HT in the Gills}

Using immunohistochemical methods, 5-HT immunoreactive neurons innervating the proximal part of the efferent arterial vasculature, the filament epithelia, and the venous sinus of the gills of rainbow trout, perch, black bass (Micropterus dolomieui), eel (Anguilla anguilla), and catfish have been identified ${ }^{64}$ In addition to serotonergic neurons, nonneuronal 5HT immunopositive cells, namely, neuroepithelial cells (NECs), have been found in the efferent part of teleost gill filaments. ${ }^{65}$
NECs displaying 5-HT immunoreactivity were detected in all fish species examined, including sturgeon (Acipenser baeri), a nonteleost, while in rainbow trout an additional 5-HT immunopositive cell type was observed and described as polymorphous granular cells. ${ }^{64}$ In trout gill filaments, these two cell types have been designated as possible sites for indoleamine synthesis based on immunohistochemical experiments using relevant polyclonal antibodies, which also revealed the intracellular presence of 5-HT as well as the metabolite 5-methoxytryptamine. Furthermore, since NECs in fish were found to be morphologically similar to mammalian oxygen chemosensors, e.g., carotid bodies, it was suggested that these cells might have a comparable function. ${ }^{66,67}$ Supporting this hypothesis, 5-HT immunoreactive NECs in the gills of zebrafish were found to respond to hypoxic conditions by exhibiting hypertrophy measured as increased projection area and higher proliferation rates, accompanied by a decrease in $\mathrm{K}^{+}$current. ${ }^{67}$ Based on these findings, it has been proposed that the reaction to hypoxia that seems to be initiated by inhibition of background $\mathrm{K}^{+}$conductance may involve serotonergic signal transmission. However, whether or to what extent 5 -HT is involved in the process of oxygen chemoreception in fish is still a matter of discussion. In a previous study on isolated rainbow trout gills, Burleson and coworkers ${ }^{68}$ examined the influence of several neurochemicals, including 5-HT, on the activity of afferent nerves innervating oxygen-sensitive chemoreceptors in the first gill arch. They reported that $0.1 \mathrm{ml}$ injections of $1 \mathrm{mM}$ 5-HT caused a weak stimulation of chemoreceptor activity followed by a weak inhibition. This slight effect compared to the strong stimulation elicited by $100 \mathrm{nM}$ acetylcholine or nicotine indicates that despite 5-HT having some modulating influence, 5-HT does not appear to be the major neurochemical effector in hypoxia reaction. However, 5-HT may affect gas exchange in fish in another way, as it seems to regulate the blood flow in the gills by constricting the arterio-arterial branchial vasculature. ${ }^{65}$ In an in vivo study with rainbow trout, intra-arterial 5-HT injections $(50-250 \mathrm{nmol} / \mathrm{kg}$ ) caused a decrease of blood pressure in the dorsal aorta and an increase of ventral aortic blood pressure, presumably by constricting arteries and arterioles in the gill filaments. ${ }^{69}$ Concomitantly, the arterial oxygen tension declined while the arterial carbon dioxide tension increased, accompanied by a reduction in extracellular $\mathrm{pH}$. Taken together, these observations can be seen as indications for an impaired gas transfer associated with 5-HT-induced vasoconstriction. Pretreatment with the 5-HT receptor antagonist methysergide can reverse these effects of 5-HT on trout gills, indicating the involvement of either the $5-\mathrm{HT}_{1}$ or the $5-\mathrm{HT}_{2}$ receptor subtype. ${ }^{69,70}$ The role of $5-\mathrm{HT}_{2}$ receptors in mediating branchial vasoconstriction in fish gills was confirmed for the bald notothen (Pagothenia borchgrevinki), an Antarctic fish, using specific pharmacological agonists and antagonists. ${ }^{71}$ The prebranchial injection of the $5-\mathrm{HT}_{2}$ receptor agonist $\alpha$-methylserotonin caused an increase of branchial vascular resistance and ventral aortic pressure, thereby mimicking the action of 5-HT, while treatment with the 5- $\mathrm{HT}_{1}$ receptor agonist piperazine had no effect. Again, branchial vasoconstriction 
caused by 5 -HT could be blocked with methysergide, while vasoconstriction induced by $\alpha$-methylserotonin was completely abolished by treatment with the specific $5-\mathrm{HT}_{2}$ receptor antagonist LY53857 maleate. All of the results just described suggest the vasoconstrictive actions of 5-HT in the bald notothen to be mediated by receptors of the $5-\mathrm{HT}_{2}$ subtype. In accordance with the aforementioned findings of Fritsche et al ${ }^{69}$ in rainbow trout, a methysergide-sensitive reduction of arterial oxygen partial pressure was also observed by Sundin and coworkers ${ }^{71}$ in the bald notothen as a consequence of 5-HT-induced $(0.1 \mathrm{nmol} / \mathrm{kg})$ branchial vasoconstriction in the arterio-arterial pathway. The effect of 5-HT on arterial oxygen tension was thought to be caused by a redistribution of the blood flow within the gill. This hypothesis was confirmed in a subsequent study with rainbow trout, which demonstrated that, despite a continuous cardiac output, the blood flow rate in the distal part of the gill filaments was clearly reduced after 5-HT treatment with $100 \mathrm{nmol} / \mathrm{kg} .{ }^{72}$ Such a redirection of the blood caused by constriction of the efferent filamental artery sphincter ${ }^{64}$ could also explain the increased flow rate through the arterio-venous system observed in Atlantic cod (Gadus morhua) after 5-HT injection. ${ }^{73}$

As well as serotonergic neurons, other neurotransmitter systems innervating the gill vasculature have been identified, i.e., cholinergic and adrenergic neurons. ${ }^{65}$ These three systems seem to interact in regulating blood flow and oxygen transfer in the gills. Indeed, serotonergic neurons have been detected in synaptic contact with catecholaminergic nerve fibers in trout gill. ${ }^{64}$ Furthermore, 5-HT-mediated release of catecholamines was observed in this system. ${ }^{69}$ Circulating catecholamines elicited dilation of the filament arterial vasculature through activation of $\beta$-adrenoreceptors, thereby representing a mechanism to reverse the vasoconstriction induced by $5-\mathrm{HT},{ }^{69}$ while acetylcholine exerted vasoconstrictive effects analogous to those of 5-HT. ${ }^{64}$

This complex regulation system controlling gill blood circulation and gas transfer in fish may be affected by exogenous factors. Fish gills are directly and permanently exposed to the aquatic environment and may therefore be particularly susceptible to nonspecific effects of pharmaceutical substances in the surrounding water. So far, studies on the impact of SSRIs on fish gills or studies testing gill tissue for accumulation of these drugs are lacking. However, as Brooks and colleagues ${ }^{18}$ found fluoxetine, sertraline, and their metabolites norfluoxetine and desmethylsertraline in fish brain, liver, and, in small amounts, muscle tissue, it is likely that SSRIs may also be found in gills. SSRIs may reach the gills via blood circulation potentially in concentrations that could modulate serotonergic signaling, i.e., may specifically induce gill filament vasoconstriction through increased availability of 5-HT. Thereby, continuous SSRI exposure may lead to a decrease of blood flow and a subsequent impairment of gas exchange in certain areas of the gills and, consequently, to sustained chronic stress. The latter may be of higher relevance in the summer months of temperate regions and during the dry seasons of tropical regions of the world, where generally lower oxygen saturation and reduced water volumes and flow rates coupled with unmitigated STP effluent volumes are encountered.

\section{Involvement of 5-HT in Light/Dark Adaptation and Circadian Rhythm}

5-HT appears to play a regulatory role in sensory perceptions, e.g., visual perception, and related circadian rhythmicity. High levels of endogenous 5-HT have been detected in the retinas of various nonmammalian species, with the highest reported concentrations found in teleost retina. ${ }^{74}$ Similar to the observations of Tornqvist et al. ${ }^{75}$ who detected serotonergic amacrine cells in the goldfish retina, Jaffé and coworkers ${ }^{76}$ localized endogenous 5-HT in amacrine cells of the retina of striped mojarra (Eugerres plumieri) using biochemical and immunohistochemical techniques. In the same fish species, possible modulatory interactions between 5-HT, dopamine and noradrenaline were studied. ${ }^{77}$ The fish were injected with different 5-HT concentrations $(1,5,10,20 \mu \mathrm{M})$ in a $10-\mu 1$ injection volume in vivo and the retinas were isolated $3 \mathrm{~h}$ later for catecholamine analysis via high-performance liquid chromatography. 5-HT was found to significantly reduce the dopamine content in the retina at the lowest applied concentration of $1 \mu \mathrm{M}$, with the maximum reduction occurring at $10 \mu \mathrm{M}$. The reverse effect was observed for noradrenaline, as 5-HT increased the retinal noradrenaline levels.

In addition to 5-HT, a 5-HT uptake mechanism has been found in the retina of different fish species. Prior to the recent detection of the sertb gene product in the inner nuclear layer of zebrafish retina,${ }^{61}$ the 5-HTT was identified and characterized with radioligand binding assays in isolated goldfish retina. ${ }^{78} 5$-HT uptake was found to be temperature- and sodium-dependent and showed an allosteric regulation, suggesting the presence of a stimulatory as well as an inhibitory site in the transporter molecule. Blockade of the 5-HT reuptake mechanism in the retina of striped mojarra by injecting $10 \mu \mathrm{l}$ of $5 \mu \mathrm{M}$ imipramine did not abolish the previously observed decreasing and increasing effect of 5-HT on dopamine and noradrenaline content, respectively. ${ }^{77}$ Thus, the action of 5-HT is apparently not connected to changes in 5-HT uptake but rather is mediated at the level of the 5-HT receptors. Indeed, experiments with the 5-HT receptor antagonists methysergide, metergoline, and cyproheptadine demonstrated that the opposing effects of serotonergic modulation on dopamine and noradrenaline content in the retina could be explained by activation of two different 5-HT receptor subtypes. ${ }^{77}$ As the diminishing effect of 5-HT on dopamine levels was significantly inhibited by methysergide and metergoline, but not by cyproheptadine (Table 4), it seems likely that it was mediated by $5-\mathrm{HT}_{1}$ receptors. In contrast to the effect on dopamine, 5-HTinduced changes in noradrenaline levels could be blocked by all three antagonists, indicating the involvement of both 5- $\mathrm{HT}_{1}$ and $5-\mathrm{HT}_{2}$ receptors in this modulatory mechanism.

5-HT has been reported to be involved in the control of retinomotor movement. ${ }^{79}$ In lower vertebrates, photoreceptors and retinal pigment epithelium show specific movement patterns 


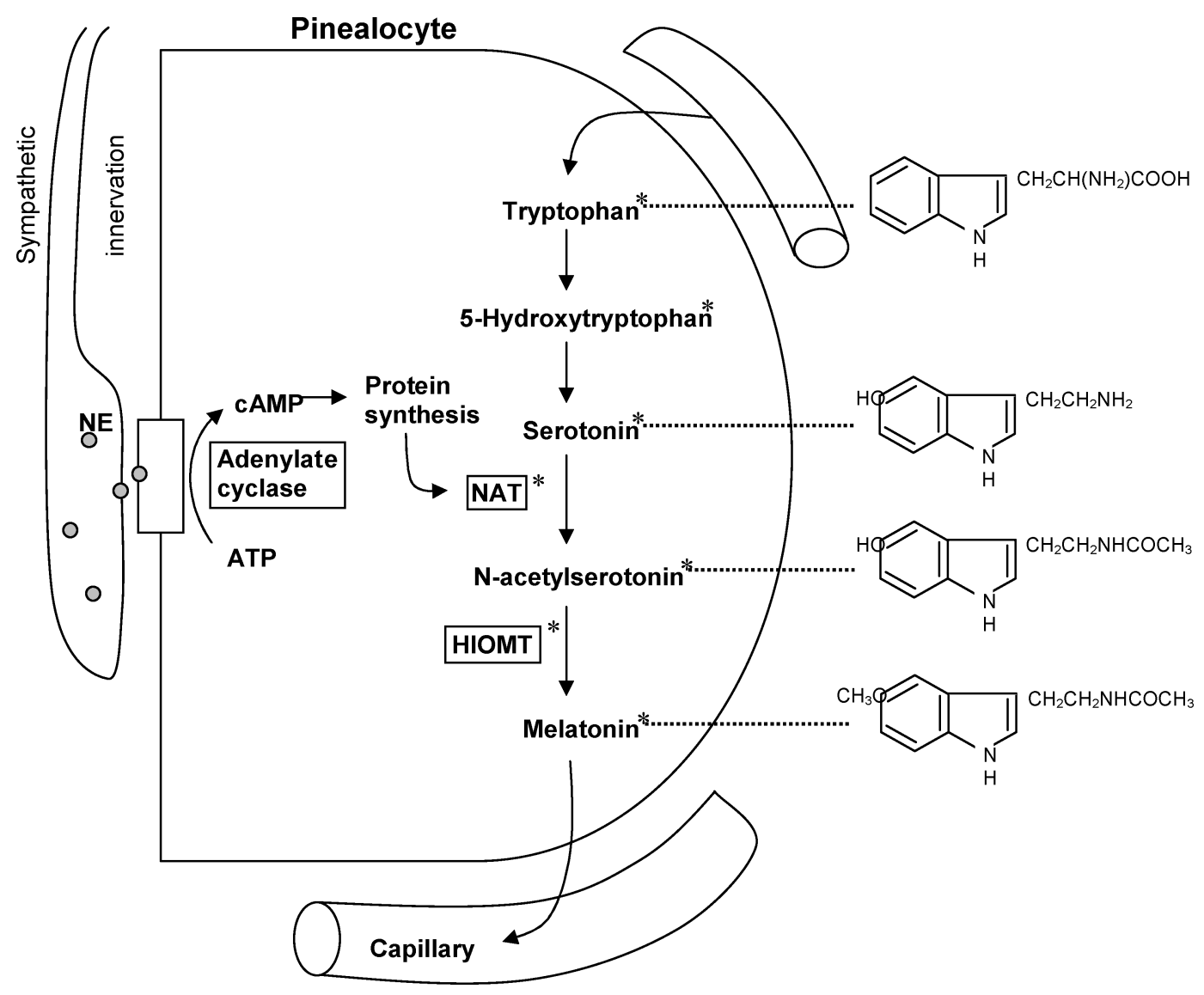

FIG. 5. Schematic of the pineal gland associated with tryptophan to melatonin conversion, modified from Heldmaier. ${ }^{199}$ NAT, serotonin $N$-acetyltransferase; NE, norepinephrine; HIOMT, hydroxyindole $O$-methyltransferase; asterisk indicates detected in fish.

as a reaction to changing light conditions or in response to an endogenous circadian signal. In a study with isolated retinas of the green sunfish (Lepomis cyanellus), Dearry and Burnside $^{79}$ demonstrated that $0.1 \mathrm{mM}$ 5-HT had an influence on the dopaminergic regulation of cone contraction by stimulating dopamine release, thus inducing light adaptation of isolated dark-adapted retina. The latter data are suggestive of a neurotransmitter function of 5-HT in the regulation of circadian rhythmicity. In addition, 5-HT is the precursor of melatonin, which is synthesized in photoreceptor cells of the retina and in the pineal organ (Figure 5) and is involved in the regulation of light/dark adaptation. Lima and Schmeer ${ }^{78}$ reported an increased uptake of $\left[{ }^{3} \mathrm{H}\right]-5-\mathrm{HT}$ into isolated retinal cells of dark-adapted compared to light-adapted goldfish and suggested that this effect may be related to the production of melatonin. Serotonin- $N$ acetyltransferase (NAT), a key enzyme of melatonin synthesis, has been found in the pineal gland (Figure 5) and retina of rainbow trout ${ }^{80,81}$ and of embryonic and adult zebrafish. ${ }^{82}$ The production of NAT is initiated by norepinephrine (NE) signaling.

Recurring changes in the activity of NAT, with peak efficiency during the dark in the pineal gland, result in varying levels of cir- culating 5-HT and, consequently, melatonin. ${ }^{80}$ In rainbow trout, 5-HT levels in the retina ${ }^{74}$ and in the pineal organ ${ }^{80}$ were found to exhibit daily fluctuations, with patterns changing under different photoperiodic conditions. It was suggested that, with a shortened photoperiod, an increased 5-HT production during the night may be necessary to ensure 5-HT availability for optimal melatonin synthesis in the pineal organ. ${ }^{80}$ Interestingly, as for vertebrates, atypical activity of NAT has been observed in fish. ${ }^{81}$ While it is generally assumed that the vertebrate retina and pineal organ both display high NAT activity in the dark, melatonin production in trout retina was actually shown to increase during the day.

Provided that SSRIs reach the retina and pineal organ in fish and affect the local 5-HT reuptake, chronic SSRI exposure may cause an alteration of normal fluctuation patterns of 5-HT and melatonin. Consequently, behavioral processes such as hunting, feeding, and reproductive behavior that are related to certain photoperiodic conditions may be affected. In salmonids, initiation and regulation of smolt transformation, referring to the change from territorial feeding behavior to downstream migration, largely depends on photoperiodic signals. ${ }^{83}$ Taking into account that NAT-dependent melatonin production in fish showed 
some unusual patterns ${ }^{81}$ the consequences of higher 5-HT levels caused by reuptake inhibition in fish may not be directly comparable to the effects in other vertebrate species. In order to elucidate whether SSRIs may have an influence on the circadian rhythm and associated behavior in fish, further investigation will be required.

\section{SEROTONERGIC MODULATION OF STRESS RESPONSE AND BEHAVIOR}

\section{5-HT in Chromaffin Tissue and Modulation of Catecholamine Release}

In addition to the aforementioned functions at the individual organ level, 5-HT may also influence various regulation systems such as stress response and correlated behavior patterns at the organism level.

Many studies with mammals have focused on investigating the mechanisms involved in acute stress reactions and it has been demonstrated that there are interactions between the adrenergic and the serotonergic system. In this context, the level of extracellular 5-HT appears to be an important factor. In 5-HTT knockout mice, several abnormal phenotypes have been observed that show similarities to clinical features of mood and anxiety disorders in humans, including increased anxiety-like behaviors and exaggerated plasma adrenaline responses to stress, as reviewed by Holmes and colleagues. ${ }^{84}$

It has been recognized that release of the catecholamines adrenaline and noradrenaline from chromaffin cells in fish is a reaction to an acute physiological challenge such as hypoxia. ${ }^{85}$ Chromaffin cells containing catecholamines have been found in the head kidney and in the walls of the posterior cardinal veins of rainbow trout. ${ }^{86,87}$ In contrast to the well-defined medulla of the adrenal gland in other vertebrates, chromaffin cells in fish form loose aggregations termed chromaffin tissue ${ }^{87}$ The cells are mostly innervated by sympathetic cholinergic fibers, which release acetylcholine in response to stimulation, thereby triggering the exocytosis of catecholamines. ${ }^{86}$ It has been proposed that 5-HT may be part of the regulation regime controlling catecholamine release. Reid and colleagues ${ }^{87}$ detected 5-HT-like immunoreactivity in chromaffin cells within the posterior cardinal vein of European eel and Atlantic cod. In rainbow trout, 5-HT was not present in chromaffin cells, but was found in a distinct population of cells located in kidney tissue. These findings provide evidence that 5-HT may act as a paracrine factor on catecholamine-releasing cells. Additionally, in an in vivo study with rainbow trout, intra-arterial injections of different 5HT doses (50-250 nmol/kg) caused dose-dependent increases in plasma noradrenaline and adrenaline levels. ${ }^{86}$ In the same study, 5 -HT treatment $(250 \mathrm{nmol} / \mathrm{kg})$ also induced the release of noradrenaline and adrenaline from chromaffin cells of the head kidney in situ.

Based on the observations in several fish studies, it is assumed that 5-HT plays a regulatory role during the acute stress reaction to conditions of low oxygen levels, ${ }^{69,71,88}$ resulting in cate- cholamine release from chromaffin cells. In both rainbow trout ${ }^{69}$ and bald notothen ${ }^{71}$ a reduction of arterial oxygen partial pressure was observed after intra-arterial 5-HT injections. In the gill filament of developing zebrafish embryos, it was observed that the formation of 5-HT-containing NECs coincided with an increased reaction to hypoxic conditions, suggesting a contribution of serotonergic neurotransmission to oxygen chemoreception. ${ }^{88}$ However, the involvement of 5-HT in hypoxia response is controversial. In an in vivo study with rainbow trout, an increase of plasma catecholamine levels was observed under hypoxic conditions, after desensitization of nicotinic receptors. ${ }^{89}$ The authors attempted to characterize the underlying mechanism and found that treatment with the $5-\mathrm{HT}_{1} / 5-\mathrm{HT}_{2}$ receptor antagonist methysergide had no effect. Therefore, it was assumed that serotonergic receptor activation was not involved in the direct stimulation of catecholamine release during acute hypoxia. Instead, the renin-angiotensin system, a regulator of cardiovascular function in fish, seemed to be activated in hypoxic trout without functional nicotinic receptors and to induce an increase in catecholamine levels. Similarly, Sundin and Nilsson ${ }^{90}$ observed that hypoxiainduced branchial vasoconstriction in rainbow trout was apparently not mediated by serotonergic signaling, as it was unaffected by methysergide. Nevertheless, it remains to be determined whether the potential modulating effect of 5-HT during hypoxia may be mediated by receptor subtypes other than $5-\mathrm{HT}_{1}$ and $5-\mathrm{HT}_{2}$.

Overall, the results of several studies indicate that 5-HT plays a role in the control of catecholamine release from chromaffin cells; however, the regulation of the specific reaction to hypoxic conditions appears to be very complex, involving a variety of modulatory factors. Consequently, the importance of potential effects of SSRIs on catecholamine release and subsequent processes are at present difficult to assess.

\section{Serotonergic Influence on the Corticotropic System}

While catecholamines are secreted during acute stress conditions, corticosteroids produced by the adrenal gland play a major role in responses to chronic stress. The regulation of these reactions appears to be quite complex. There are indications of a correlation between the brain serotonergic system and the hypothalamus-pituitary-adrenal (HPA) axis in mammals ${ }^{91}$ or in fish the hypothalamus-pituitary-interrenal (HPI) axis, which is recognized as homolog of the HPA axis. Numerous stressors seem to increase the synthesis and turnover of 5-HT, possibly mediated by stress-related corticosteroid production. Reciprocally, 5-HT appears to be involved in the regulation of corticosteroid release as several studies have demonstrated treatment with 5-HT precursors or 5-HT receptor agonists to cause an elevation of plasma glucocorticoid concentrations in humans, as reviewed by Dinan. ${ }^{92}$

Evidently, 5-HT may exert its effects at different levels of the HPA axis. As one possible mechanism, it has been proposed that 5-HT induces the secretion of ACTH from the 
pituitary and, ultimately, the release of corticosteroids by stimulating the release of corticotropin releasing hormone (CRH) in the hypothalamus. ${ }^{91,92}$ 5-HT and CRH immunopositive cells have been detected in corresponding areas in rat brain with direct synaptic contact between serotonergic nerve terminals and CRH neurons. ${ }^{93}$ In addition, an in vitro study with explanted rat hypothalami confirmed the stimulating effect of the serotonergic system on CRH secretion. ${ }^{94}$ This action of 5-HT is probably mediated through $5-\mathrm{HT}_{1 A}$ and $5-\mathrm{HT}_{2}$ receptors, as it could be blocked by metergoline, ketanserin, and ritanserin and mimicked by 8-hydroxy-2-(di-n-propylamino) tetralin (8-OH-DPAT) (Table 4). Furthermore, a direct serotonergic stimulation of ACTH release in the pituitary has been suggested. Again, this action of 5-HT appears to be associated with an activation of postsynaptic $5-\mathrm{HT}_{1 A}$ and $5-\mathrm{HT}_{2}$ receptors. ${ }^{91} 5-\mathrm{HT}_{2}$ receptors have also been implicated in mediating a paracrine effect of 5-HT on the HPA axis in rats, namely, the direct triggering of corticosteroid release at the adrenocortical level. ${ }^{95}$
In regard to a potential interaction of SSRIs with the HPA axis, it is interesting to note that knockout mice lacking the 5-HTT showed a disproportionate plasma adrenocorticotropic hormone (corticotropin, ACTH) response to stress. ${ }^{84}$ Therefore, blockage of the 5-HT reuptake by SSRIs and consequential prolonged serotonergic signaling may have similar consequences, albeit to a lesser extent, as not all existent 5-HTT molecules will be completely inhibited.

Like the HPA axis, the HPI axis in fish mediates the stress response of the organism by activating the corticotropic system with the key substances CRH, ACTH, and cortisol $^{96}$ (Figure 6 ), although slight differences in anatomy and regulation of the pathway have been noted. In mammals, hypothalamus and pituitary are interconnected by a median eminence, thereby providing an interface for the transfer of hypothalamic factors. ${ }^{97} \mathrm{In}$ fish, such a blood portal system is lacking. Instead, there is a direct connection formed by $\mathrm{CRH}$-positive neurons that innervate the anterior region of the pituitary. With regard to regulatory

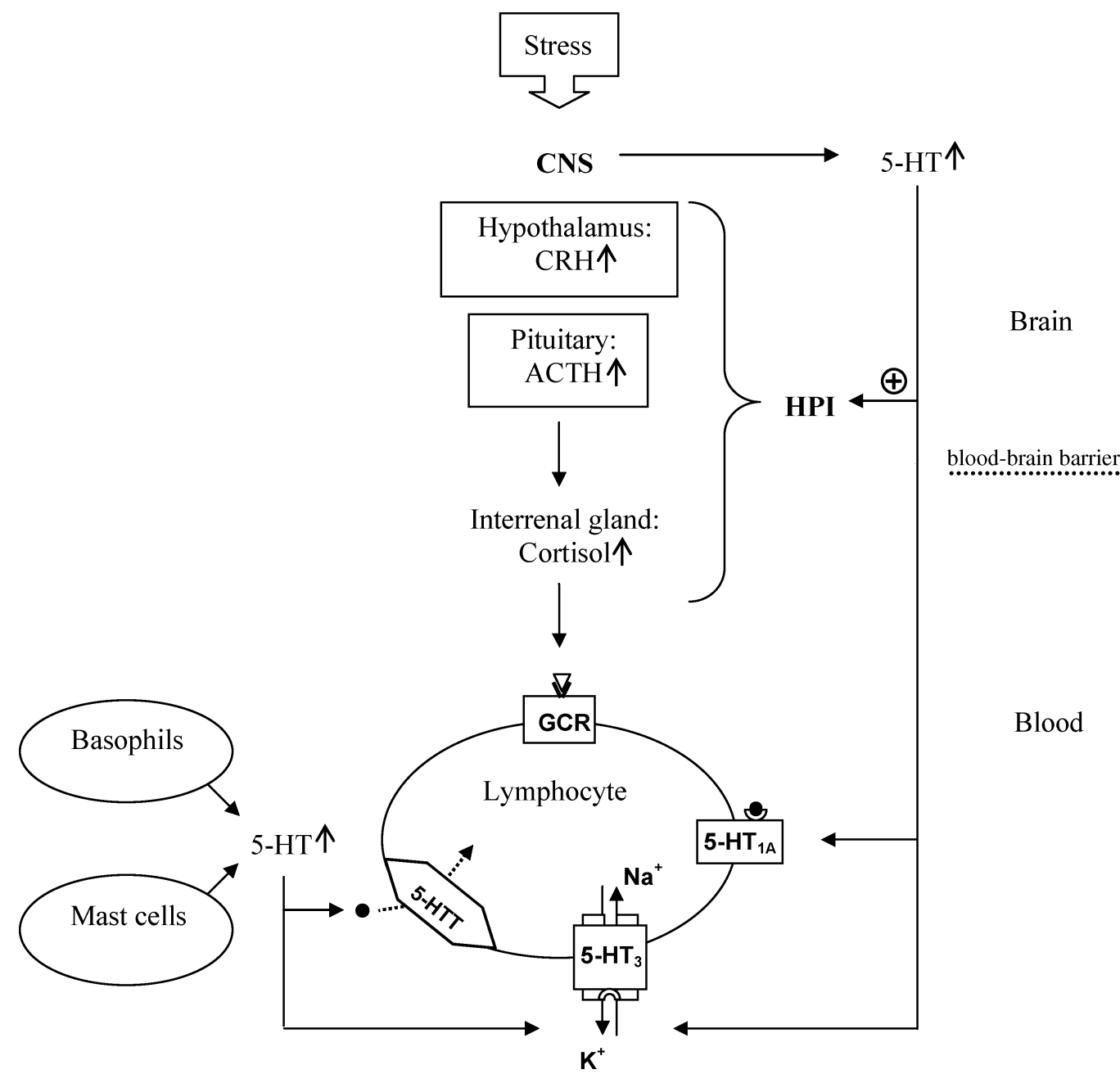

FIG. 6. Schematic of serotonergic interaction with the HPI axis and immune system in fish. GCR, glucocorticoid receptor; $\bullet=$ 5-HT; $\nabla=$ cortisol; $\cdots \cdots \cdot \cdots=$ transport. 
mechanisms, it has been found that the release of the major corticosteroid in fish, cortisol, is apparently controlled not only by ACTH but also by $\alpha$-melanophore-stimulating hormone. ${ }^{96}$ Nevertheless, as in mammals, 5 -HT seems to play a regulatory role in the piscene HPI axis ${ }^{98,99}$; therefore, the corticotropic system represents a potential target for SSRI action in fish during environmental exposure.

The assumption that 5-HT modulates cortisol release is supported by the observation that serotonergic and corticotropic systems in fish appear to exist in close physical proximity to each other, and indeed in some areas actually overlap. CRHpositive neurons were detected in the preoptic region and in the basal hypothalamus of rainbow trout, ${ }^{100,101}$ brain areas that were both also found to be innervated by numerous serotonergic fibers. ${ }^{102}$ In addition to morphological studies, physiological experiments have provided evidence for an interaction between 5-HT and the cortisol secretion system in fish. Using an in vitro radioimmunoassay approach, Pepels and colleagues ${ }^{103}$ found that $5 \mu \mathrm{M}(1.1 \mathrm{mg} / \mathrm{L}) 5-\mathrm{HT}$ stimulated CRH release from superfused telencephalic tissues of tilapia (Oreochromis mossambicus). Furthermore, 5-HT also seems to exert an influence on the periphery of the HPI axis, as it does in the mammalian HPA axis. An in vivo study with rainbow trout demonstrated that different doses of the 5- $\mathrm{HT}_{1 \mathrm{~A}}$ receptor agonist 8-OH-DPAT $(1,10,40 \mu \mathrm{g} / \mathrm{kg})$, injected through a catheter into the dorsal aorta, caused an increase in plasma cortisol levels compared to controls injected with saline. ${ }^{99}$ It was observed that cortisol concentrations were significantly elevated after application of 10 and $40 \mu \mathrm{g} / \mathrm{kg} 8-\mathrm{OH}-\mathrm{DPAT}$. These results show that 5HT may affect the HPI axis via activation of $5-\mathrm{HT}_{1 \mathrm{~A}}$ receptors, thereby triggering cortisol release from the interrenal tissue. Consequently, by increasing the availability of 5-HT over a prolonged period of time, SSRIs could have a similar effect on cortisol levels in fish. However, long-term fluoxetine treatment of chinook salmon (Oncorhynchus tshawytscha) did not reveal any changes in plasma cortisol concentrations when measured after a prolonged stress period caused by behavioral testing. ${ }^{104}$ The latter finding indicates that it may be difficult to assess whether potential molecular changes during SSRI exposure will have repercussions for the whole organism, as, comparable to the situation in mammals, ${ }^{91,95}$ the regulatory interaction between 5-HT and the HPI axis in fish seems to be reciprocal-that is, there are indications for the influence of chronic stress on internal 5-HT concentrations. In a study with Arctic charr (Salvelinus alpinus), Winberg and coworkers ${ }^{105}$ demonstrated that stress induction by daily handling over a period of 4 weeks resulted in an elevated concentration of the main 5-HT metabolite 5-HIAA and increased 5-HIAA/5-HT ratios; these two parameters are considered to be indicators for 5-HT turnover in the fish brain.

Social stress in a population hierarchy also seems to affect the serotonergic system, as higher 5-HIAA concentrations and 5-HIAA/5-HT ratios were detected in subordinate fish which experience higher stress levels than dominant individuals. ${ }^{98,105,106}$ In contrast, a higher dopaminergic activity, represented by the ratio of dopamine to the primary metabolite 3,4-dihydroxyphenylacetic acid, may counter the stress-induced increase in plasma cortisol concentration and 5-HT activity, thereby inducing social dominance. ${ }^{107}$ Evidently, the dopaminergic system in fish brain interacts with the serotonergic system in an antagonistic manner. In this context, low concentrations of SSRIs may have the potential to exert subtle effects, in this case by inducing an imbalance between these two neurotransmitters.

The biomolecular changes in connection with social status may be accompanied by behavioral inhibitions. It was observed that subordinate Arctic charr displayed a lower locomotor activity than dominant fish, ${ }^{108}$ while subordinate status in rainbow trout was marked by decreased food intake. ${ }^{109}$ Additionally, subordination in fish appears to be characterized not only by an increased serotonergic activity in the brain and moderated behavioral reactions but also by higher plasma cortisol concentrations than in dominant individuals, ${ }^{110}$ presenting an additional link between the serotonergic system and the HPI axis. Indeed, when investigating the effect of cortisol treatment on social status and brain 5-HT levels in juvenile female rainbow trout, DiBattista et al. ${ }^{110}$ showed that elevation of plasma cortisol concentrations appeared to predispose the fish towards subordination. As brain monoaminergic activity was changed as a result of cortisol administration, this effect may have been mediated by an antagonistic activity of the serotonergic and dopaminergic systems. It was shown that the effects of cortisol treatment were converse in hypothalamus and telencephalon, with higher serotonergic and lower dopaminergic activity in the telencephalon and the opposite effect in the hypothalamus. Based on the latter observations, the authors suggested that the decrease in hypothalamic serotonergic activity in juvenile rainbow trout after cortisol administration was due to a negative feedback mechanism abating cortisol secretion. However, in a study with sexually mature male Arctic charr, aimed at examining the effects of inter-male competition on concentrations of brain monoamines and endocrine stress responses, brain 5-HT activity did not appear to be correlated with plasma cortisol levels. ${ }^{111}$ The contrasting results demonstrate that interactions may not only be species- and gender-specific but may also depend on the reproductive status of the respective animals. These parameters must be considered in the evaluation of the relationship between serotonergic activity and HPI axis as well as in the ecotoxicological risk assessment of SSRIs as potentiators of 5-HT signaling.

\section{Serotonergic Modulation of Behavior Patterns}

As described earlier, the physiological reaction to social stress in connection with hierarchical ranking is often accompanied by distinct changes in behavior patterns that may be mediated by 5-HT. In general, the serotonergic system has been implicated in the modulation of feeding, sexual, and aggressive behavior in various animal phyla, including coelenterates, platyhelminths, nematodes, molluscs, annelids, crustaceans, echinoderms, and chordates, as reviewed by Weiger. ${ }^{112}$ In most vertebrate species examined so far, increased serotonergic activity 
has been associated with an inhibition of aggressive behavior. ${ }^{107}$ For instance, the antiaggressive effect of 5-HT has been noted in rat, mink, and pigeon, as well as in several fish species ${ }^{107}$ such as the bluehead wrasse (Thalassoma bifasciatum). To increase serotonergic neurotransmission, male bluehead wrasses, representing a behaviorally dominant phenotype, were injected intraperitoneally with either a single acute fluoxetine dose of $10 \mu \mathrm{g} / \mathrm{g}$ in a field experiment or with a daily fluoxetine dose of $6 \mu \mathrm{g} / \mathrm{g}$ in a chronic 14-day laboratory test. ${ }^{113}$ The fish from both experiments were then subjected to resident-intruder tests. Acute fluoxetine treatment resulted in a significant reduction of aggression against the intruder compared to controls, regarding chase frequency and chase duration. Chronic fluoxetine administration similarly reduced aggressive behavior. Additionally, males treated chronically with fluoxetine displayed lower activity levels before intruder introduction. This appeared to be a distinct effect, as there was no correlation observed between activity and aggression in individual fish.

It has also been proposed that the pineal hormone melatonin (Figure 5), a derivative of 5-HT that is involved in the synchronization of the circadian rhythm, may modulate aggressive behavior and may therefore be responsible for the antiaggressive effect of 5-HT treatment observed in fish. ${ }^{114}$ However, this hypothesis was not supported by the results of a recent study by Lepage and colleagues. ${ }^{115}$ These authors conducted resident-intruder tests to evaluate the level of aggression in 2year-old rainbow trout and subsequently treated the fish either with tryptophan, the SSRI citalopram, or melatonin. Fish of the first two treatment groups were fed with special experimental food that was supplemented with tryptophan or citalopram (100 $\mu \mathrm{g} / \mathrm{kg}$ ). In the third group, melatonin was administered via intraperitoneally implanted capsules. While tryptophan as well as citalopram treatment resulted in decreased aggression and lower plasma cortisol levels compared to controls, melatonin treatment had no significant effect on either parameter. These results indicate 5-HT itself to be the antiaggressive agent in fish.

In summary, 5-HT has been recognized as a regulatory factor of stress reactions mediated by the HPI axis and, furthermore, as a modulator of behavior patterns associated with social status. It has also been shown that the SSRIs fluoxetine and citalopram may be able to modulate aggressive behavior in fish. As there are fish species, e.g., salmonids, that require aggressive interactions to define social relationships between individuals ${ }^{116}$ and predominance in reproduction, ${ }^{117}$ chronic exposure to SSRIs could affect established dominance hierarchies in fish populations, especially during sensitive periods in the reproductive cycle. This may result in a higher reproduction rate of formerly subordinate fish with an unfavorable genetic predisposition that would normally be subdued by dominant — and arguably healthierindividuals. Therefore, long-term SSRI-induced imbalance of social hierarchy could possibly impair the genetic balance in a given population. Furthermore, rank-dependent differences in physiological processes such as ion regulation have been observed in salmonid populations that show distinctive hierarchi- cal relationships. ${ }^{118}$ These physiological variations between fish of different dominance status have toxicological implications insofar as specific social ranks may be more strongly affected by aquatic contaminants. Therefore, alterations in 5-HT levels by SSRIs and a subsequent shift in social position may render an individual susceptible to toxicant exposure. Such potential consequences at the population level are, however, impossible to predict by simple toxicity tests. ${ }^{118}$

Apart from the rather extensively studied relationship between the serotonergic system and aggression-related behaviors in fish, there are some other behavioral patterns that seem to be modulated by 5 -HT via the corticotropic pathway and may also be affected by SSRIs. As already mentioned, subordinate social status, which is associated with stress and higher 5-HT levels, may lead to repressed feeding and locomotor activity. In goldfish, intracerebroventricular injections of 5-HT $(10 \mu \mathrm{g} / \mu \mathrm{L})$ caused a significant reduction in food intake. This inhibitory effect could be partially abolished by co-administration of a CRH antagonist, indicating an influence of the HPI axis. ${ }^{119}$ Decreased locomotor activity was observed in juvenile chinook salmon after chronic (20 days) treatment with a fluoxetine dose of $2.5 \mathrm{mg} / \mathrm{kg}$, repeatedly administered by intraperitoneal injection, in comparison to fish given long-term saline injections. The increased activity in the saline-treated fish was attributed to the stress induced by handling and injections. ${ }^{104}$

In addition to affecting behavior through the HPI axis, 5-HT may mediate its control in conjunction with other neurotransmitter systems. In salmonids, the serotonergic and the dopaminergic system seem to play a role in the onset of migration behavior, which is a fundamental part of their specific life cycle. ${ }^{120}$ In coho salmon (Oncorhynchus kisutch), brain 5-HT content and dopamine levels were found to increase significantly during smolt transformation. Examination of the brains of fluoxetinetreated male bluehead wrasses from chronic experiments $(6 \mu \mathrm{g} / \mathrm{g}$ daily over 14 days) ${ }^{113}$ revealed evidence for the involvement of the arginine vasotocin (AVT) system in mediating serotonergic effects on aggressive behavior and social status. ${ }^{121}$ The fish brains were sectioned and analyzed for AVT mRNA abundance in the preoptic area of the hypothalamus using in situ hybridization. It was observed that the amount of AVT mRNA was significantly lower in bluehead wrasse males treated with fluoxetine than in control fish. The results of a previous study conducted by the same research group had already provided evidence for a link between decreased AVT mRNA expression and subordinate behavior in bluehead wrasse. ${ }^{122}$ Therefore, it has been suggested that serotonergic effects on aggressive behavior and related social status may be mediated by this neuropeptide system in fish. In goldfish, 5-HT enhanced the presynaptic release of the inhibitory factor glycin at the synaptic connection to specialized neurons, which coordinate locomotor activity. ${ }^{112}$ These examples illustrate that even slight changes in extracellular 5-HT levels, as potentially caused by environmental SSRI exposure, may alter behavioral output by modulating other signaling cascades. In other words, potential SSRI-induced increases in 5-HT 
availability could result in abnormal behavior pattern and a disruption of established social hierarchies in fish. As an additional unfavorable factor, low social status may cause chronic stress, ${ }^{116}$ and heightened cortisol release under chronically stressful conditions has been implicated in the decrease of antibody production and the reduction of the number of antibody-producing cells in fish, thereby impairing the immune response. ${ }^{96}$ The serotonergic system has been proposed to act as a mediator between HPI axis and the immune system, but may furthermore modulate the immune response directly. ${ }^{123}$

\section{5-HT AND THE IMMUNE SYSTEM}

It has long been recognized that stress affects the immune response in mammals ${ }^{124,125}$ and that 5-HT may be involved as a modulating factor. ${ }^{126}$ Indeed, blockade of 5-HT synthesis using the TPH antagonist $p$-chlorophenylalanine resulted in the inhibition of interleukin-2-stimulated human $\mathrm{T}$ cell proliferation. ${ }^{127}$ Administration of a selective 5- $\mathrm{HT}_{1 \mathrm{~A}}$ receptor antagonist had the same effect, suggesting that this 5-HT receptor subtype is present in human lymphocytes and involved in the signal transduction process. In addition, several other 5-HT receptor subtypes and a high-affinity 5-HT uptake mechanism have been identified in human lymphocytes and macrophages, as reviewed by Mössner and Lesch. ${ }^{34,128}$ The concentration-dependent and saturable 5-HT transport system of lymphocytes displayed characteristics similar to the 5-HTT in neuronal tissues, in that it was shown to be dependent on temperature, sodium, and chloride and could be inhibited by the 5-HT reuptake inhibitors fluoxetine $\left(\mathrm{IC}_{50}=45 \pm 7.5 \mathrm{nM}\right)$, fluvoxamine $\left(\mathrm{IC}_{50}=27 \pm 4.3 \mathrm{nM}\right)$, and clomipramine $\left(\mathrm{IC}_{50}=3.5 \pm 0.56 \mathrm{nM}\right) .{ }^{128}$ Furthermore, there are numerous studies dealing with serotonergic effects on different components of the mammalian immune system. ${ }^{34}$ Reciprocally, the immune response may influence serotonergic signaling; e.g., interleukin-4 was found to cause a decrease of 5-HT uptake into human B-lymphocytes. ${ }^{129}$

In stressed fish, the metabolism of 5-HT and catecholamines (noradrenaline, dopamine) was found to be elevated. Since monoamines are able to pass the blood-brain barrier in teleost fish, the stress response of the organism may also cause an increase in peripheral monoamine concentrations ${ }^{123}$ (Figure 6). It is assumed that circulating 5-HT also exerts an immunomodulatory effect in fish by activating specific receptors on lymphocyte membranes. ${ }^{123}$ Using classical receptor binding studies with 2-methyl-5-HT as competing ligand, $5-\mathrm{HT}_{3}$ receptors were identified in lymphocytes of rainbow trout based on the displacement of $\left[{ }^{3} \mathrm{H}\right] 5-\mathrm{HT} .{ }^{130}$ Further evidence for the presence of $5-\mathrm{HT}_{3}$ receptors in trout lymphocytes was provided by Ferrière and colleagues. ${ }^{131}$ As increases in intracellular $\mathrm{Ca}^{2+}$ levels have been associated with an induction of leukocyte proliferation in catfish, ${ }^{132}$ the main objective of their experiments was to examine the effects of 5-HT on calcium signaling in peripheral blood lymphocytes of rainbow trout. Isolated trout lymphocytes were exposed to $25 \mu \mathrm{M}$ and $50 \mu \mathrm{M}$ 5-HT and cytosolic $\mathrm{Ca}^{2+}$ concentrations were calculated based on fluorescence measurements. ${ }^{131}$ In $\mathrm{Ca}^{2+}$-replete cell culture medium, 5-HT exposure resulted in increased intracellular $\mathrm{Ca}^{2+}$ levels. In contrast, no serotonergic effect was observed in $\mathrm{Ca}^{2+}$-free medium, suggesting a 5-HT-induced mobilization of $\mathrm{Ca}^{2+}$ from extracellular sources. Neither the $5-\mathrm{HT}_{1 \mathrm{~A}}$ receptor agonist 8-OH-DPAT $(25$ or $50 \mu \mathrm{M})$ nor the $5-\mathrm{HT}_{2}$ receptor antagonist ketanserin $(10 \mu \mathrm{M})$ had any effect on intracellular $\mathrm{Ca}^{2+}$ concentrations, whereas treatment with 2-methyl-5-HT $(20 \mu \mathrm{M})$ resulted in elevated $\mathrm{Ca}^{2+}$ levels in the cells. Moreover, this stimulating effect could be blocked by administration of $20 \mu \mathrm{M}$ metoclopramide, indicating that 5-HT may mediate an immunomodulatory effect in rainbow trout via activation of $5-\mathrm{HT}_{3}$ receptors. In a related study conducted by Meyniel and coworkers, ${ }^{130}$ it was shown that increasing concentrations of 5-HT $(0,62.5,125,250 \mathrm{nM})$ inhibited the phytohemagglutinin-induced proliferation of $\mathrm{T}$ cells, presumably via $5-\mathrm{HT}_{3}$ receptors, as 2-methyl-5-HT had a similar effect in a concentration range of 0.5 to $100 \mu \mathrm{M}$. Analysis of cell cycle progression revealed that 5-HT and 2-methyl-5HT prevented the transition of activated $T$ cells from $\mathrm{G}_{0} / \mathrm{G}_{1}$ - to S-phase during the cell cycle.

Even though 8-OH-DPAT had no effect on intracellular $\mathrm{Ca}^{2+}$ concentrations in trout lymphocytes, ${ }^{131} 5-\mathrm{HT}_{1 \mathrm{~A}}$ receptors may still be involved in mediating an immunosuppressive effect of 5-HT on T- as well as on B-lymphocytes ${ }^{133}$ via different signaling pathways. The inhibiting influence of 5-HT $(250 \mathrm{nM})$ on lymphocyte proliferation was mimicked by 8 -OH-DPAT (100 $\mathrm{nM}$ ) in rainbow trout, while the $5-\mathrm{HT}_{1 \mathrm{~A} / 1 \mathrm{~B}}$ receptor antagonist spiperone reversed this effect. ${ }^{133}$ These results suggested that trout lymphocytes express functional receptors of the $5-\mathrm{HT}_{1 \mathrm{~A}}$ subtype, at least after mitogenic stimulation with lipopolysaccharides and phytohemagglutinin.

In addition to 5-HT receptors, fish lymphocytes have also been found to express a transporter for 5-HT that may be regulated via $5-\mathrm{HT}_{1 \mathrm{~A}}$ receptors. ${ }^{134}$ Transport of 5-HT into isolated trout lymphocytes was shown to require the presence of $\mathrm{Na}^{+}$ ions in the extracellular medium, which corresponds to the $\mathrm{Na}^{+}$dependent transport mechanism found in mammals. In the same study, it was observed that the uptake rate of the trout 5-HTT was adjusted to changing levels of intracellular 5-HT. To investigate the underlying processes, isolated lymphocytes were incubated with substances known to increase intracellular cyclic adenosine monophosphate (caMP) concentrations, including cholera toxin and forskolin. All agents had a stimulatory effect on 5HT transport into the cells, suggesting that modulation of the 5-HTT may be mediated by $5-\mathrm{HT}_{1 \mathrm{~A}}$ receptors, which are negatively coupled to adenylate cyclase and cAMP production (Table 3). Since a monoamine and a specific 5-HT uptake mechanism with distinct pharmacological profiles had been described, it was attempted to determine which transporter was responsible for 5-HT uptake in trout lymphocytes. While the 5-HTT located in the plasma membrane is susceptible to inhibition by SSRIs such as fluoxetine, the unspecific vesicular monoamine transporter, which was isolated from bovine chromaffin granules, has been found to be specifically blocked by the antihypertensive 
drug reserpine. ${ }^{135}$ As reserpine did not alter 5-HT transport in isolated rainbow trout lymphocytes, it has been suggested that the vesicular monoamine transporter may not exist in fish lymphocytes. ${ }^{134}$ In contrast, exposure to the SSRIs fluoxetine, paroxetine, and sertraline at concentrations of 5, 10, and 20 $\mu \mathrm{M}$ (fluoxetine: $1.73,3.46$, and $6.92 \mathrm{mg} / \mathrm{L}$ ) caused a decrease of 5-HT uptake into the immune cells. These findings seem to confirm the presence of the plasma membrane-bound type of 5HTT in trout lymphocytes, although this hypothesis needs to be corroborated as the concentrations employed were exceedingly high. In addition to the identification and characterization of the 5-HT transport mechanism in peripheral blood lymphocytes of rainbow trout, a potential serotonergic effect on the proliferation of isolated lymphocytes was examined in the same study. Following a $96 \mathrm{~h}$ exposure to $0.1,1$, and $10 \mu \mathrm{M}$ of the SSRI formulations alaproclate, zimelidine, fluoxetine, paroxetine, and sertraline (fluoxetine: $0.03,0.35$, and $3.46 \mathrm{mg} / \mathrm{L}$ ), the incorporation of $\left[{ }^{3} \mathrm{H}\right]$ thymidine was assessed. Fluoxetine, paroxetine, and sertraline significantly blocked the phytohemagglutinin-induced proliferation of trout lymphocytes in a concentration-dependent manner, starting at $0.1 \mu \mathrm{M}$, while alaproclate and zimelidine only had a significant effect at the highest concentration of 10 $\mu \mathrm{M}$.

The above-mentioned results have demonstrated that 5-HT may play a role as modulator of the immune response in fish and that SSRIs may mimic these immunomodulatory effects. It has been shown that isolated fish lymphocytes may express a functional 5-HTT that can be blocked by SSRIs, thereby inhibiting 5-HT uptake into the cells. Moreover, 5-HT as well as SSRIs appear to inhibit the PHA-induced proliferation of Tcells in rainbow trout. ${ }^{134}$ In view of these findings and despite the difficulties associated with extrapolating from effects observed following acute exposure to potential chronic scenarios, the presently available data suggest that continual exposure to environmental concentrations of SSRIs may have an effect on the immunocompetence of fish.

\section{ROLE OF 5-HT IN REPRODUCTIVE PROCESSES}

The potential role of the serotonergic system in the modulation of reproductive processes has been addressed extensively in invertebrate studies primarily evaluating descriptive rather than mechanistic endpoints either using 5-HT or SSRIs (Table 5). In invertebrate species, including clams, mussels, crustaceans, echinoderms, and worms, 5-HT was demonstrated to regulate spawning and oocyte maturation. Fong and colleagues ${ }^{136-138}$ showed that SSRIs may affect the spawning process in mollusc species. Treatment of zebra mussels with fluoxetine resulted in an induction of spawning at concentrations of $100 \mathrm{nM}(\sim 30$ $\mu \mathrm{g} / \mathrm{L})$ in males and $1 \mu \mathrm{M}$ in females. ${ }^{137}$ Fluvoxamine proved to be even more potent than fluoxetine, as it induced spawning in male zebra mussels at concentrations as low as $1 \mathrm{nM}(318$ $\mathrm{ng} / \mathrm{L}$ ). The latter findings were corroborated by similar observations by Honkoop et al. ${ }^{139}$ and Krantic et al. ${ }^{140}$ in marine clams.
In the crustacean Daphnia magna, subchronic (30 days) fluoxetine exposure to $36 \mu \mathrm{g} / \mathrm{L}$ significantly increased fecundity. ${ }^{141} \mathrm{In}$ most invertebrate studies (Table 5), the concentrations of 5-HT and SSRIs employed were well above the levels measured in the environment and thus the results should be interpreted with caution as to their relevance for environmental risk assessment.

In contrast to the situation in invertebrates, more mechanistic, albeit limited, data are available on the function of 5-HT and the potential influence of SSRIs on aquatic vertebrate reproduction (Table 6). The endocrine regulation of reproduction in vertebrates is mediated via the hypothalamus-pituitary-gonad (HPG) axis. Like the HPA/HPI axis, the HPG axis displays a hierarchical organization with the hypothalamus representing the highest-ranking level. The main hypothalamic factors controlling this system are gonadotropin-releasing hormones (GnRHs). In mammals, GnRHs are secreted into the blood portal system located in the neurohypophyseal median eminence and transported to the anterior pituitary, ${ }^{142}$ where they stimulate the release of gonadotropic hormones, namely, follicle-stimulating hormone (FSH) and luteinizing hormone (LH). ${ }^{142}$ 5-HT appears to play a modulatory role in the regulation of gonadotropin release. Indeed, electron-microscopic autoradiographic observations confirmed the presence of 5-HT fibers in the medial preoptic region of the rat brain, with several of these in synaptic contact with LHRH-immunoreactive neurons. ${ }^{143}$ It has also been shown that 5-HT in the preoptic region of the rat brain has a stimulatory effect on LH secretion, probably mediated by 5- $\mathrm{HT}_{1}$ and 5- $\mathrm{HT}_{2}$ receptors. ${ }^{144}$ Moreover, modulation of HPG signaling by 5 -HT may not be restricted to the brain level, but may also be directly effective in the gonads. Key components of the serotonergic system including 5-HT, TPH (TPH-1), and the specific 5-HT transporter (SLC6A4) were localized in mouse cumulus oophorous granulosa cells, oocytes, and early embryos by means of reverse-transcription polymerase chain reaction analysis and immunofluorescence confocal microscopy. ${ }^{145} 5$ HT and SLC6A4 were detected in both ovarian cell types as well as in embryonic tissue, while TPH-1 expression was restricted to cumulus cells. The latter observations indicate that ovarian cells may be the local source of 5-HT as a paracrine agent. The same authors demonstrated that 5-HT caused a dose-dependent increase of cAMP and $\mathrm{Ca}^{2+}$ levels in cumulus cells, presumably via $5-\mathrm{HT}_{7}$ and $5-\mathrm{HT}_{2 A} / 5-\mathrm{HT}_{2 B}$ receptors, respectively. ${ }^{146}$ Furthermore, 5-HT was shown to modulate gonadotropininduced steroid secretion of human granulosa cells in vitro. ${ }^{147}$

In fish, the functional relationship of hypothalamus and pituitary regions varies between different species, but in general, the formation of neurological interfaces during phylogeny resulted in increased hypothalamic control of pituitary function. ${ }^{148}$ This is accompanied by a stronger influence of the pituitary on gonad development. The HPG axis regulates reproductive processes including gonad differentiation and maturation in fish. As in mammals, GnRHs are mainly responsible for the stimulation of gonadotropic hormone (gonadotropin, GTH) release from the 


\section{TABLE 5}

Effects of 5-HT and SSRIs on reproduction-related processes in aquatic invertebrates. Note. 5-HT, 5-hydroxytryptamine; bw, body weight; Conc., concentration; d, days; (f), female; FX, fluoxetine, FLV, fluvoxamine; (m), male; n.a., not available

\begin{tabular}{|c|c|c|c|c|c|}
\hline Invertebrate species & Substance & Conc./dose & $\begin{array}{l}\text { Application, } \\
\text { duration }\end{array}$ & Pathway/endpoint & References \\
\hline \multicolumn{6}{|l|}{ Molluscs } \\
\hline \multirow[t]{2}{*}{$\begin{array}{l}\text { Zebra mussel (Dreissena } \\
\text { polymorpha) }\end{array}$} & $5-\mathrm{HT}$ & $10 \mathrm{mM}$ & in vivo, $30 \mathrm{~min}$ & $\begin{array}{l}\text { Induces oocyte maturation and } \\
\text { germinal vesicle breakdown }\end{array}$ & 136 \\
\hline & & $100 \mu \mathrm{M}$ & $\begin{array}{l}\text { in vitro, } 80 \\
\text { min }\end{array}$ & $\begin{array}{l}\text { Induces germinal vesicle } \\
\text { breakdown }\end{array}$ & \\
\hline \multirow{4}{*}{$\begin{array}{l}\text { Zebra mussel (Dreissena } \\
\text { polymorpha) }\end{array}$} & FLV & $1 \mathrm{nM}(\mathrm{m})$ & in vivo, $4 \mathrm{~h}$ & Induces spawning & 137 \\
\hline & & $100 \mathrm{nM}(\mathrm{f})$ & & & \\
\hline & FX & $\begin{array}{l}50 \mathrm{nM}(\mathrm{m}) \\
5 \mu \mathrm{M}(\mathrm{f})\end{array}$ & in vivo, $4 \mathrm{~h}$ & Induces spawning & \\
\hline & PX & $1 \mu \mathrm{M}(\mathrm{m})$ & in vivo, $4 \mathrm{~h}$ & Induces spawning & \\
\hline \multirow{3}{*}{$\begin{array}{l}\text { Fingernail clam (Sphaerium } \\
\text { striatinum) }\end{array}$} & FLV & $10 \mathrm{nM}$ & in vivo, $4 \mathrm{~h}$ & Stimulate parturition & 209 \\
\hline & PX & $10 \mu \mathrm{M}$ & in vivo, $4 \mathrm{~h}$ & & \\
\hline & FX & $5 \mu \mathrm{M}$ & in vivo, $12 \mathrm{~h}$ & $\begin{array}{l}\text { Amplifies 5-HT-induced } \\
\text { stimulation of parturition }\end{array}$ & \\
\hline $\begin{array}{l}\text { Baltic clam (Macoma } \\
\text { balthica) }\end{array}$ & FX & $1 \mathrm{ppm}$ & in vivo, $30 \mathrm{~min}$ & $\begin{array}{l}\text { Induces spawning (extension of } \\
\text { spawning season) }\end{array}$ & 139 \\
\hline $\begin{array}{l}\text { Surf clam (Spisula } \\
\text { solidissima) }\end{array}$ & $5-\mathrm{HT}$ & $\begin{array}{l}1 \mathrm{nM}-100 \mu \mathrm{M} \\
\left(\mathrm{EC}_{50}=0.55\right. \\
\mu \mathrm{M})\end{array}$ & $\begin{array}{l}\text { in vitro, } 30 \\
\text { min }\end{array}$ & $\begin{array}{l}\text { Induces germinal vesicle } \\
\text { breakdown }\end{array}$ & 140 \\
\hline \multicolumn{6}{|l|}{ Crustaceans } \\
\hline Water flea (Daphnia magna) & FX & $36 \mu \mathrm{g} / \mathrm{L}$ & in vivo, $30 \mathrm{~d}$ & Increases fecundity & 141 \\
\hline \multirow[t]{3}{*}{$\begin{array}{l}\text { Red swamp crayfish } \\
\quad \text { (Procambarus clarkii) }\end{array}$} & $5-\mathrm{HT}$ & $15 \mu \mathrm{g} / \mathrm{g}$ bw & $\begin{array}{l}\text { in vivo, } 15 \mathrm{~d} \\
\quad \text { (injection at } \\
1,5,10 \mathrm{~d} \text { ) }\end{array}$ & $\begin{array}{l}\text { Increases ovarian index and } \\
\text { oocyte size }\end{array}$ & 210 \\
\hline & FX & $15 \mu \mathrm{g} / \mathrm{g}$ bw & $\begin{array}{l}\text { in vivo, } 15 \mathrm{~d} \\
\quad \text { (injection at } \\
1,5,10 \mathrm{~d} \text { ) }\end{array}$ & $\begin{array}{l}\text { Increases ovarian index and } \\
\text { oocyte size, amplifies } \\
\text { 5-HT-induced effect }\end{array}$ & \\
\hline & $5-\mathrm{HT}$ & $15 \mu \mathrm{g} / \mathrm{g}$ bw & in vitro, $24 \mathrm{~h}$ & $\begin{array}{l}\text { Stimulates release of } \\
\text { ovary-stimulating hormone }\end{array}$ & 211 \\
\hline Fiddler crab (Uca pugilator) & $5-\mathrm{HT}$ & $\begin{array}{l}125 \mathrm{nmol} / \mathrm{crab} \\
(2.5 \mathrm{mM})\end{array}$ & $\begin{array}{l}\text { in vivo, } 7 \mathrm{~d} \\
\quad \text { (injection at } \\
1,3,5 \mathrm{~d} \text { ) }\end{array}$ & $\begin{array}{l}\text { Stimulates ovarian and testicular } \\
\text { development }\end{array}$ & 212 \\
\hline \multicolumn{6}{|l|}{ Echinoderms } \\
\hline $\begin{array}{l}\text { Starfish sp. (Patiria } \\
\text { pectinifera }+ \\
\text { Aphelasterias japonica) }\end{array}$ & $5-\mathrm{HT}$ & $10-100 \mu \mathrm{M}$ & in vitro, n.a. & $\begin{array}{l}\text { Amplifies maturation-inducing } \\
\text { effect of 1-methyladenine in } \\
\text { oocytes }\end{array}$ & 213 \\
\hline \multicolumn{6}{|l|}{ Nemertea } \\
\hline $\begin{array}{l}\text { Milky ribbon worm } \\
\text { (Cerebratulus lacteus) }\end{array}$ & $5-\mathrm{HT}$ & $1 \mu \mathrm{M}$ & in vitro, $2-3 \mathrm{~h}$ & $\begin{array}{l}\text { Stimulates oocyte maturation via } \\
\text { cAMP increase }\end{array}$ & 214 \\
\hline \multicolumn{6}{|l|}{$\begin{array}{l}\text { Salmon white headed ribbon } \\
\text { worm (Micrura alaskensis) }\end{array}$} \\
\hline \multicolumn{6}{|l|}{ Nematoda } \\
\hline \multirow{2}{*}{$\begin{array}{l}\text { Roundworm } \\
\quad \text { (Caenorhabditis elegans) }\end{array}$} & $5-\mathrm{HT}$ & $5 \mathrm{mg} / \mathrm{ml}$ & in vivo, $60 \mathrm{~min}$ & Induces egg laying & 215 \\
\hline & FX & $0.5 \mathrm{mg} / \mathrm{ml}$ & in vivo, $60 \mathrm{~min}$ & Induces egg laying & \\
\hline
\end{tabular}


TABLE 6

Effects of 5-HT and SSRIs on reproduction-related processes in aquatic vertebrates Note 5-HT, 5-hydroxytryptamine; bw, body weight; Conc., concentration; DiOH-p, 17 $\alpha, 20 \beta$-dihydroxy-4-pregnen-3-one; FX, fluoxetine; GnRH, gonadotropin releasing hormone; ip, intraperitoneal; LHRHa, luteinizing hormone-releasing hormone analog; max., maximal; n.a., not available; PAH, preoptic anterior hypothalamus

\begin{tabular}{|c|c|c|c|c|c|}
\hline Vertebrate species & Substance & Conc./dose & $\begin{array}{l}\text { Application, } \\
\text { duration }\end{array}$ & Pathway/endpoint & Reference \\
\hline \multicolumn{6}{|l|}{ Amphibians } \\
\hline $\begin{array}{l}\text { African clawed frog } \\
\text { (Xenopus laevis) }\end{array}$ & $5-\mathrm{HT}$ & $1.2 \mu \mathrm{M}$ & in vitro, n.a. & $\begin{array}{l}\text { Inhibits progesterone-induced } \\
\text { oocyte maturation }\end{array}$ & 213 \\
\hline \multicolumn{6}{|l|}{$\begin{array}{l}\text { European green toad } \\
\text { (Bufo viridis) }\end{array}$} \\
\hline \multicolumn{6}{|l|}{ Fish } \\
\hline \multirow[t]{3}{*}{$\begin{array}{l}\text { Goldfish (Carassius } \\
\text { auratus) }\end{array}$} & $5-\mathrm{HT}$ & $10 \mu \mathrm{M}$ & in vitro, $30 \mathrm{~min}$ & $\begin{array}{l}\text { Stimulates GnRH release in } \\
\text { mature females }\end{array}$ & 159 \\
\hline & $5-\mathrm{HT}$ & $\begin{array}{l}2.5 \mu \mathrm{g} / \mathrm{g} \text { bw (f) } \\
5 \mu \mathrm{g} / \mathrm{g} \text { bw (m) }\end{array}$ & $\begin{array}{l}\text { in vivo, } 30 \mathrm{~min} \\
\text { (ip injection) }\end{array}$ & $\begin{array}{l}\text { Stimulates release of serum } \\
\text { gonadotropin in sexually } \\
\text { mature females (f) and males } \\
\text { (m) }\end{array}$ & 157 \\
\hline & $\mathrm{FX}+5-\mathrm{HT}$ & $\begin{array}{l}10 \mu \mathrm{g} / \mathrm{g} \text { bw }+2.5 \\
\mu \mathrm{g} / \mathrm{g} \text { bw }\end{array}$ & $\begin{array}{l}\text { in vivo, } 90+30 \\
\text { min (ip } \\
\text { injection) }\end{array}$ & $\begin{array}{l}\text { Amplifies 5-HT-induced } \\
\text { increase in serum } \\
\text { gonadotropin }\end{array}$ & \\
\hline \multirow{2}{*}{$\begin{array}{l}\text { Atlantic croaker } \\
\text { (Micropogonias } \\
\text { undulatus) }\end{array}$} & $5-\mathrm{HT}$ & $20 \mu \mathrm{g} / \mathrm{g}$ bw & $\begin{array}{l}\text { in vivo, } 60 \mathrm{~min} \\
\text { (ip injection) }\end{array}$ & $\begin{array}{l}\text { In conjunction with LHRHa, } \\
\text { increases gonadotropin level }\end{array}$ & 153 \\
\hline & $\mathrm{FX}+5-\mathrm{HT}$ & $\begin{array}{l}10 \mu \mathrm{g} / \mathrm{g} \mathrm{bw}+20 \\
\mu \mathrm{g} / \mathrm{g} \mathrm{bw}\end{array}$ & $\begin{array}{l}\text { in vivo, } 90+60 \\
\text { min (ip } \\
\text { injection) }\end{array}$ & $\begin{array}{l}\text { Amplifies 5-HT-induced } \\
\text { increase in gonadotropin level }\end{array}$ & \\
\hline $\begin{array}{l}\text { Mummichog (Fundulus } \\
\text { heteroclitus) }\end{array}$ & $5-\mathrm{HT}$ & $\begin{array}{l}50 \mathrm{nM}(10.6 \\
\mu \mathrm{g} / \mathrm{L})\end{array}$ & in vitro, $\max .72 \mathrm{~h}$ & $\begin{array}{l}\text { Inhibits steroid-induced oocyte } \\
\text { maturation }\end{array}$ & 163 \\
\hline $\begin{array}{l}\text { Medaka (Oryzias } \\
\text { latipes) }\end{array}$ & $5-\mathrm{HT}$ & $10 \mu \mathrm{g} / \mathrm{L}$ & in vitro, $10 \mathrm{~h}$ & $\begin{array}{l}\text { Stimulates oocyte maturation } \\
\text { and production of } \\
17 \beta \text {-estradiol and } \mathrm{DiOH}-\mathrm{p}\end{array}$ & 164 \\
\hline $\begin{array}{l}\text { Sea bream (Pagrus } \\
\text { major) }\end{array}$ & $5-\mathrm{HT}$ & $1 \mu \mathrm{M}$ & in vitro, $30 \mathrm{~min}$ & $\begin{array}{l}\text { Induces GnRH secretion from } \\
\text { PAH }\end{array}$ & 155 \\
\hline
\end{tabular}

fish pituitary (Figure 7). Additionally, GnRHs have been found to induce ovulation and increase plasma concentrations of the steroid hormones cortisol, progesterone, and testosterone, while reducing the plasma estradiol level in catfish (Heteropneustes fossilis). ${ }^{149}$ As fish do not possess a blood portal system connecting the hypothalamus with the pituitary, GnRHs appear to reach the anterior pituitary by direct innervation, ${ }^{97,150}$ stimulating gonadotrope cells to produce GTHs. To date, two different forms of GTH have been described in fish. GTH I and II have been identified as functionally homologous to the mammalian FSH and LH, respectively. ${ }^{151}$ GTH synthesis and release from the pituitary are apparently controlled by the interaction of several neurotransmitters and neuropeptides (Figure 7), which are produced in the hypothalamus and the preoptic area of the fish brain. ${ }^{152}$ Several substances, among them 5-HT and gamma- aminobutyric acid (GABA), display a stimulatory influence on gonadotrope cells, while the dopaminergic system appears to maintain an inhibitory function.

It has been demonstrated in several studies that 5-HT induces the release of GTH-II at different levels of the fish HPG axis. ${ }^{153-159}$ Khan and Thomas ${ }^{154}$ examined the brain of mature male and female Atlantic croaker in vitro to localize 5-HT and GnRH immunoreactive elements and found similar neuronal distribution patterns, especially in the preoptic-anterior region of the hypothalamus and in the olfactory bulb. Evidence for interaction between 5-HT and GnRH was found by studying the effects of 5-HT on GnRH release in mature female goldfish ex vivo, as $10 \mu \mathrm{M}$ and $100 \mu \mathrm{M} 5$-HT significantly stimulated $\mathrm{GnRH}$ secretion from the preoptic-anterior hypothalamus and the pituitary. ${ }^{159}$ Dopamine had the reverse effect, inhibiting GnRH 
TABLE 7

SSRI ecotoxicological data Note. CP, citalopram; EC, effective concentration; FX, fluoxetine; FL, fluvoxamine; LC, lethal concentration; LOEC, lowest observable effect concentration; NOEC, no effect concentration; PX, paroxetine; ST, sertraline; d, days.

\begin{tabular}{|c|c|c|c|c|}
\hline Species & Substance & Endpoint & Concentration/dose & Reference \\
\hline \multicolumn{5}{|l|}{ Invertebrates (free-swimming) } \\
\hline Water flea (Ceriodaphnia dubia) & FX & $\mathrm{LC}_{50}(48 \mathrm{~h})$ & $0.756 \mu \mathrm{M}(0.23 \mathrm{mg} / \mathrm{L})$ & 185 \\
\hline \multirow[t]{5}{*}{ Water flea (Ceriodaphnia dubia) } & $\mathrm{CP}$ & $\mathrm{LC}_{50}(48 \mathrm{~h})$ & $3.90 \pm 0.27 \mathrm{mg} / \mathrm{L}$ & 216 \\
\hline & FL & & $0.84 \pm 0.41 \mathrm{mg} / \mathrm{L}$ & \\
\hline & FX & & $0.51 \pm 0.07 \mathrm{mg} / \mathrm{L}$ & \\
\hline & PX & & $0.58 \pm 0.13 \mathrm{mg} / \mathrm{L}$ & \\
\hline & ST & & $0.12 \pm 0.05 \mathrm{mg} / \mathrm{L}$ & \\
\hline \multirow[t]{10}{*}{ Water flea (Ceriodaphnia dubia) } & $\mathrm{CP}$ & $\operatorname{NOEC}(8 \mathrm{~d})$ & $0.80 \mathrm{mg} / \mathrm{L}$ & 216 \\
\hline & & $\operatorname{LOEC}(8 \mathrm{~d})$ & $4.00 \mathrm{mg} / \mathrm{L}$ & \\
\hline & FL & $\operatorname{NOEC}(8 \mathrm{~d})$ & $0.366 \mathrm{mg} / \mathrm{L}$ & \\
\hline & & $\operatorname{LOEC}(8 \mathrm{~d})$ & $1.466 \mathrm{mg} / \mathrm{L}$ & \\
\hline & FX & $\operatorname{NOEC}(8 \mathrm{~d})$ & $0.089 \mathrm{mg} / \mathrm{L}$ & \\
\hline & & LOEC (8 d) & $0.447 \mathrm{mg} / \mathrm{L}$ & \\
\hline & PX & $\operatorname{NOEC}(8 \mathrm{~d})$ & $0.22 \mathrm{mg} / \mathrm{L}$ & \\
\hline & & $\operatorname{LOEC}(8 \mathrm{~d})$ & $0.44 \mathrm{mg} / \mathrm{L}$ & \\
\hline & ST & $\operatorname{NOEC}(8 \mathrm{~d})$ & $0.009 \mathrm{mg} / \mathrm{L}$ & \\
\hline & & LOEC $(8 \mathrm{~d})$ & $0.045 \mathrm{mg} / \mathrm{L}$ & \\
\hline Water flea (Daphnia magna) & FX & $\mathrm{LC}_{50}(48 \mathrm{~h})$ & $2.65 \mu \mathrm{M}(0.82 \mathrm{mg} / \mathrm{L})$ & 185 \\
\hline \multirow{5}{*}{ Water flea (Daphnia magna) } & $\mathrm{CP}$ & $\mathrm{EC}_{50}(48 \mathrm{~h})$ & $20 \pm 4.0 \mathrm{mg} / \mathrm{L}$ & 217 \\
\hline & FL & & $13 \mathrm{mg} / \mathrm{L}$ & \\
\hline & FX & & $6.4 \pm 1.3 \mathrm{mg} / \mathrm{L}$ & \\
\hline & PX & & $6.3 \mathrm{mg} / \mathrm{L}$ & \\
\hline & ST & & $0.92 \pm 0.17 \mathrm{mg} / \mathrm{L}$ & \\
\hline Water flea (Daphnia magna) & PX & $\mathrm{EC}_{50}(48 \mathrm{~h})$ & $2.5 \mathrm{mg} / \mathrm{L}$ & 218 \\
\hline \multicolumn{5}{|l|}{ Invertebrates (sediment-dwelling) } \\
\hline Midge (Chironomus tentans) & FX & $\mathrm{LC}_{50}(48 \mathrm{~h})$ & $15.2 \mathrm{mg} / \mathrm{kg}$ & 185 \\
\hline Scud (Hyalella azteca) & FX & $\mathrm{LC}_{50}(48 \mathrm{~h})$ & $>43 \mathrm{mg} / \mathrm{kg}$ & 185 \\
\hline \multicolumn{5}{|l|}{ Vertebrates } \\
\hline \multirow{12}{*}{$\begin{array}{l}\text { African clawed frog } \\
\text { (Xenopus laevis) }\end{array}$} & FX & $\mathrm{EC}_{10}(96 \mathrm{~h})$ & $3.0 \mathrm{mg} / \mathrm{L}$ & 183 \\
\hline & & $\mathrm{EC}_{50}(96 \mathrm{~h})$ & $4.9 \mathrm{mg} / \mathrm{L}$ & \\
\hline & & $\mathrm{LC}_{10}(96 \mathrm{~h})$ & $7.1 \mathrm{mg} / \mathrm{L}$ & \\
\hline & & $\mathrm{LC}_{50}(96 \mathrm{~h})$ & $7.5 \mathrm{mg} / \mathrm{L}$ & \\
\hline & $\mathrm{PX}$ & $\mathrm{EC}_{10}(96 \mathrm{~h})$ & $3.6 \mathrm{mg} / \mathrm{L}$ & \\
\hline & & $\mathrm{EC}_{50}(96 \mathrm{~h})$ & $4.1 \mathrm{mg} / \mathrm{L}$ & \\
\hline & & $\mathrm{LC}_{10}(96 \mathrm{~h})$ & $4.4 \mathrm{mg} / \mathrm{L}$ & \\
\hline & & $\mathrm{LC}_{50}(96 \mathrm{~h})$ & $5.12 \mathrm{mg} / \mathrm{L}$ & \\
\hline & ST & $\mathrm{EC}_{10}(96 \mathrm{~h})$ & $3.0 \mathrm{mg} / \mathrm{L}$ & \\
\hline & & $\mathrm{EC}_{50}(96 \mathrm{~h})$ & $3.3 \mathrm{mg} / \mathrm{L}$ & \\
\hline & & $\mathrm{LC}_{10}(96 \mathrm{~h})$ & $3.6 \mathrm{mg} / \mathrm{L}$ & \\
\hline & & $\mathrm{LC}_{50}(96 \mathrm{~h})$ & $3.9 \mathrm{mg} / \mathrm{L}$ & \\
\hline Fathead minnow (Pimephales promelas) & $\mathrm{FX}$ & $\mathrm{LC}_{50}(48 \mathrm{~h})$ & $2.28 \mu \mathrm{M}(0.71 \mathrm{mg} / \mathrm{L})$ & 185 \\
\hline Japanese medaka (Oryzias latipes) & FX & $\mathrm{LC}_{50}(48 \mathrm{~h})$ & $>28.9 \mu \mathrm{M}(8.9 \mathrm{mg} / \mathrm{L})$ & 185 \\
\hline
\end{tabular}

release in these brain regions at concentrations of $10 \mu \mathrm{M}$ and $100 \mu \mathrm{M}$. In sea bream (Pagrus major), 5-HT concentrations of $1 \mu \mathrm{M}$ significantly induced GnRH secretion from the preopticanterior hypothalamus of juvenile and adult fish ex vivo. ${ }^{155}$ This action seemed to be mediated by $5-\mathrm{HT}_{2}$ receptors, since it could be blocked by ketanserin (Table 4). Reciprocally, GnRH appears to influence the serotonergic system in fish. The intra-peritoneal application of $0.15 \mu \mathrm{g}$ GnRH analog per gram body weight resulted in an increase of 5-HT and noradrenaline concentrations in the hypothalamus and pituitary of female 


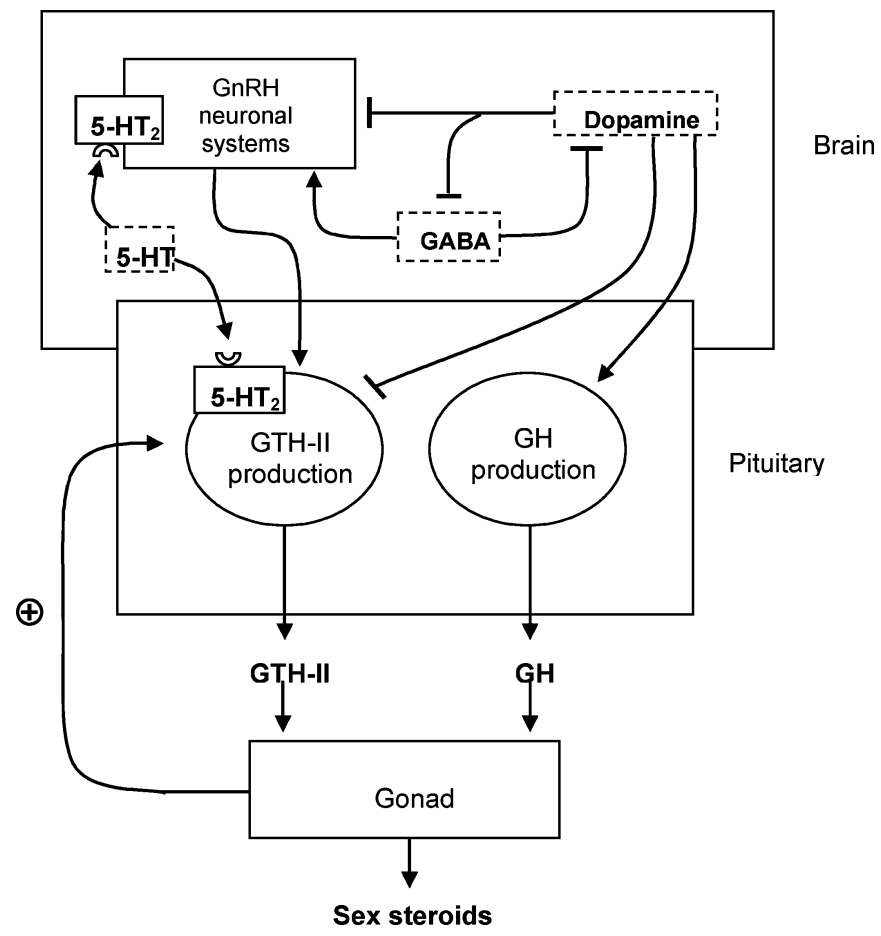

FIG. 7. Simplified schematic of HPG axis in fish. GABA, gamma-aminobutyric acid; $\mathrm{GH}$, growth hormone; $-\mathrm{H}=$ inhibition; $\longrightarrow=$ stimulation.

catfish. ${ }^{149}$ Simultaneously, dopamine concentrations decreased, again revealing a counterbalancing relationship between these neurotransmitters.

In addition to its suggested stimulation of $\mathrm{GnRH}$ secretion, it has been assumed that 5-HT may be able to increase serum concentrations of GTHs by directly acting on gonadotrope cells in the pituitary. Somoza and colleagues ${ }^{157}$ examined the effects of 5-HT on the serum GTH-II concentration in male and female goldfish at different maturational stages in vivo. In both sexes, intraperitoneal administration of different doses of 5-HT (2.5, $5,10,20 \mu \mathrm{g} / \mathrm{g}$ body weight) resulted in a dose-dependent increase of the GTH-II concentration. Pretreatment with $10 \mu \mathrm{g} / \mathrm{g}$ fluoxetine enhanced this effect, while $10 \mu \mathrm{g} / \mathrm{g}$ of ketanserin blocked the stimulating action of 5-HT. In contrast, injection of different 5 -HT doses $(5,10,20 \mu \mathrm{g} / \mathrm{g})$ in the preoptic brain area had no effect on serum GTH-II concentrations, suggesting that 5-HT exerts its effects on the HPG axis in goldfish specifically at the pituitary level. In a similar study with Atlantic croaker, it was shown that the effect of 5-HT on the HPG axis may depend on the reproductive status of test animals. ${ }^{153}$ Indeed, intraperitoneal injections of $20 \mu \mathrm{g} / \mathrm{g} \mathrm{5-HT}$ in 1-yearold females within their first reproductive cycle did not change GTH-II plasma concentrations, while cotreatment with a GnRH analog (LHRHa, $20 \mathrm{ng} / \mathrm{g}$ ) induced a stimulation of GTH-II release. Administration of $10 \mu \mathrm{g} / \mathrm{g}$ fluoxetine prior to cotreatment with 5-HT and LHRHa amplified the effect of 5-HT, corrobo- rating the observations by Somoza and coworkers ${ }^{157}$ in goldfish. In older female Atlantic croaker (2-3 years of age), treatment with 5-HT alone was sufficient to increase plasma GTH-II levels. ${ }^{153}$ Interestingly, the regulatory system controlling GTHII secretion in Atlantic croaker appears to be organized differently than in other fish species studied so far, as dopamine had no inhibitory effect on GTH-II release. In vitro experiments with perfused pituitary fragments of goldfish ${ }^{156,158}$ and Atlantic croaker ${ }^{153}$ confirmed that 5 -HT stimulates the release of GTHII from the pituitary. Again, this effect could be blocked by the antagonists ketanserin ${ }^{156}$ or methiothepin and mianserin ${ }^{158}$ (Table 4).

In the yellow snapper (Lutjanus argentiventris), considerable fluctuations of 5-HT, dopamine, and noradrenaline concentrations in both hypothalamus and pituitary were noticed during gonadal development. ${ }^{160}$ Indications for serotonergic modulation of the HPG axis at the hypothalamus level were also found in rainbow trout. While no changes of either 5-HT or 5-HIAA concentrations in connection with reproductive processes could be detected in the pituitary, ${ }^{161}$ the observed monoamine levels in the telencephalon and hypothalamus of trout varied depending on the developmental stage. ${ }^{162}$ In both brain regions, 5-HT turnover increased during the periovulatory phase, whereas dopaminergic activity declined in both pituitary and hypothalamus. In contrast, the situation was reversed during vitellogenesis, with the serotonergic activity decreasing in the telencephalon and the preoptic-anterior hypothalamus and dopamine concentrations rising in the hypothalamus. ${ }^{162}$ These observations suggest that the relative concentrations of these hormones, i.e., their overall balance, may be important for the regulation of GTH-II release, either indirectly by modulating GnRH secretion in the hypothalamus or directly via the pituitary. Therefore, specific increases of 5-HT availability caused by SSRI action may affect the 5$\mathrm{HT} /$ dopamine ratio in the fish brain and lead to a disruption of this interaction regulating reproductive processes via the HPG axis. Apart from its influence on the hypothalamus and pituitary level, 5-HT also seems to have an effect at the gonad level. This hypothesis is supported by the observation of 5-HT in mid- to late-vitellogenic follicles of zebrafish using immunohistochemical methods (Krieger, personal communication). Based on an in vitro study with mummichog (killifish, Fundulus heteroclitus), Cerdà and coworkers ${ }^{163}$ reported that the meiotic maturation of oocytes, stimulated by maturation-inducing steroid (MIS), was blocked by adding $0.05 \mu \mathrm{M} 5-\mathrm{HT}$ hydrochloride $(10.6 \mu \mathrm{g} / \mathrm{L})$ to the cell culture medium. Furthermore, treatment with $100 \mu \mathrm{M} 5$ HT hydrochloride induced an increase of cAMP concentrations inside the follicles. This indirectly indicates the presence of 5$\mathrm{HT}_{4}, 5-\mathrm{HT}_{6}$, or $5-\mathrm{HT}_{7}$ receptors on killifish follicles, as these 5-HT receptor subtypes are thought to be positively coupled to adenylate cyclase in mammals ${ }^{32}$ (Table 3 ). The definitive nature of the receptor types involved in this signal transduction pathway remains to be elucidated. In contrast to the observed inhibitory influence in killifish, $10 \mu \mathrm{g} / \mathrm{L}$ and $100 \mu \mathrm{g} / \mathrm{L}$ of 5-HT had a stimulatory effect on oocyte maturation in Japanese medaka in vitro 
by inducing synthesis of estradiol and MIS in granulosa cells, resulting in germinal vesicle breakdown. ${ }^{164}$ Overall, these studies demonstrate the complexity of serotonergic actions involved in the control of the HPG axis in fish. Moreover, the modulatory function of 5-HT appears to be largely dependent on reproductive status and may vary considerably in different fish species. These factors also make it very difficult to determine whether exposure to environmental concentrations of SSRIs will affect the reproductive system to an extent that may have consequences at the individual or population level. It must be taken into account that in most fish studies using SSRIs to influence serotonergic transmission the agents were administered by injection and at rather high doses, e.g., in the milligrams per kilogram range. ${ }^{157}$ As a result, the substances are more likely to reach a specific target site, while the application via tank water, simulating environmental exposure, depends on the stability of the compounds in water and their absorption via the gill and, to a lesser extent, the gastrointestinal tract. Furthermore, when pharmaceutical substances are absorbed from water they become subject to metabolism that may lead to their degradation and deactivation. In the case of fluoxetine, however, metabolic conversion leads to its active demethylated form, norfluoxetine. It is feasible to assume, however, that SSRIs may exert adverse effects on fish reproduction, especially during vitellogenesis, when under normal physiological conditions 5-HT levels should be low. Chronic exposure to SSRIs may induce chronically elevated 5HT concentrations, altering normal seasonal and daily variations and thus resulting in a subtle but decisive hormonal imbalance, which could influence regular gametogenesis and reproductive behavior. Consequently, SSRI environmental risk assessment demands specific ecotoxicological tests with well-defined and mechanistically plausible endpoints to discern possible subtle effects on reproduction.

\section{SEROTONERGIC REGULATION OF EMBRYO DEVELOPMENT}

In connection with the modulatory influence on reproductive processes, 5-HT is also involved in the regulation of invertebrate ${ }^{165,166}$ and vertebrate embryo development. ${ }^{165,167}$ To date, it has been reported that oocytes of starfish, fish, amphibians, and mammals contain 5-HT, and 5-HT receptors have been detected on the cell surface of oocytes as well as follicular cells of various species. ${ }^{168}$ Even prior to the presence of differentiated serotonergic neurons releasing neurotransmitter, 5-HT is involved in the regulation of basic developmental processes related to early embryogenesis, including cell proliferation, migration, differentiation, and morphogenetic cell movements during gastrulation and postgastrulation. ${ }^{165}$ By controlling morphogenesis, for instance, 5-HT of maternal origin appears to influence the development and maturation of the mouse brain. ${ }^{169}$ Furthermore, it has been shown that 5-HT induces neurogenesis and neuronal differentiation, which includes neurite outgrowth and synaptogenesis, through 5-HT1A receptors in other mammals. ${ }^{170,171}$
In several in vitro studies using both vascular and nonvascular cells of various mammalian species, 5-HT has been recognized to elicit a mitogenic effect, either mediated by extracellular receptors or by internalization of 5-HT via the 5-HTT. ${ }^{172}$ This may be connected to the stimulatory effect of 5-HT on neuroembryogenesis. ${ }^{170}$

The reuptake of 5-HT via active transport and thus termination of 5-HT signaling appears to be an important cue in early embryonic stages; therefore, SSRIs may have the potential to interfere with normal embryo development. In a review by Lauder, ${ }^{173}$ it was reported that exposure of cultured mouse embryos to 5-HT uptake inhibitors including fluoxetine, in low micromolar concentrations that did not result in general embryotoxic effects, caused craniofacial malformations, reduced cell proliferation, and increased cell death in craniofacial and cardiac mesenchyme. Blockade of the 5-HTT with $1 \mu \mathrm{M}$ of paroxetine also decreased proliferation of rat fetal heart cells in vitro. ${ }^{174}$ In another study, the presence of 5-HTT mRNA was detected in the developing rat brain. ${ }^{175}$ Transient expression of the 5HTT in some brain areas during embryogenesis suggested that, in mammalian ontogeny, there may be critical periods for the regulation of brain 5-HT levels, during which the embryo may be particularly susceptible to SSRI exposure. Developing invertebrate and amphibian embryos may reach an SSRI-sensitive stage when genomic activity switches from transcription of maternal to zygotic genes during the so-called mid-blastula transition. ${ }^{165}$ In sea urchins, the binding of 5-HT agonists and antagonists to intracellular or extracellular serotonergic receptors may disrupt mid-blastula transition and lead to increased incidences of malformations, as reviewed by Buznikov and colleagues. ${ }^{165}$

One particular role of 5-HT and the pre-nervous serotonergic system during embryogenesis may be a modulatory influence on the development of the invariant left-right (LR) asymmetry of heart, viscera (liver, spleen, gut), and brain ${ }^{167}$ (Figure 8). Since 5-HT is a relatively small charged molecule, it fits the profile of a molecular determinant that may be distributed through gap junctions in the early embryo. Therefore, 5-HT appears to represent an ideal candidate to participate in the initiation of LR axis formation, which involves the breaking of bilateral symmetry. ${ }^{176-178}$ It is known that deviations in LR determination at this stage result in abnormal laterality phenotypes that are generally classified as either complete inversion (Situs inversus) or heterotaxia (Situs ambiguus), i.e., displaying a combination of discordant normal and abnormal LR asymmetries. ${ }^{179}$ In some cases, normally asymmetrical organs may be duplicated or missing. In mammals, errors in laterality development are often associated with complex heart defects. ${ }^{179}$

Indications for serotonergic signaling as an early step in the patterning of the LR axis have been found in studies with chick and frog embryos. ${ }^{176,177}$ In Xenopus laevis embryos, 5-HT was localized asymmetrically in specific cells of early cleavage stages. ${ }^{176,180}$ When early Xenopus embryos were exposed to subtoxic concentrations of pharmacological agents blocking 


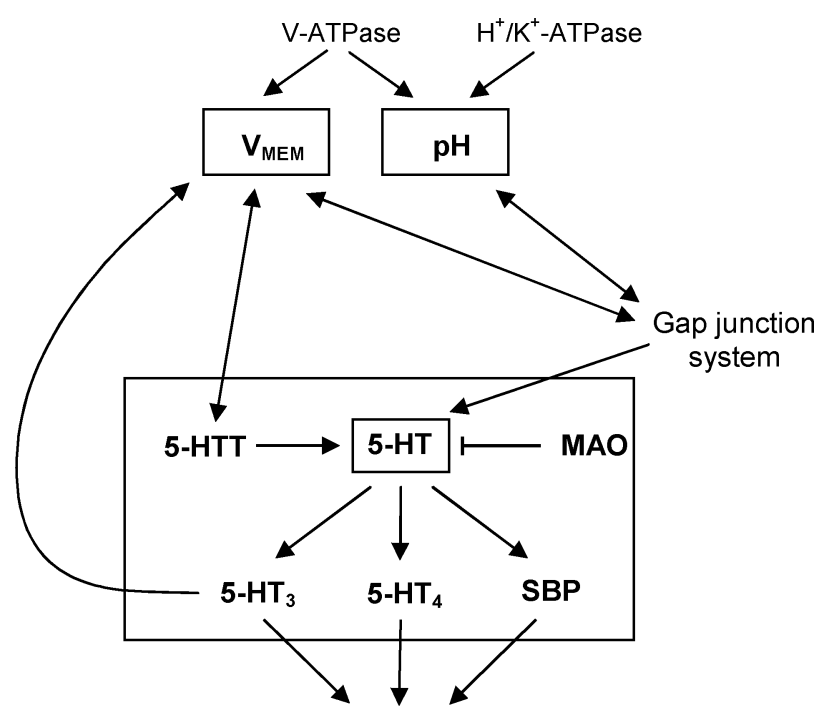

Asymmetric gene cascade in the LR pathway

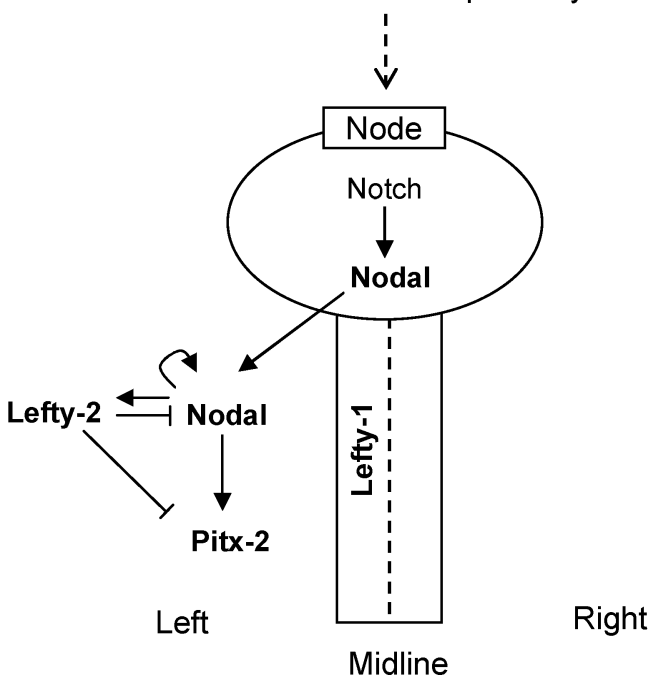

FIG. 8. Proposed interaction of ion flow, serotonergic system and the regulation of LR asymmetry development via the nodal pathway during early embryogenesis, modified from Levin ${ }^{167}$ and Schier. ${ }^{200}$ LR, left-right; SBP, serotonin binding protein; $\mathrm{V}_{\mathrm{MEM}}$, membrane voltage.

$5-\mathrm{HT}_{3}$ or $5-\mathrm{HT}_{4}$ receptor subtypes or the two isoforms of the 5HT-degrading enzyme MAO, a randomization of visceral organ position was observed; i.e., the incidence of heart, gut, and gallbladder heterotaxia was significantly increased. ${ }^{176}$ In addition, blocking the already-mentioned components of the 5-HT signaling pathway altered the normal left-sided expression pattern of the earliest known asymmetrically transcribed nodal-related gene $x n r-1$. These data suggest that serotonergic actions occur upstream of the early asymmetric gene cascade (Figure 8). It is assumed that the 5-HT-gated ion channel 5- $\mathrm{HT}_{3}$, which is permeable for potassium ions, may interact with $\mathrm{H}^{+} / \mathrm{K}^{+}$-ATPase in the regulation of ion flow during the initial phases of LR asymmetry. Fukumoto and colleagues ${ }^{177}$ tested the hypothesis that the two known 5-HT transporters, the specific 5-HTT and the unspecific VMAT, may play a role in LR patterning events in Xenopus. Directly after fertilization, Xenopus embryos were exposed to low micromolar concentrations of different SSRIs including fluoxetine and citalopram or VMAT inhibitors (e.g., reserpine) from fertilization to stage $16(\sim 18 \mathrm{~h})$ and evaluated for visceral organ laterality. All pharmacological inhibitors were shown to induce heterotaxia, primarily during cleavage stages. Moreover, fluoxetine and reserpine induced bilateral expression of the normally left-sided $x n r-1$. Although pharmacological experiments alone are insufficient to prove the involvement of the target molecule, the results of this study strongly support the assumption that 5-HT transport is an important process for the establishment of LR asymmetry. Concurrently, it was demonstrated that the normal development of LR asymmetry may be disrupted by SSRIs. The involvement of 5-HTT and VMAT in LR-relevant regulation was also confirmed in chick embryos. In view of the considerable differences in the gastrulation process of birds compared to amphibian species, the latter finding points to a stringent evolutionary conservation of these developmental mechanisms.

As most of the studies investigating the serotonergic actions in early embryo development of lower vertebrates have been conducted with amphibian or chick embryos, there is a dearth of information on the function of 5-HT and potential effects of SSRIs during fish embryogenesis. Nevertheless, considering that developmental processes in vertebrate embryos are generally very similar and that the LR determination pathway appears to be highly conserved, it can be assumed that LR asymmetry in fish embryos may also be affected by SSRIs. As a consequence, fish may exhibit organ dysfunctions, e.g., heart defects, or show behavioral aberrations as a result of abnormal brain laterality. ${ }^{181}$ Whether exposure to environmental SSRI concentrations has an influence on fish ontogeny remains to be investigated.

\section{PAST AND CURRENT EFFORTS TO DETECT ECOTOXICOLOGICAL EFFECTS OF SSRIS}

To date there is only limited information available regarding the ecotoxicological potential of SSRIs, especially under chronic exposure conditions. Most of the standardized testing methods that are currently employed in environmental risk assessment of pharmaceuticals including SSRIs examine acute effects in systems in vitro or in vivo. Using cultures of primary hepatocytes from immature rainbow trout (PRTH) and the PLHC-1 cell line, derived from a hepatocellular carcinoma in topminnow (Poeciliopsis lucida), the toxicity of fluoxetine was determined by assessing cell viability, activity of cytochrome P450 1A enzyme, and generation of reactive oxygen species (ROS). ${ }^{182}$ Both cell types were exposed to fluoxetine concentrations up to $140 \mu \mathrm{M}(48.4 \mathrm{mg} / \mathrm{L})$ for $24 \mathrm{~h}$. The cell cultures were then analyzed with 3-(4,5-dimethylthiazol-2-yl)- 
2,5-diphenyltetrasodium bromide tetrazolium (MTT) and 7ethoxyresorufin- $O$-deethylase (EROD) assays. The MTT assays showed effective concentration $\left(\mathrm{EC}_{50}\right)$ values of $5 \mu \mathrm{M}(1.73$ $\mathrm{mg} / \mathrm{L})$ and $66 \mu \mathrm{M}(22.8 \mathrm{mg} / \mathrm{L})$ for PLHC-1 and PRTH, respectively, and the EROD assay resulted in an $\mathrm{EC}_{50}$ value of 77 $\mu \mathrm{M}(26.6 \mathrm{mg} / \mathrm{L})$ for PRTH. Changes in ROS levels were only determined for PLHC-1 cells. Fluoxetine exposure had only a marginal stimulatory effect on ROS production (a significant increase was found only at $40 \mu \mathrm{M}[13.8 \mathrm{mg} / \mathrm{L}])$, thus demonstrating limited cytotoxicity, as would be expected from a pharmaceutical designed for chronic therapeutic intervention. It has to be emphasized that the fluoxetine concentrations employed in this cytotoxicity study were several orders of magnitude higher than detected environmental levels.

Potential embryotoxic effects of fluoxetine, paroxetine and sertraline were tested by Richards and Cole ${ }^{183}$ using the acute (96-h) Frog Embryo Teratogenicity Assay Xenopus (FETAX) ${ }^{184}$ SSRIs demonstrated a teratogenic potential only at high concentrations with malformations and lethality detected at concentrations above $2 \mathrm{mg} / \mathrm{L}$. All three SSRIs induced skeletal and muscular tail flexures. Fluoxetine exposure also induced facial malformations that may be interpreted as being the result of serotonergic regulation of craniofacial morphogenesis in Xenopus embryos. These results are in agreement with the observation that neither fluoxetine nor fluvoxamine caused any effects in Xenopus embryos up to a concentration of $1 \mathrm{mg} / \mathrm{L}$ using the FETAX system (Kreke, unpublished data). However, the endpoints examined with the FETAX are not specific enough to detect potentially subtle effects of SSRIs on embrogenesis.

Brooks and colleagues ${ }^{185}$ conducted in vivo tests to examine the acute effects of fluoxetine exposure on different phyla including algae, daphnids, and fish species (Japanese medaka and fathead minnow). Juvenile fathead minnows (Pimephales promelas) and medaka (Oryzias latipes) were exposed to nominal concentrations of fluoxetine $(1.8,3.6,7.2,14.5,28.9 \mu \mathrm{M})$ for $48 \mathrm{~h}$. The $\mathrm{LC}_{50}$ values for fathead minnow, intrapolated from two tests with 11- and 14-day-old fish, were rather high, i.e., $2.22 \mu \mathrm{M}$ and $2.88 \mu \mathrm{M}$, respectively. Medaka were evidently not susceptible to fluoxetine exposure, as their survival rate was unaffected at all fluoxetine treatment levels. These findings are not surprising, as acute effects would not a priori be expected, but rather confirm the notion that pharmaceuticals designed for chronic therapeutic intervention are not acutely toxic in any species. In view of the pharmacological characteristics and the current understanding of SSRIs in mammals and other species, i.e., their potential influence on normal physiological function, and in view of the prevailing environmental conditions, further in vivo experiments focusing on the potentially subtle effects of low SSRI levels (ng/L) in fish over an extended period of time are required. Long-term effects may occur at much lower concentrations and follow different toxicodynamic mechanisms than extrapolated from acute exposure studies. ${ }^{186}$ Indeed, some indications for subtle effects of SSRIs on behavioral and reproductive processes in nontarget organisms were found in several studies with aquatic invertebrates (Table 5), even though these investigations often had an economic rather than an ecological purpose, e.g., yield increase in mussel farming. ${ }^{2}$ Nevertheless, these investigations represent a starting point for the understanding of potential impact of SSRIs in the aquatic environment. Interestingly, it was also discovered in studies with invertebrates that lower concentrations of SSRIs may have a more pronounced effect than higher concentrations. In exposure experiments with the marine snail Ilyanassa obsoleta, injections of $1 \mu \mathrm{M}$ fluoxetine caused a higher stimulation of larval metamorphosis than a concentration of $100 \mu \mathrm{M} .{ }^{187}$ However, these findings need further confirmation, as many of the studies investigating the impact of SSRI exposure on invertebrates were conducted with a limited degree of replication such that reporting of false positive (chance) effects cannot be excluded.

In fish, SSRIs such as fluoxetine have been used as pharmacological agents to manipulate and characterize serotonergic action. It has been observed that fluoxetine had a stimulating influence on GnRH and GTH-II release ${ }^{157,159}$; therefore, SSRIs may interfere with fish reproductive processes by altering endogenous 5-HT concentrations. Foran and colleagues ${ }^{188}$ evaluated the reproductive capabilities of adult Japanese medaka following a 4-week exposure to nominal fluoxetine concentrations of $0.1,0.5,1$, and $5 \mu \mathrm{g} / \mathrm{L}$. After 14 days of treatment in single-sex groups, fish were paired in separate exposure tanks to assess reproductive endpoints, including number of eggs produced (total and per day), spawning frequency, percentage of fertilized eggs, hatching success, and proportion of malformed hatchlings. Additionally, somatic and physiological parameters such as condition factor, gonadal somatic index, hepatic vitellogenin content, and circulating steroid concentrations were measured. No changes in fecundity, fertility, spawning rate, and hatching success were observed. A slightly higher frequency of developmental abnormalities compared to embryos of control animals was noted in all fluoxetine-treated groups; however, these effects did not appear to be concentration-dependent. The only physiological endpoint that appeared to be affected by fluoxetine exposure was the concentration of circulating estradiol, which was elevated in females exposed to $0.1 \mu \mathrm{g} / \mathrm{L}$. However, as this increase of estradiol levels was only significant at the lowest fluoxetine treatment concentration and no dose-response relationship was observed, these findings have to be considered with caution. The lack of significant response to higher fluoxetine concentrations may be due to saturation effects and/or feedback inhibition. Therefore, the current data suggest that fluoxetine does not elicit an effect on reproductive function in Japanese medaka even following 4 weeks of exposure. Nevertheless, the endpoints chosen in this study may not have been sufficiently specific, i.e., not incorporating the known mode of action of fluoxetine, to detect a potentially subtle influence of this SSRI under prolonged exposure conditions. It should also be considered that these findings refer to a single test organism and that medaka may be less sensitive to fluoxetine than other fish species; indeed, species-specific differences regarding susceptibility to chemical exposure have 
already been observed in a study using medaka compared to tests with fathead minnow. ${ }^{189}$

One problem of the environmental risk assessment of pharmaceutical substances is that even when the known mode of action is considered in the selection of ecotoxicity tests and endpoints, the existence of other molecular targets and associated pathways cannot be excluded. ${ }^{2}$ Indeed, although SSRIs are propagated as having almost no nonspecific effects in humans, also implied by the term "selective" in the naming of this pharmaceutical class, there are some indications that these compounds may not only interact with the 5-HTT but also with MAO enzymes and certain 5-HT and even acetylcholine receptors. ${ }^{190-193}$ The three SSRIs fluoxetine, fluvoxamine, and citalopram, for instance, demonstrated a competitive inhibitory activity toward rat brain MAO in the micromolar range. ${ }^{190} \mathrm{In}$ an in vitro study with Xenopus laevis oocytes expressing cloned rat $5-\mathrm{HT}_{2 C}$ receptors, $\mathrm{Ni}$ and Miledi ${ }^{191}$ observed that micromolar concentrations of fluoxetine blocked the responses of these receptor previously elicited by 5 -HT. Using the same model system, fluoxetine was also shown to block both muscle and neuronal nicotinic acetycholine receptors (nAChR) in a noncompetitive and voltagedependent manner. ${ }^{192}$ Similarly, sertraline and paroxetine displayed a noncompetitive inhibitory effect on two human and one chick nAChR subtypes in a low to intermediate micromolar concentration range. ${ }^{193}$ It has to be emphasized, however, that the SSRI levels used in the latter studies are not environmentally relevant; nor are they applicable to a chronic exposure situation. In addition to the already-mentioned enzymes and receptors, nontarget organisms may possess yet other signal transduction pathways, not common in humans or other mammals, that may be affected by SSRIs. In this context, biochemical and cellular responses may serve as early warning signals that exposure to SSRIs may have deleterious effects at the organism level. ${ }^{194}$ In addition, the analysis of defined behavioral endpoints, especially associated with reproductive processes, may be advantageous.

Theoretical models aiming to predict the environmental impact of SSRIs are inconclusive when they are not supported by experimental data. So far, these models primarily rely on parameters such as physicochemical properties of the compound in question, pharmacological data obtained in mammalian studies, measured or predicted environmental concentrations, ${ }^{195}$ and the limited amount of ecotoxicological data. Ideally, such a model could be used to evaluate the ecotoxic potential of SSRI formulations. However, there may be some problems with the implementation in actual risk assessment as long as analytical data sets are inconsistent-an example is the high variability of the fluoxetine $\log K_{\text {ow }}$ (Table 2) - and information on environmental toxicology is unavailable. In a recent survey in Switzerland, the ecotoxicological hazard potential of fluoxetine and citalopram along with other pharmaceuticals and their metabolites was estimated. ${ }^{196}$ The theoretical analyses were based on Swiss sales data, human metabolism, and a baseline toxicity that was derived from acute Daphnia toxicity tests. For the two SSRI formulations, no indications for an ecotoxicological risk in Swiss wastewater were found. However, the authors reported that the proposed screening method showed some limitations as specific toxicological effects or chronic exposure conditions were not considered in the calculations, because the required experimental data were lacking. Furthermore, the model employed did not take into account specifically acting metabolites of baseline toxic parent compounds, which may be critical regarding substances such as fluoxetine and its bioactive metabolite norfluoxetine. This clearly illustrates that an "easy" model to estimate the potential ecotoxicity of SSRIs as a pharmaceutical class is not available.

For an adequate risk assessment of SSRIs, a combination of theoretical and practical approaches would be advantageous, incorporating physicochemical parameters, known physiological interactions, and specific endpoints, as well as respective experimental data that should preferably be derived from chronic studies with different fish species commonly used in environmental monitoring and laboratory research. However, instead of conducting life-cycle tests with standardized endpoints, a more mechanistic approach incorporating the characteristics of the pharmacological target system is required. Although analytical data on the presence of SSRIs in the aquatic environment are scarce and should be considered with caution as they may not be representative, the results of the preliminary study conducted by Brooks and colleagues ${ }^{18}$ who detected SSRIs and metabolites in fish tissues should not be ignored. Therefore, analogous to the suggestions of Owen and colleagues ${ }^{20}$ concerning the potential interactions of $\beta$-blockers with the fish adrenergic system, a better understanding of the serotonergic system in fish species, including 5-HT receptor and transporter function, would be advisable to define suitable evaluation parameters and biomarkers for SSRI ecotoxicology testing. The information gained in physiological investigations could then also be used to estimate the potential impact of other pharmaceutical agents modulating 5-HT availability such as tricyclic antidepressants and MAO inhibitors.

\section{CONCLUDING REMARKS}

The presence of pharmaceutical residues in the aquatic environment has become an issue of public, political, and also scientific concern. Neuroactive drugs such as SSRIs may affect nontarget organisms due to the presence of phylogenetically highly conserved signaling mechanisms with similar functions. By summarizing the currently available information, it is demonstrated that the serotonergic system plays a modulatory role in several physiological processes in fish and that 5-HT signal transduction may be mediated by neuronal, endocrine, and paracrine pathways. The influence of 5-HT on different target organs and tissues appears to be species-specific and may also depend on gender and/or the developmental and reproductive status of the individual. Because of the complexity of the serotonergic system and in view of the limited amount of experimental data on the effects of SSRIs, it is difficult to assess the potential consequences of continuous SSRI exposure for 
fish populations. Clearly, current experimental approaches used for routine environmental risk assessment of pharmaceuticals, including SSRIs, are inadequate if not entirely inappropriate, especially as relevant endpoints are not assessed or impossible to determine in the experimental designs employed. Future toxicology testing of environmentally relevant compounds must encompass and reflect the known pharmacological effects of those substances and should therefore focus more strongly on specific molecular targets, rather than being simply descriptive. In the case of SSRIs, this will primarily comprise the 5-HT transporter and receptors; however, the interactions of 5-HT-specific pathways with other hormonal and neurotransmitter systems should not be ignored.

\section{ACKNOWLEDGMENTS}

The authors thank the Bundesamt für Umwelt (BAFU, Switzerland) for the financial support of this project (BUWAL/810.3189.004 2004.H.06) and Bettina Hitzfeld, Evelyn O'Brien, and Heiko Krieger for proofreading and helpful comments.

\section{REFERENCES}

1. Dietrich, D.R., Webb, S.F., and Petry, T. (2002). Hot spot pollutants: pharmaceuticals in the environment. Toxicol. Lett. 131:1.

2. Daughton, C.G., and Ternes, T.A. (1999). Pharmaceuticals and personal care products in the environment: Agents of subtle change? Environ. Health Perspect. 107 Suppl 6:907.

3. Nash, J.P., Kime, D.E., Van der Ven, L.T., Wester, P.W., Brion, F., et al. (2004). Long-term exposure to environmental concentrations of the pharmaceutical ethynylestradiol causes reproductive failure in fish. Environ. Health Perspect. 112:1725.

4. Kidd, K.A., Blanchfield, P.J., Mills, K.H., Palace, V.P., Evans, R.E., et al. (2007). Collapse of a fish population after exposure to a synthetic estrogen. Proc. Natl. Acad. Sci. USA 104:8897.

5. Seiler, J.P. (2002). Pharmacodynamic activity of drugs and ecotoxicology-Can the two be connected? Toxicol. Lett. 131:105.

6. Hiemke, C., and Härtter, S. (2000). Pharmacokinetics of selective serotonin reuptake inhibitors. Pharmacol. Ther. 85:11.

7. IMS Health Canada (2004). In Canada, depression ranks as fastgrowing diagnosis. IMS Health, Inc. (http://www.imshealth.com/ ims/portal/front/articleC/0,2777,6599_41382706_57069115,00. html). Cited 25 October 2006.

8. IMS Health (2006). Commonly Requested Therapeutic Class and Product Information. IMS Health, Inc. (http://www.imshealth. com/ims/portal/front/articleC/0,2777,6599_18731_77056778,00. html). Cited 22 June 2006.

9. RxList (2005). RxList Inc. (http://www.rxlist.com/script/ main/art.asp?articlekey=79509). Cited 19 June 2007.

10. McManus, P., Mant, A., Mitchell, P.B., Montgomery, W.S., Marley, J., et al. (2000). Recent trends in the use of antidepressant drugs in Australia, 1990-1998. Med. J. Aust. 173:458.

11. Vasskog, T., Berger, U., Samuelsen, P.J., Kallenborn, R., and Jensen, E. (2006). Selective serotonin reuptake inhibitors in sewage influents and effluents from Tromso, Norway. J. Chromatogr. A 1115:187.
12. Weigel, S., Berger, U., Jensen, E., Kallenborn, R., Thoresen, H., et al. (2004). Determination of selected pharmaceuticals and caffeine in sewage and seawater from Tromso/Norway with emphasis on ibuprofen and its metabolites. Chemosphere 56:583.

13. Kolpin, D.W., Furlong, E.T., Meyer, M.T., Thurman, E.M., Zaugg, S.D., et al. (2002). Pharmaceuticals, hormones, and other organic wastewater contaminants in U.S. streams, 1999-2000: A national reconnaissance. Environ. Sci. Technol. 36:1202.

14. Brooks, B.W., Foran, C.M., Richards, S.M., Weston, J., Turner, P.K., et al. (2003). Aquatic ecotoxicology of fluoxetine. Toxicol. Lett. 142:169.

15. Metcalfe, C.D., Miao, X.S., Koenig, B.G., and Struger, J. (2003). Distribution of acidic and neutral drugs in surface waters near sewage treatment plants in the lower Great Lakes, Canada. Environ. Toxicol. Chem. 22:2881.

16. Vanderford, B.J., and Snyder, S.A. (2006). Analysis of pharmaceuticals in water by isotope dilution liquid chromatography/tandem mass spectrometry. Environ. Sci. Technol. 40:7312.

17. Kwon, J.W., and Armbrust, K.L. (2006). Laboratory persistence and fate of fluoxetine in aquatic environments. Environ. Toxicol. Chem. 25:2561.

18. Brooks, B.W., Chambliss, C.K., Stanley, J.K., Ramirez, A., Banks, K.E., et al. (2005). Determination of select antidepressants in fish from an effluent-dominated stream. Environ. Toxicol. Chem. 24:464.

19. Randall, D.J., Connell, D.W., Yang, R., and Wu, S.S. (1998). Concentrations of persistent lipophilic compounds in fish are determined by exchange across the gills, not through the food chain. Chemosphere 37:1263.

20. Owen, S.F., Giltrow, E., Huggett, D.B., Hutchinson, T.H., Saye, J., et al. (2007). Comparative physiology, pharmacology and toxicology of beta-blockers: Mammals versus fish. Aquat. Toxicol. 82:145.

21. Hemeryck, A., and Belpaire, F.M. (2002). Selective serotonin reuptake inhibitors and cytochrome P-450 mediated drug-drug interactions: an update. Curr. Drug Metab. 3:13.

22. Mandrioli, R., Forti, G.C., and Raggi, M.A. (2006). Fluoxetine metabolism and pharmacological interactions: The role of cytochrome P450. Curr. Drug Metab. 7:127.

23. von Moltke, L.L., Greenblatt, D.J., Schmider, J., Duan, S.X., Wright, C.E., et al. (1996). Midazolam hydroxylation by human liver microsomes in vitro: Inhibition by fluoxetine, norfluoxetine, and by azole antifungal agents. J. Clin. Pharmacol. 36: 783.

24. Bertelsen, K.M., Venkatakrishnan, K., Von Moltke, L.L., Obach, R.S., and Greenblatt, D.J. (2003). Apparent mechanism-based inhibition of human CYP2D6 in vitro by paroxetine: Comparison with fluoxetine and quinidine. Drug Metab. Dispos. 31: 289.

25. Park, B.K., Pirmohamed, M., and Kitteringham, N.R. (1995). The role of cytochrome P450 enzymes in hepatic and extrahepatic human drug toxicity. Pharmacol. Ther. 68:385.

26. Thibaut, R., Schnell, S., and Porte, C. (2006). The interference of pharmaceuticals with endogenous and xenobiotic metabolizing enzymes in carp liver: An in-vitro study. Environ. Sci. Technol. 40:5154.

27. Nelson, D.R. (2003). Comparison of P450s from human and fugu: 420 Million years of vertebrate P450 evolution. Arch. Biochem. Biophys. 409:18. 
28. McArthur, A.G., Hegelund, T., Cox, R.L., Stegeman, J.J., Liljenberg, M., et al. (2003). Phylogenetic analysis of the cytochrome P450 3 (CYP3) gene family. J. Mol. Evolut. 57:200.

29. Parent, A., Poitras, D., and Dubé, L. (1984). Comparative anatomy of central monoaminergic systems. In: Classical transmitters in the CNS, Part I, A. Björklund, and T. Hökfelt, eds., Handbook of Chemical Neuroanatomy, Vol. 2. Elsevier, Amsterdam, p. 409.

30. Hamon, M., Bourgoin, S., Artaud, F., and El Mestikawy, S. (1981). The respective roles of tryptophan uptake and tryptophan hydroxylase in the regulation of serotonin synthesis in the central nervous system. J. Physiol. (Paris) 77:269.

31. Aghajanian, G.K. (1995). Electrophysiology of serotonin receptor subtypes and signal transduction pathways. In: Psychopharmacology: The fourth generation of progress, F.R. Bloom, and Kupfer, D.J., eds., Raven Press, New York, p. 1451.

32. Hoyer, D., Hannon, J.P., and Martin, G.R. (2002). Molecular, pharmacological and functional diversity of 5-HT receptors. Pharmacol. Biochem. Behav. 71:533.

33. Adayev, T., Ranasinghe, B., and Banerjee, P. (2005). Transmembrane signaling in the brain by serotonin, a key regulator of physiology and emotion. Biosci. Rep. 25:363.

34. Mössner, R., and Lesch, K.P. (1998). Role of serotonin in the immune system and in neuroimmune interactions. Brain Behav. Immun. 12:249.

35. Hoffman, B.J., Hansson, S.R., Mezey, E., and Palkovits, M. (1998). Localization and dynamic regulation of biogenic amine transporters in the mammalian central nervous system. Front. Neuroendocrinol. 19:187.

36. Senatori, O., Pierucci, F., Parvez, S.H., Scopelliti, R., and Nicotra, A. (2003). Monoamine oxidase in teleosts. Biogenic Amines 17:199.

37. Hall, T.R., Olcese, J.M., Figueroa, H.R., and deVlaming, V.L. (1982). Effects of inhibitors on monoamine oxidase activity in perch (Perca flavescens) brain in vitro. Comp. Biochem. Physiol. C Comp. Pharmacol. 71:141.

38. Blakely, R.D., Berson, H.E., Fremeau, R.T., Jr., Caron, M.G., Peek, M.M., et al. (1991). Cloning and expression of a functional serotonin transporter from rat brain. Nature 354:66.

39. Caveney, S., Cladman, W., Verellen, L., and Donly, C. (2006). Ancestry of neuronal monoamine transporters in the Metazoa. $J$. Exp. Biol. 209:4858.

40. Nelson, N. (1998). The family of $\mathrm{Na}^{+} / \mathrm{Cl}^{-}$neurotransmitter transporters. J. Neurochem. 71:1785.

41. Ramamoorthy, S., Giovanetti, E., Qian, Y., and Blakely, R.D. (1998). Phosphorylation and regulation of antidepressantsensitive serotonin transporters. . Biol. Chem. 273:2458.

42. Qian, Y., Melikian, H.E., Rye, D.B., Levey, A.I., and Blakely, R.D. (1995). Identification and characterization of antidepressantsensitive serotonin transporter proteins using site-specific antibodies. J. Neurosci. 15:1261.

43. Ramamoorthy, S., Bauman, A.L., Moore, K.R., Han, H., YangFeng, T., et al. (1993). Antidepressant- and cocaine-sensitive human serotonin transporter: Molecular cloning, expression, and chromosomal localization. Proc. Natl. Acad. Sci. USA 90: 2542.

44. Lesch, K.-P. (1997). Molecular biology, pharmacology, and genetics of the serotonin transporter: Psychobiological and clinical implications. In: Serotonergic neurons and 5-HT receptors in the CNS, H.G. Baumgarten, and M. Göthert, eds., Handbook of
Experimental Pharmacology, Vol. 129. Springer-Verlag, Berlin, Heidelberg, New York, p. 671.

45. Qian, Y., Galli, A., Ramamoorthy, S., Risso, S., DeFelice, L.J., et al. (1997). Protein kinase C activation regulates human serotonin transporters in HEK-293 cells via altered cell surface expression. J. Neurosci. 17:45.

46. Tollefson, G.D. (1995). Selective Serotonin Reuptake Inhibitors. In: The American Psychiatric Press textbook of psychopharmacology, A.F. Schatzberg, und Nemeroff, C.B., eds., American Psychiatric Press, Inc., Washington, DC, p. 161.

47. Kah, O., and Chambolle, P. (1983). Serotonin in the brain of the goldfish, Carassius auratus. An immunocytochemical study. Cell Tissue Res. 234:319.

48. Kaslin, J., and Panula, P. (2001). Comparative anatomy of the histaminergic and other aminergic systems in zebrafish (Danio rerio). J. Comp. Neurol. 440:342.

49. Bégay, V., Falcón, J., Cahill, G.M., Klein, D.C., and Coon, S.L. (1998). Transcripts encoding two melatonin synthesis enzymes in the teleost pineal organ: Circadian regulation in pike and zebrafish, but not in trout. Endocrinology 139:905.

50. Khan, I.A., and Thomas, P. (2001). Disruption of neuroendocrine control of luteinizing hormone secretion by Aroclor 1254 involves inhibition of hypothalamic tryptophan hydroxylase activity. Biol. Reprod. 64:955.

51. Bellipanni, G., Rink, E., and Bally-Cuif, L. (2002). Cloning of two tryptophan hydroxylase genes expressed in the diencephalon of the developing zebrafish brain. Mech. Dev. 119 Suppl 1: S215.

52. Teraoka, H., Russell, C., Regan, J., Chandrasekhar, A., Concha, M.L., et al. (2004). Hedgehog and Fgf signaling pathways regulate the development of tphR-expressing serotonergic raphe neurons in zebrafish embryos. J. Neurobiol. 60:275.

53. Hall, T.R., and Uruena, G. (1982). Monoamine oxidase activity in several tissues of the goldfish, Carassius auratus. Comp. Biochem. Physiol. C Comp. Pharmacol. 71:145.

54. Edwards, D., Hall, T.R., and Brown, J.A. (1986). The characteristics and distribution of monoamine oxidase (MAO) activity in different tissues of the rainbow trout, Salmo gairdneri. Comp. Biochem. Physiol. C 84:73.

55. Nicotra, A., and Senatori, O. (1989). Some characteristics of mitochondrial monoamine oxidase activity in eggs of carp (Cyprinus carpio) and rainbow trout (Salmo gairdneri). Comp. Biochem. Physiol. C 92:401.

56. Senatori, O., Nicotra, A., and Scopelliti, R. (1990). Monoamine oxidase activity in embryos of pike (Esox lucius). Comp.Biochem. Physiol. C 96:87.

57. Senthilkumaran, B., and Joy, K.P. (1995). A turnover study of hypothalamic monoamine oxidase (MAO) and effects of MAO inhibition on gonadotropin secretion in the female catfish, Heteropneustes fossilis. Gen. Comp. Endocrinol. 97:1.

58. Setini, A., Pierucci, F., Senatori, O., and Nicotra, A. (2005). Molecular characterization of monoamine oxidase in zebrafish (Danio rerio). Comp. Biochem. Physiol. B 140:153.

59. Yamaguchi, F., and Brenner, S. (1997). Molecular cloning of 5-hydroxytryptamine (5-HT) type 1 receptor genes from the Japanese puffer fish, Fugu rubripes. Gene 191:219.

60. NCBI Nucleotide Database (2006). U.S. National Library of Medicine (NLM) (http://www.ncbi.nlm.nih.gov/entrez/query. fcgi?db=Nucleotide\&itool=toolbar). Cited 25 October 2006. 
61. Wang, Y., Takai, R., Yoshioka, H., and Shirabe, K. (2006). Characterization and expression of serotonin transporter genes in zebrafish. Tohoku J. Exp. Med. 208:267.

62. Mortensen, O.V., Kristensen, A.S., and Wiborg, O. (2001). Species-scanning mutagenesis of the serotonin transporter reveals residues essential in selective, high-affinity recognition of antidepressants. J. Neurochem. 79:237.

63. Roubert, C., Sagne, C., Kapsimali, M., Vernier, P., Bourrat, F., et al. (2001). A Na(+)/Cl(-)-dependent transporter for catecholamines, identified as a norepinephrine transporter, is expressed in the brain of the teleost fish medaka (Oryzias latipes). Mol. Pharmacol. 60:462.

64. Bailly, Y., Dunel-Erb, S., Geffard, M., and Laurent, P. (1989). The vascular and epithelial serotonergic innervation of the actinopterygian gill filament with special reference to the trout, Salmo gairdneri. Cell Tissue Res. 258:349.

65. Nilsson, S., and Sundin, L. (1998). Gill blood flow control. Comp. Biochem. Physiol. : Mol. Integrat. Physiol. 119:137.

66. Dunel-Erb, S., Bailly, Y., and Laurent, P. (1982). Neuroepithelial cells in fish gill primary lamellae. J. Appl. Physiol. 53:1342.

67. Jonz, M.G., Fearon, I.M., and Nurse, C.A. (2004). Neuroepithelial oxygen chemoreceptors of the zebrafish gill. J. Physiol. 560:737.

68. Burleson, M.L., and Milsom, W.K. (1995). Cardio-ventilatory control in rainbow trout: I. Pharmacology of branchial, oxygen-sensitive chemoreceptors. Respir. Physiology 100: 231.

69. Fritsche, R., Thomas, S., and Perry, S.F. (1992). Effects of serotonin on circulation and respiration in the rainbow trout, Oncorhynchus mykiss. J. Exp. Biol. 173:59.

70. Sundin, L., Nilsson, G.E., Block, M., and Lofman, C.O. (1995). Control of gill filament blood flow by serotonin in the rainbow trout, Oncorhynchus mykiss. Am. J. Physiol. 268:R1224.

71. Sundin, L., Davison, W., Forster, M., and Axelsson, M. (1998). A role of 5-HT2 receptors in the gill vasculature of the antarctic fish Pagothenia borchgrevinki. J. Exp. Biol. 201:2129.

72. Sundin, L., and Nilsson, G.E. (2000). Branchial and circulatory responses to serotonin and rapid ambient water acidification in rainbow trout. J. Exp. Zool. 287:113.

73. Sundin, L., and Nilsson, S. (1992). Arterio-venous branchial blood flow in the Atlantic cod Gadus morhua.J. Exp. Biol. 165:73.

74. Zaunreiter, M., Brandstätter, R., and Goldschmid, A. (1998). Evidence for an endogenous clock in the retina of rainbow trout: II. Circadian rhythmicity of serotonin metabolism. Neuroreport 9:1475.

75. Tornqvist, K., Hansson, C., and Ehinger, B. (1983). Immunohistochemical and quantitative analysis of 5-hydroxytryptamine in the retina of some vertebrates. Neurochem. Int. 5:299.

76. Jaffé, E.H., Urbina, M., Ayala, C., and Chemello, M.E. (1987). Serotonin containing neurons in the retina of the teleost Eugerres plumieri. Vision Res. 27:2015.

77. Jaffé, E.H., Urbina, M., Ayala, C., Drujan, Y., and Drujan, B.D. (1987). Dopamine and noradrenaline content in fish retina: Modulation by serotonin. J. Neurosci. Res. 18:345.

78. Lima, L., and Schmeer, C. (1994). Characterization of serotonin transporter in goldfish retina by the binding of $[3 \mathrm{H}]$ paroxetine and the uptake of $[3 \mathrm{H}]$ serotonin: Modulation by light. J. Neurochem. 62:528.

79. Dearry, A., and Burnside, B. (1986). Dopaminergic regulation of cone retinomotor movement in isolated teleost retinas: II. Modu- lation by gamma-aminobutyric acid and serotonin. J. Neurochem. 46:1022.

80. Ceinos, R.M., Rábade, S., Soengas, J.L., and Míguez, J.M. (2005). Indoleamines and 5-methoxyindoles in trout pineal organ in vivo: Daily changes and influence of photoperiod. Gen. Comp. Endocrinol. 144:67.

81. Besseau, L., Benyassi, A., Moller, M., Coon, S.L., Weller, J.L., et al. (2006). Melatonin pathway: Breaking the 'high-at-night' rule in trout retina. Exp. Eye Res. 82:620.

82. Gothilf, Y., Coon, S.L., Toyama, R., Chitnis, A., Namboodiri, M.A., et al. (1999). Zebrafish serotonin N-acetyltransferase-2: Marker for development of pineal photoreceptors and circadian clock function. Endocrinology 140:4895.

83. Ebbesson, L.O.E. (2003). Neural circuits and their structural and chemical reorganization in the light-brain-pituitary axis during parr-smolt transformation in salmon. Aquaculture 222:59.

84. Holmes, A., Murphy, D.L., and Crawley, J.N. (2003). Abnormal behavioral phenotypes of serotonin transporter knockout mice: Parallels with human anxiety and depression. Biological Psychiatry 54:953.

85. Hazon, N., and Balment, R.J. (1998). Endocrinology. In: The physiology of fishes, D.H. Evans, eds., Marines Science, CRC Press, Boca Raton, FL, p. 441.

86. Fritsche, R., Reid, S.G., Thomas, S., and Perry, S.F. (1993). Serotonin-mediated release of catecholamines in the rainbow trout Oncorhynchus mykiss. J. Exp. Biol. 178:191.

87. Reid, S.G., Fritsche, R., and Jonsson, A.C. (1995). Immunohistochemical localization of bioactive peptides and amines associated with the chromaffin tissue of five species of fish. Cell Tissue Res. 280:499.

88. Jonz, M.G., and Nurse, C.A. (2005). Development of oxygen sensing in the gills of zebrafish. J. Exp. Biol. 208:1537.

89. Lapner, K.N., and Perry, S.F. (2001). The role of angiotensin II in regulating catecholamine secretion during hypoxia in rainbow trout Oncorhynchus mykiss. J. Exp. Biol. 204:4169.

90. Sundin, L., and Nilsson, G.E. (1997). Neurochemical mechanisms behind gill microcirculatory responses to hypoxia in trout: in vivo microscopy study. Am. J. Physiol. 272:R576.

91. Chaouloff, F. (1993). Physiopharmacological interactions between stress hormones and central serotonergic systems. Brain Res. Rev. 18:1.

92. Dinan, T.G. (1996). Serotonin and the regulation of hypothalamicpituitary-adrenal axis function. Life Sci. 58:1683.

93. Liposits, Z., Phelix, C., and Paull, W.K. (1987). Synaptic interaction of serotonergic axons and corticotropin releasing factor (CRF) synthesizing neurons in the hypothalamic paraventricular nucleus of the rat. A light and electron microscopic immunocytochemical study. Histochemistry 86:541.

94. Calogero, A.E., Bernardini, R., Margioris, A.N., Bagdy, G., Gallucci, W.T., et al. (1989). Effects of serotonergic agonists and antagonists on corticotropin-releasing hormone secretion by explanted rat hypothalami. Peptides 10:189.

95. Alper, R.H. (1990). Evidence for central and peripheral serotonergic control of corticosterone secretion in the conscious rat. Neuroendocrinology 51:255.

96. Weyts, F.A.A., Cohen, N., Flik, G., and Verburg-van Kemenade, B. (1999). Interactions between the immune system and the hypothalamo-pituitary-interrenal axis in fish. Fish Shellfish Immunol. 9:1. 
97. Peter, R.E., Habibi, H.R., Chang, J.P., Nahorniak, C.S., Yu, K.L., et al. (1990). Actions of gonadotropin-releasing hormone (GnRH) in the goldfish. Prog. Clin. Biol Res. 342:393.

98. Winberg, S., and Lepage, O. (1998). Elevation of brain 5-HT activity, POMC expression, and plasma cortisol in socially subordinate rainbow trout. Am. J. Physiol. 274:R645.

99. Winberg, S., Nilsson, A., Hylland, P., Soderstom, V., and Nilsson, G.E. (1997). Serotonin as a regulator of hypothalamic-pituitaryinterrenal activity in teleost fish. Neurosci. Lett. 230:113.

100. Doyon, C., Gilmour, K.M., Trudeau, V.L., and Moon, T.W. (2003). Corticotropin-releasing factor and neuropeptide Y mRNA levels are elevated in the preoptic area of socially subordinate rainbow trout. Gen. Comp. Endocrinol. 133:260.

101. Teitsma, C.A., Anglade, I., Toutirais, G., Munoz-Cueto, J.A., Saligaut, D., et al. (1998). Immunohistochemical localization of glucocorticoid receptors in the forebrain of the rainbow trout $(\mathrm{On}$ corhynchus mykiss). J. Comp. Neurol. 401:395.

102. Frankenhuis-van den Heuvel, T.H., and Nieuwenhuys, R. (1984). Distribution of serotonin-immunoreactivity in the diencephalon and mesencephalon of the trout, Salmo gairdneri. Cellbodies, fibres and terminals. Anat. Embryol. (Berlin) 169:193.

103. Pepels, P.P., Bonga, S.E., and Balm, P.H. (2004). Bacterial lipopolysaccharide (LPS) modulates corticotropin-releasing hormone $(\mathrm{CRH})$ content and release in the brain of juvenile and adult tilapia (Oreochromis mossambicus; Teleostei). J. Exp. Biol. 207:4479.

104. Clements, S., and Schreck, C.B. (2007). Chronic administration of fluoxetine alters locomotor behavior, but does not potentiate the locomotor stimulating effects of CRH in juvenile Chinook salmon (Oncorhynchus tshawytscha). Comp. Biochem. Physiol. A Mol. Integrat. Physiol. 147:43.

105. Winberg, S., Nilsson, G.E., and Olsen, K.H. (1992). Changes in brain serotonergic activity during hierarchic behavior in Arctic charr (Salvelinus alpinus L.) are socially induced. J. Comp. Physiol. A Mol. Integrat. Physiol. 170:93.

106. Winberg, S., and Nilsson, G. (1993). Time course of changes in brain serotonergic activity and brain tryptophan levels in dominant and subordinate juvenile Arctic charr. J. Exp. Biol. 179:181.

107. Winberg, S., and Nilsson, G.E. (1993). Roles of brain monoamine neurotransmitters in agonistic behaviour and stress reactions, with special reference to fish. Comp. Biochem. Physiol. C Pharmacol. Toxicol. Endocrinol. 10:597.

108. Winberg, S., Nilsson, G.E., Spruijt, B.E., and Höglund, U. (1993). Spontaneous locomotor activity in Arctic charr measured by a computerized imaging technique: Role of brain serotonergic activity. J. Exp. Biol. 179:213.

109. Winberg, S., Carter, C.G., McCarthy, I.D., He, Z.-Y., Nilsson, G.E., et al. (1993). Feeding rank and brain serotonergic activity in rainbow trout Oncorhynchus mykiss. J. Exp. Biol. 179: 197.

110. DiBattista, J.D., Anisman, H., Whitehead, M., and Gilmour, K.M. (2005). The effects of cortisol administration on social status and brain monoaminergic activity in rainbow trout Oncorhynchus mykiss. J. Exp. Biol. 208:2707.

111. Elofsson, U.O., Mayer, I., Damsgard, B., and Winberg, S. (2000). Intermale competition in sexually mature arctic charr: Effects on brain monoamines, endocrine stress responses, sex hormone levels, and behavior. Gen. Comp. Endocrinol. 118:450.
112. Weiger, W.A. (1997). Serotonergic modulation of behaviour: A phylogenetic overview. Biol. Rev. Cambridge Philos. Soc. 72:61.

113. Perreault, H.A., Semsar, K., and Godwin, J. (2003). Fluoxetine treatment decreases territorial aggression in a coral reef fish. Physiology and Behavior 79:719.

114. Munro, A.D. (1986). Effects of melatonin, serotonin, and naloxone on aggression in isolated cichlid fish (Aequidens pulcher). $J$. Pineal Res. 3:257.

115. Lepage, O., Larson, E.T., Mayer, I., and Winberg, S. (2005). Serotonin, but not melatonin, plays a role in shaping dominantsubordinate relationships and aggression in rainbow trout. Hormones Behav. 48:233.

116. Gilmour, K.M., DiBattista, J.D., and Thomas, J.B. (2005). Physiological causes and consequences of social status in salmonid fish. Integrat. Comp. Biol. 45:263.

117. Cardwell, J.R., Sorensen, P.W., Van der Kraak, G.J., and Liley, N.R. (1996). Effect of dominance status on sex hormone levels in laboratory and wild-spawning male trout. Gen. Comp. Endocrinol. 101:333.

118. Sloman, K.A. (2007). Effects of trace metals on salmonid fish: The role of social hierarchies. Appl. Anim. Behav. Sci. 104:326.

119. De Pedro, N., Pinillos, M.L., Valenciano, A.I., Alonso-Bedate, M., and Delgado, M.J. (1998). Inhibitory effect of serotonin on feeding behavior in goldfish: Involvement of CRF. Peptides 19:505.

120. Ebbesson, S.O.E., Bazer, G.T., Bailey, R.P., Reynolds, J.B., and Smith, J.E. (1987). Changes with age in total brain concentrations of biogenic amine neurotransmitters in coho salmon (Oncorhynchus kisutch Walbaum). Brain Res. 405:175.

121. Semsar, K., Perreault, H.A., and Godwin, J. (2004). Fluoxetinetreated male wrasses exhibit low AVT expression. Brain Res. 1029:141.

122. Semsar, K., Kandel, F.L., and Godwin, J. (2001). Manipulations of the AVT system shift social status and related courtship and aggressive behavior in the bluehead wrasse. Hormones Behav. 40:21.

123. Khan, N., and Deschaux, P. (1997). Role of serotonin in fish immunomodulation. J. Exp. Biol. 200:1833.

124. Besedovsky, H.O., del Rey, A.E., and Sorkin, E. (1985). Immuneneuroendocrine interactions. J. Immunol. 135:750s.

125. Fleshner, M., Watkins, L.R., Lockwood, L.L., Bellgrau, D., Laudenslager, M.L., et al. (1992). Specific changes in lymphocyte subpopulations: A potential mechanism for stress-induced immunomodulation. J. Neuroimmunol. 41:131.

126. Jankovic, B.D. (1989). Neuroimmunomodulation: facts and dilemmas. Immunol. Lett. 21:101.

127. Aune, T.M., Kelley, K.A., Ranges, G.E., and Bombara, M.P. (1990). Serotonin-activated signal transduction via serotonin receptors on Jurkat cells. J. Immunol. 145:1826.

128. Faraj, B.A., Olkowski, Z.L., and Jackson, R.T. (1994). Expression of a high-affinity serotonin transporter in human lymphocytes. Int. J. Immunopharmacol. 16:561.

129. Mössner, R., Daniel, S., Schmitt, A., Albert, D., and Lesch, K.P. (2001). Modulation of serotonin transporter function by interleukin-4. Life Sci. 68:873.

130. Meyniel, J.P., Khan, N.A., Ferriere, F., and Deschaux, P. (1997). Identification of lymphocyte 5-HT-3 receptor subtype and its implication in fish T-cell proliferation. Immunol. Lett. 55:151. 
131. Ferrière, F., Khan, N.A., Meyniel, J.P., and Deschaux, P. (1997). 5-Hydroxytryptamine-induced calcium-channel gating in rainbow trout (Oncorhynchus mykiss) peripheral blood lymphocytes. Biochem. J. 323 (Pt 1):251.

132. Lin, G.L., Ellsaesser, C.F., Clem, L.W., and Miller, N.W. (1992). Phorbol ester/calcium ionophore activate fish leukocytes and induce long-term cultures. Dev. Comp. Immunol. 16:153.

133. Ferrière, F., Khan, N.A., Troutaud, D., and Deschaux, P. (1996). Serotonin modulation of lymphocyte proliferation via 5-HT1A receptors in rainbow trout (Oncorhynchus mykiss). Dev. Comp. Immunol. 20:273.

134. Ferrière, F., Khan, N.A., Meyniel, J.P., and Deschaux, P. (1999). Characterisation of serotonin transport mechanisms in rainbow trout peripheral blood lymphocytes: Role in PHA-induced lymphoproliferation. Dev. Comp. Immunol. 23:37.

135. Stern-Bach, Y., Greenberg-Ofrath, N., Flechner, I., and Schuldiner, S. (1990). Identification and purification of a functional amine transporter from bovine chromaffin granules. . Biol. Chem. 265:3961.

136. Fong, P.P., Kyozuka, K., Abdelghani, H., Hardege, J.D., and Ram, J.L. (1994). In vivo and in vitro induction of germinal vesicle breakdown in a freshwater bivalve, the zebra mussel Dreissena polymorpha (Pallas). J. Exp. Zool. 269:467.

137. Fong, P.P. (1998). Zebra mussel spawning is induced in low concentrations of putative serotonin re-uptake inhibitors. Biol. Bull. 194:143.

138. Fong, P.P., Huminski, P.T., and D’Urso, L.M. (1998). Induction and potentiation of parturition in fingernail clams (Sphaerium striatinum) by selective serotonin re-uptake inhibitors (SSRIs). $J$. Exp. Zool. 280:260.

139. Honkoop, P.J.C., Luttikhuizen, P.C., and Piersma, T. (1999). Experimentally extending the spawning season of a marine bivalve using temperature change and fluoxetine as synergistic triggers. Mar. Ecol. Prog. Ser. 180:297.

140. Krantic, S., Dube, F., Quirion, R., and Guerrier, P. (1991). Pharmacology of the serotonin-induced meiosis reinitiation in Spisula solidissima oocytes. Dev. Biol. 146:491.

141. Flaherty, C.M., and Dodson, S.I. (2005). Effects of pharmaceuticals on Daphnia survival, growth, and reproduction. Chemosphere 61:200.

142. McCann, S.M., and Ojeda, S.R. (1992). The anterior pituitary and hypothalamus. In: Textbook of endocrine physiology, J.E. Griffin, and S.R. Ojeda, eds., Oxford University Press, New York, p. 75 .

143. Kiss, J., and Halasz, B. (1985). Demonstration of serotoninergic axons terminating on luteinizing hormone-releasing hormone neurons in the preoptic area of the rat using a combination of immunocytochemistry and high resolution autoradiography. Neuroscience 14:69.

144. Gouveia, E.M., and Franci, C.R. (2004). Involvement of serotonin 5HT1 and 5HT2 receptors and nitric oxide synthase in the medial preoptic area on gonadotropin secretion. Brain Res. Bull. 63:243.

145. Amireault, P., and Dubé, F. (2005). Serotonin and its antidepressant-sensitive transport in mouse cumulus-oocyte complexes and early embryos. Biol. Reprod. 73:358.

146. Amireault, P., and Dubé, F. (2005). Intracellular cAMP and calcium signaling by serotonin in mouse cumulus-oocyte complexes. Mol. Pharmacol. 68:1678.
147. Koppan, M., Bodis, J., Verzar, Z., Tinneberg, H.R., and Torok, A. (2004). Serotonin may alter the pattern of gonadotropin-induced progesterone release of human granulosa cells in superfusion. Endocrine 24:155.

148. Scott, A.P. (1987). Reproductive Endocrinology of Fish. In: Comparative vertebrate endocrinology, I. Chester-Jones, P.M. Ingleton, and J.G. Phillips, eds., Academic Press, London, p. 223.

149. Joy, K.P., Senthilkumaran, B., and Sudhakumari, C.C. (1998). Periovulatory changes in hypothalamic and pituitary monoamines following GnRH analogue treatment in the catfish Heteropneustes fossilis: A study correlating changes in plasma hormone profiles. J. Endocrinol. 156:365.

150. Blázquez, M., Bosma, P.T., Fraser, E.J., Van Look, K.J., and Trudeau, V.L. (1998). Fish as models for the neuroendocrine regulation of reproduction and growth. Comp. Biochem. Physiol. C Pharmacol. Toxicol. Endocrinol. 119:345.

151. Trudeau, V.L. (1997). Neuroendocrine regulation of gonadotrophin II release and gonadal growth in the goldfish, Carassius auratus. Rev. Reprod. 2:55.

152. Trudeau, V.L., C.D. Metcalfe, C. Mimeault, and Moon, T.W. (2005). Pharmaceuticals in the environment: Drugged fish? In: Environmental toxicology, P.W. Hochachka and T.P. Mommsen, eds., Biochemistry and Molecular Biology of Fishes, Vol. 6. Elsevier, Amsterdam, p. 475.

153. Khan, I.A., and Thomas, P. (1992). Stimulatory effects of serotonin on maturational gonadotropin release in the Atlantic croaker, Micropogonias undulatus. Gen. Comp. Endocrinol. 88:388.

154. Khan, I.A., and Thomas, P. (1993). Immunocytochemical localization of serotonin and gonadotropin-releasing hormone in the brain and pituitary gland of the Atlantic croaker Micropogonias undulatus. Gen. Comp. Endocrinol. 91:167.

155. Senthilkumaran, B., Okuzawa, K., Gen, K., and Kagawa, H. (2001). Effects of serotonin, GABA and neuropeptide Y on seabream gonadotropin releasing hormone release in vitro from preoptic-anterior hypothalamus and pituitary of red seabream, Pagrus major. J. Neuroendocrinology 13:395.

156. Somoza, G.M., and Peter, R.E. (1991). Effects of serotonin on gonadotropin and growth hormone release from in vitro perifused goldfish pituitary fragments. Gen. Comp. Endocrinol. 82:103.

157. Somoza, G.M., Yu, K.L., and Peter, R.E. (1988). Serotonin stimulates gonadotropin release in female and male goldfish, Carassius auratus L. Gen. Comp. Endocrinol. 72:374.

158. Wong, A.O.L., Murphy, C.K., Chang, J.P., Neumann, C.M., Lo, A., et al. (1998). Direct actions of serotonin on gonadotropin-II and growth hormone release from goldfish pituitary cells: Interactions with gonadotropin-releasing hormone and dopamine and further evaluation of serotonin receptor specificity. Fish Physiol. Biochem. 19:23.

159. Yu, K.L., Rosenblum, P.M., and Peter, R.E. (1991). In vitro release of gonadotropin-releasing hormone from the brain preopticanterior hypothalamic region and pituitary of female goldfish. Gen. Comp. Endocrinol. 81:256.

160. Hernandez-Rauda, R., and Aldegunde, M. (2002). Changes in dopamine, norepinephrine and serotonin levels in the pituitary, telencephalon and hypothalamus during gonadal development of male Lutjanus argentiventris (Teleostei). Mar. Biol. 141: 209. 
161. Hernandez-Rauda, R., Otero, J., Rey, P., Rozas, G., and Aldegunde, M. (1996). Dopamine and serotonin in the trout (Oncorhynchus mykiss) pituitary: Main metabolites and changes during gonadal recrudescence. Gen. Comp. Endocrinol. 103:13.

162. Saligaut, C., Salbert, G., Bailhache, T., Bennani, S., and Jego, P. (1992). Serotonin and dopamine turnover in the female rainbow trout (Oncorhynchus mykiss) brain and pituitary: changes during the annual reproductive cycle. Gen. Comp. Endocrinol. 85:261.

163. Cerdà, J., Reich, G., Wallace, R.A., and Selman, K. (1998). Serotonin inhibition of steroid-induced meiotic maturation in the teleost Fundulus heteroclitus: role of cyclic AMP and protein kinases. Mol. Reprod. Dev. 49:333.

164. Iwamatsu, T., Toya, Y., Sakai, N., Terada, Y., Nagata, R., et al. (1993). Effect of 5-hydroxytryptamine on steroidogenesis and oocyte maturation in pre-ovulatory follicles of the medaka Oryzias latipes. Dev. Growth Differ. 35:625.

165. Buznikov, G.A., Lambert, H.W., and Lauder, J.M. (2001). Serotonin and serotonin-like substances as regulators of early embryogenesis and morphogenesis. Cell Tissue Res. 305:177.

166. Pennati, R., Groppelli, S., Sotgia, C., Candiani, S., Pestarino, M., et al. (2001). Serotonin localization in Phallusia mammillata larvae and effects of 5-HT antagonists during larval development. Dev. Growth Differ. 43:647.

167. Levin, M. (2006). Is the early left-right axis like a plant, a kidney, or a neuron? The integration of physiological signals in embryonic asymmetry. Birth Defects Res. C Embryo Today 78: 191.

168. Buznikov, G.A., Shmukler Yu, B., and Lauder, J.M. (1999). Changes in the physiological roles of neurotransmitters during individual development. Neurosci. Behav. Physiol. 29:11.

169. Coté, F., Fligny, C., Bayard, E., Launay, J.M., Gershon, M.D., et al. (2007). Maternal serotonin is crucial for murine embryonic development. Proc. Natl. Acad. Sci. USA 104:329.

170. Lauder, J.M. (1990). Ontogeny of the serotonergic system in the rat: Serotonin as a developmental signal. Ann. NY Acad. Sci. 600:297.

171. Whitaker-Azmitia, P.M., Druse, M., Walker, P., and Lauder, J.M. (1996). Serotonin as a developmental signal. Behav. Brain Res. 73:19.

172. Fanburg, B.L., and Lee, S.L. (1997). A new role for an old molecule: Serotonin as a mitogen. Am. J. Physiol. 272:L795.

173. Lauder, J.M. (1993). Neurotransmitters as growth regulatory signals: Role of receptors and second messengers. Trends Neurosci. 16:233.

174. Sari, Y., and Zhou, F.C. (2003). Serotonin and its transporter on proliferation of fetal heart cells. Int. J. Dev. Neurosci. 21:417.

175. Hansson, S.R., Mezey, E., and Hoffman, B.J. (1998). Serotonin transporter messenger RNA in the developing rat brain: Early expression in serotonergic neurons and transient expression in nonserotonergic neurons. Neuroscience 83:1185.

176. Fukumoto, T., Kema, I.P., and Levin, M. (2005). Serotonin signaling is a very early step in patterning of the left-right axis in chick and frog embryos. Curr. Biol. 15:794.

177. Fukumoto, T., Blakely, R., and Levin, M. (2005). Serotonin transporter function is an early step in left-right patterning in chick and frog embryos. Dev. Neurosci. 27:349.

178. Levin, M. (2005). Left-right asymmetry in embryonic development: A comprehensive review. Mech. Dev. 122:3.
179. Ramsdell, A.F. (2005). Left-right asymmetry and congenital cardiac defects: Getting to the heart of the matter in vertebrate leftright axis determination. Dev. Biol. 288:1.

180. Blum, M., Schweickert, A., Beyer, T., Weber, T., Andre, P., et al. (2006). A leftward fluid flow precedes nodal induction in Xenopus. Dev. Biol. 295:443.

181. Bisazza, A., and de Santi, A. (2003). Lateralization of aggression in fish. Behav. Brain Res. 141:131.

182. Laville, N., Ait-Aissa, S., Gomez, E., Casellas, C., and Porcher, J.M. (2004). Effects of human pharmaceuticals on cytotoxicity, EROD activity and ROS production in fish hepatocytes. Toxicology 196:41.

183. Richards, S.M., and Cole, S.E. (2006). A toxicity and hazard assessment of fourteen pharmaceuticals to Xenopus laevis larvae. Ecotoxicology 15:647.

184. ASTM (1991). Standard Guide for Conducting the Frog Embryo Teratogenesis Assay-Xenopus (Fetax). E1439-91. In: Annual book of ASTM standards, American Society for Testing and Material, Philadelphia, p. 1.

185. Brooks, B.W., Turner, P.K., Stanley, J.K., Weston, J.J., Glidewell, E.A., et al. (2003). Waterborne and sediment toxicity of fluoxetine to select organisms. Chemosphere 52:135.

186. Länge, R., and Dietrich, D.R. (2002). Environmental risk assessment of pharmaceutical drug substances-conceptual considerations. Toxicol. Lett. 131:97.

187. Couper, J.M., and Leise, E.M. (1996). Serotonin injections induce metamorphosis in larvae of the gastropod mollusc Illyanassa $o b$ soleta. Biol. Bull. 191:178.

188. Foran, C.M., Weston, J., Slattery, M., Brooks, B.W., and Huggett, D.B. (2004). Reproductive assessment of Japanese medaka (Oryzias latipes) following a four-week fluoxetine (SSRI) exposure. Arch. Environ. Contam. Toxicol. 46:511.

189. Holcombe, G.W., Benoit, D.A., Hammermeister, D.E., Leonard, E.N., and Johnson, R.D. (1995). Acute and long-term effects of nine chemicals on the Japanese medaka (Oryzias latipes). Arch. Environ. Contam. Toxicol. 28:287.

190. Gnerre, C., Kosel, M., Baumann, P., Carrupt, P.A., and Testa, B. (2001). Interaction of psychotropic drugs with monoamine oxidase in rat brain. J. Pharm. Pharmacol. 53:1125.

191. Ni, Y.G., and Miledi, R. (1997). Blockage of 5-HT $2 C$ serotonin receptors by fluoxetine (Prozac). Proc. Natl. Acad. Sci. USA 94:2036.

192. García-Colunga, J., Awad, J.N., and Miledi, R. (1997). Blockage of muscle and neuronal nicotinic acetylcholine receptors by fluoxetine (Prozac). Proc. Natl. Acad. Sci. USA 94:2041.

193. Fryer, J.D., and Lukas, R.J. (1999). Antidepressants noncompetitively inhibit nicotinic acetylcholine receptor function. $\mathrm{J}$. Neurochem. 72:1117.

194. Weis, J.S., Smith, G., Zhou, T., Santiago-Bass, C., and Weis, P. (2001). Effects of contaminants on behavior: Biochemical mechanisms and ecological consequences. BioScience 51: 209.

195. Huggett, D., Cook, J.C., Ericson, J.F., and Williams, R.T. (2003). A theoretical model for utilizing mammalian pharmacology and safety data to prioritize potential impacts of human pharmaceuticals to fish. Hum. Ecol. Risk Assess. 9:1789.

196. Lienert, J., Gudel, K., and Escher, B.I. (2007). Screening method for ecotoxicological hazard assessment of 42 pharmaceuticals 
considering human metabolism and excretory routes. Environ. Sci. Technol. 41:4471.

197. Fuller, R.W. (1985). Drugs altering serotonin synthesis and metabolism. In: Neuropharmacology of serotonin, A.R. Green, ed., Oxford University Press, Oxford, p. 1.

198. Wullimann, M.F., Rupp, B., and Reichert, H. (1996). Neuroanatomy of the zebrafish brain-A topological atlas. Birkhäuser Verlag, Basel, p. 144.

199. Heldmaier, G. (2004). Vergleichende Tierphysiologie, Band 2: Vegetative Physiologie. Springer-Verlag, Berlin, Heidelberg.

200. Schier, A.F. (2003). Nodal signaling in vertebrate development. Annu. Rev. Cell Dev. Biol. 19:589.

201. Wishart, D.S., Knox, C., Guo, A.C., Shrivastava, S., Hassanali, M., et al. (2006). DrugBank: A comprehensive resource for in silico drug discovery and exploration. Nucleic Acids Res. 34:D668.

202. NCBI (2006). Pubchem. U. S. National Library of Medicine (NLM) (http://pubchem.ncbi.nlm.nih.gov/). Cited 23 March 2006.

203. SRC Environmental Science (2006). Estimation Software: interactive LogKow (KowWin) Demo. Syracuse Research Corporation. (http://www.syrres.com/esc/est_kowdemo.htm). Cited 10 Apr 2006

204. Bourin, M., Chue, P., and Guillon, Y. (2001). Paroxetine: A review. CNS Drug Rev. 7:25.

205. NLM (2006). ChemIDplus. U. S. National Library of Medicine (NLM) (http://chem.sis.nlm.nih.gov/chemidplus/chemidlite.jsp). Cited 27 March 2006.

206. Søgaard, B., Mengel, H., Rao, N., and Larsen, F. (2005). The pharmacokinetics of escitalopram after oral and intravenous administration of single and multiple doses to healthy subjects. $J$. Clin. Pharmacol. 45:1400.

207. Hoyer, D., Clarke, D.E., Fozard, J.R., Hartig, P.R., Martin, G.R., et al. (1994). International Union of Pharmacology classification of receptors for 5-hydroxytryptamine (Serotonin). Pharmacol. Rev. 46:157.

208. Saudou, F., and Hen, R. (1994). 5-Hydroxytryptamine receptor subtypes in vertebrates and invertebrates. Neurochem. Int. 25:503.

209. Fong, P.P., Huminski, P.T., and D’Urso, L.M. (1998). Induction and potentiation of parturition in fingernail clams (Sphaerium striatinum) by selective serotonin re-uptake inhibitors (SSRIs). $J$. Exp. Zool. 280:260.

210. Kulkarni, G.K., Nagabhushanam, R., Amaldoss, G., Jaiswal, R.G., and Fingerman, M. (1992). In vivo stimulation of ovarian development in the red swamp crayfish, Procambarus clarkii (Girard), by 5-hydroxytryptamine. Invertebrate Reproduction and Development 21:231.

211. Sarojini, R., Nagabhushanam, R., and Fingerman, M. (1995). Mode of action of the neurotransmitter 5-hydroxytryptamine in stimulating ovarian maturation in the red swamp crayfish, Procambarus clarkii: An in vivo and in vitro study. J. Exp. Zool. 271:395.

212. Richardson, H.G., Deecaraman, M., and Fingerman, M. (1991). The effect of biogenic amines on ovarian development in the fiddler crab, Uca pugilator. Comp. Biochem. Physiol. C Comp. Pharmacol. 99: 53.

213. Buznikov, G.A., Nikitina, L.A., Galanov, A., Malchenko, L.A., and Trubnikova, O.B. (1993). The control of oocyte maturation in the starfish and amphibians by serotonin and its antagonists. Int. J. Dev. Biol. 37:363.

214. Stricker, S.A., and Smythe, T.L. (2001). 5-HT causes an increase in cAMP that stimulates, rather than inhibits, oocyte maturation in marine nemertean worms. Development 128:1415.

215. Dempsey, C.M., Mackenzie, S.M., Gargus, A., Blanco, G., and Sze, J.Y. (2005). Serotonin (5HT), fluoxetine, imipramine and dopamine target distinct 5HT receptor signaling to modulate Caenorhabditis elegans egg-laying behavior. Genetics 169: 1425.

216. Henry, T.B., Kwon, J.W., Armbrust, K.L., and Black, M.C. (2004). Acute and chronic toxicity of five selective serotonin reuptake inhibitors in Ceriodaphnia dubia. Environ. Toxicol. Chem. 23: 2229.

217. Christensen, A.M., Faaborg-Andersen, S., Ingerslev, F., and Baun, A. (2007). Mixture and single-substance toxicity of selective serotonin reuptake inhibitors toward algae and crustaceans. Environ. Toxicol. Chem. 26:85.

218. Cunningham, V.L., Constable, D.J., and Hannah, R.E. (2004). Environmental risk assessment of paroxetine. Environ. Sci. Technol. 38:3351. 